
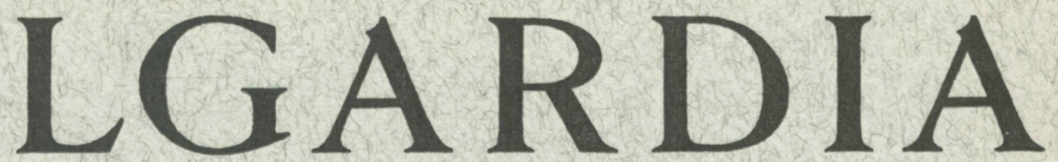

A Journal of Agricultural Science Published by the California Agricultural Experiment Station

\title{
ECONOMETRIC ANALYSIS OF THE MARKET FOR CALIFORNIA EARLY POTATOES
}

\author{
PINHAS ZUSMAN
}

UNIVERSITY OF CALIFORNIA - BERKELEY, CALIFORNIA 
The market position of California early potatoes is influenced by a variety of factors. Most prominent among these are the demand conditions during the early season, the supply response of early crop producers in other states, and the carry-over of preceding year late potatoes into the early market.

The quantitative analysis of the market for California early potatoes was accomplished in three phases. An econometric model of the potato market consisting of fourteen equations in fourteen endogenous and fifteen exogenous variables was developed and estimated in the first phase. The sample period consisted of the years 1930 through 1958 excluding the years 1942 through 1950.

In the second phase, an analysis of the market static and dynamic characteristics was undertaken. The static analysis was essentially a comparative one. In this analysis the short run and long run effects of variation in exogenous variables were derived and expressed as systems of multipliers.

The analysis of the market dynamics was concerned mainly with the system stability and its time path under ever-changing environmental conditions. It was found that deterministically the system is stable with a relatively high dampening factor. The large observed fluctuations of prices and quantities are, therefore, due to exogenous shocks. When various sources of exogenous shocks were analyzed, it was found that random disturbances were of prime importance while erratic variation in exogenous variables was only secondary in generating the observed fluctuations.

The analysis of the system time path under ever-changing exogenous variables led to the conclusion that the rate of adjustment of the potato industry to changing conditions is relatively high, and the actual rates of change in exogenous variables generate only slight discrepancies between the system's time path and its equilibrium values.

In the third phase, an attempt was made to use the estimated model in formulating optimum production policies for a collusion of California potato growers. When a "shortsighted" policy, based on a planning horizon of one year, was considered, it was found that such a policy leads eventually to a "stationary" optimum policy, but increases the instability of the system. The long run optimum policy problem was solved only for the special case of a "stationary" optimum policy. A general conclusion suggested by the analysis is that California growers could have benefited by some reduction of output.

Finally, a general method for long-run forecasts was developed and applied in predicting future trends of the potato market. 


\title{
H I L G A R D I A
}

A Journal of Agricultural Science Published by

the California Agricultural Experiment Station

\begin{tabular}{lll}
\hline VoL. 33 & DECEMBER, 1962 & No. 11 \\
\hline
\end{tabular}

\section{ECONOMETRIC ANALYSIS OF THE MARKET FOR CALIFORNIA EARLY POTATOES ${ }^{1}$}

\author{
PINHAS ZUSMAN ${ }^{2}$
}

\section{INTRODUCTION}

The oвJEctive of this study is to analyze quantitatively the static and dynamic properties of the market for California early potatoes. The market for California early potatoes represents a complex system in which many factors interact in a rather complicated way, thus generating the observed prices and quantities. Accordingly, the method of analysis adopted consists of developing and estimating an econometric model for the early potato market. In this model the behavioral and definitional relations among various variables are represented by a system of equations.

Increasing emphasis has been placed during the past two decades on empirical analysis of multiequational systems. In 1939, J. Tinbergen ${ }^{3}$ used this approach in an empirical analysis of business cycles in the United States. In more recent years, econometric models have been constructed and estimated for the economy as a whole and for individual commodities and sectors of the economy. Most attempts involving multiequational analysis have been oriented toward the evaluation of various estimation procedures and the application of the resulting models in forecasting. Relatively few have undertaken a comprehensive analysis of the static and dynamic properties of the economic systems specified. ${ }^{4}$

${ }^{1}$ Submitted for publication October 18, 1961.

${ }^{2}$ Instructor, Agricultural Economics, Hebrew University, Israel; Assistant Research Agricultural Economist II, University of California, Berkeley, to July 10, 1961.

${ }^{3}$ J. Tinbergen, Statistical Testing of Business-Cycle Theories. Vol. II: Business Cycles in the United States of America, 1919-1932 (Geneva: League of Nations Economic Intelligence Service, 1939), $244 \mathrm{p}$.

${ }^{4}$ Among the recent multiequational analyses, one may cite studies such as:

L. R. Klein and A. S. Goldberger, An Econometric Model of the United States, 1929-1952 (Amsterdam: North-Holland Publ. Co., 1955), 165 p.

A. S. Goldberger, Impact Multipliers and Dynamic Properties of the Klein-Goldberger Model (Amsterdam: North-Holland Publ. Co., 1959), 138 p.

C. Hidreth and F. G. Jarrett, A Statistical Study of Livestock Production and Marketing, Cowles Comm. for Res. in Econ. Mono. 15 (New York: John Wiley and Sons, 1955), $156 \mathrm{p}$. 
In the present analysis, estimation procedures and forecasting are of secondary interest. Attention is focussed on the comparative analysis of static and dynamic properties of the potato market.

In the first part of the study (pages 552 to 583), the general structure and functioning of the potato industry in the United States are surveyed in an historical framework. The objective at this phase is to identify the various factors operating in the system and their temporal and geographical interrelations. This survey provides the basis for subsequent formulation of the econometric model in the second chapter (pages 584 to 603). In the first chapter (pages 552 to 583), economic theory relevant to the model of the potato industry is set out with the purpose of specifying the various relations and variables. In this stage the signs of various derivatives implied by theoretical considerations are derived. These are subsequently referred to in judging the a priori acceptability of particular econometric formulations. Statistical estimates of the relations are then presented.

Having formulated and estimated the complete econometric model, a comparative static and dynamic analysis of the system is undertaken in the third chapter, pages 604 to 640 . Short-run and long-run multipliers are derived, and the stationary states of the system during the sample period are analyzed in implementing the comparative static analysis.

The time path of the stationary states as determined by the evolution of the exogenous variables is of particular interest in as much as it represents (in a stable system) the time path about which the system fluctuates. Thus in evaluating the impact of government programs on the potato industry, it is possible to obtain a measure of the displacement of long-run equilibrium values of the main variables due to governmental intervention during 1943-1950. In recent years, there has been a growing interest in the estimation of longrun elasticities of supply and demand. Valuable as these elasticities may be, it would seem that their usefulness in the analysis of long-run equilibrium is fully realized only in the framework of a complete system.

In the dynamic analysis, main emphasis is placed on the stability properties of the system, the role of random shocks and erratic behavior of exogenous variables, and the evolution of the system in a changing environment. Marked fluctuations in prices and quantities have characterized the potato industry. The origin and development of these fluctuations is the subject of the stability conditions analysis.

M. R. Fisher, "A Sector Model: The Poultry Industry of the U.S.A.," Econometrica, 26 (1): 37-66, 1958.

M. A. Girshik and T. Haavelmo, "Statistical Analysis of Demand for Foods," Econometrica, $15(2): 79-110,1947$.

and others. The most comprehensive static and dynamic analysis of the United States economy is presented by Goldberger.

For certain agricultural commodities, an analysis of dynamic properties of relatively simple models is presented in:

I. B. Suits, "An Econometric Model of the Watermelon Market," Journal of Farm Economics, 37 (2): 237-51, 1955.

D. B. Suits and S. Koizumi, "The Dynamics of the Onion Market," Journal of Farm Economics, 38 (2): 475-84, 1956. 
The economic magnitudes characterizing the potato market may be regarded as generated by a complex interaction of two basic processes-a deterministic process and a stochastic process. In the present analysis, the deterministic process is first studied. It leads to the conclusion that the potato market is deterministically stable and to the somewhat surprising, but not unexplainable, suggestion that a cobweb behavior of the potato market is indeed a recent development.

As the analysis of the deterministic process fails to explain the observed fluctuations, attention next turns to the stochastic process. This analysis supports the conclusion that random disturbances are the main source of instability in the potato market. Erratic variation in exogenous variables is found to be of secondary importance only. The implications of these findings with respect to any stabilization policy are considered important.

During the period analyzed, the exogenous variables have changed considerably. It is therefore of interest to evaluate the impact of these changes on the time path of the endogenous variables. The resulting change in the stationary state is subject to a comparative static analysis. The importance of this analysis to the study has been indicated above. It is clear, however, that in light of the time needed for adjustment, the time path of stationary states will never be achieved in an ever-changing environment. A "dynamic discrepancy" is thus generated. In the present study, the magnitude of this discrepancy is estimated and is found to be relatively unimportant. This type of analysis may be regarded as an exploration into comparative dynamic analysis.

In the fourth chapter, pages 641 to 651 , illustrative applications of the econometric model to policy formulations and forecasting are undertaken. In this context, various production policies which might be considered under collusive action by California potato growers are formulated. Since new production policies imply changes in certain behavioral equations, the consequences of these changes are explored and evaluated.

Development of optimum policies for a dynamic system calls for methods of dynamic programming and calculus of variations. These methods are not applied in the present study. Instead, simplified situations are dealt with which can be solved by the more pedestrian methods of ordinary calculus. These are by no means trivial situations, and it is suggested that the solutions obtained have important implications for practical policy decisions.

Treatment of the prediction problem is confined to the problem of developing long-run forecasts - an important aspect of the more general forecasting problem often neglected in econometric analysis. 
Figures 1 to 11 , pictured on pages 542 to 551 , are referred to in chapter 1 immediately following.

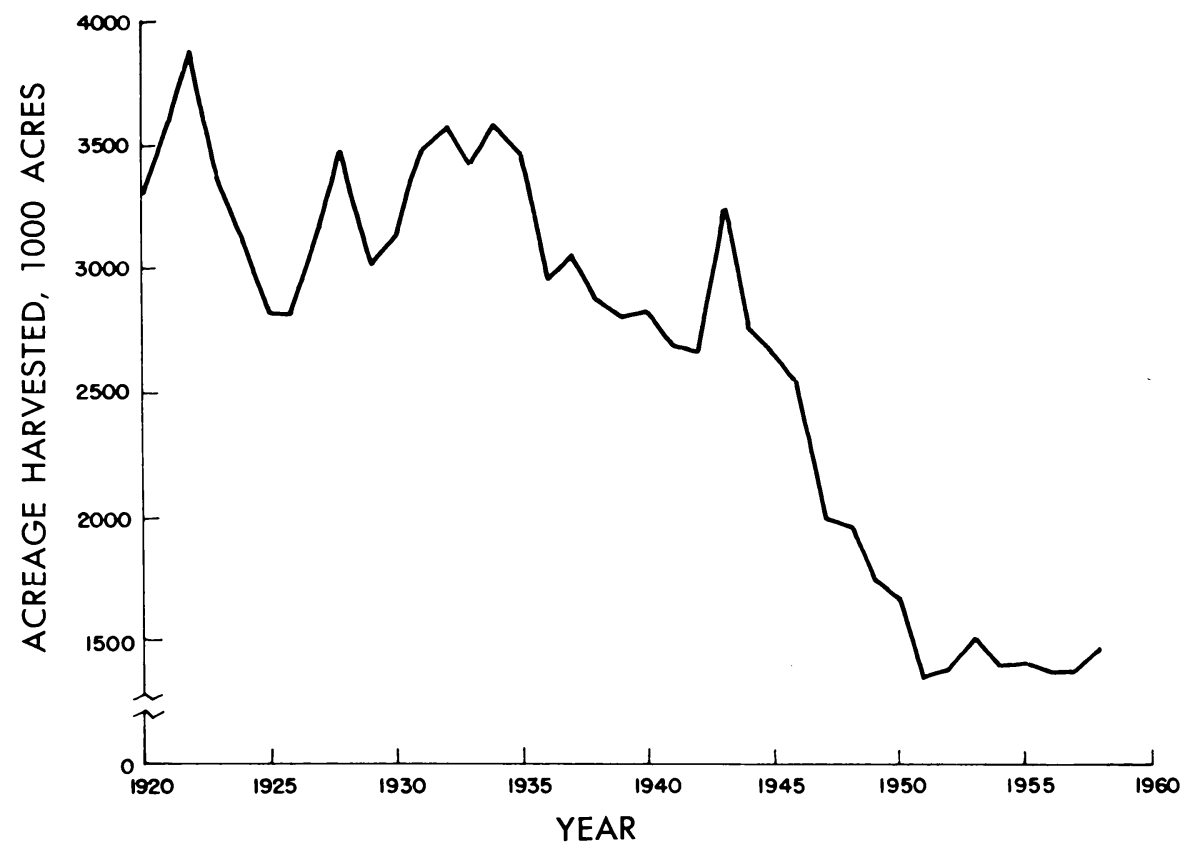

Fig. 1. Irish potatoes--acreage harvested, 1920-1958. Sources: See fig. 3. 


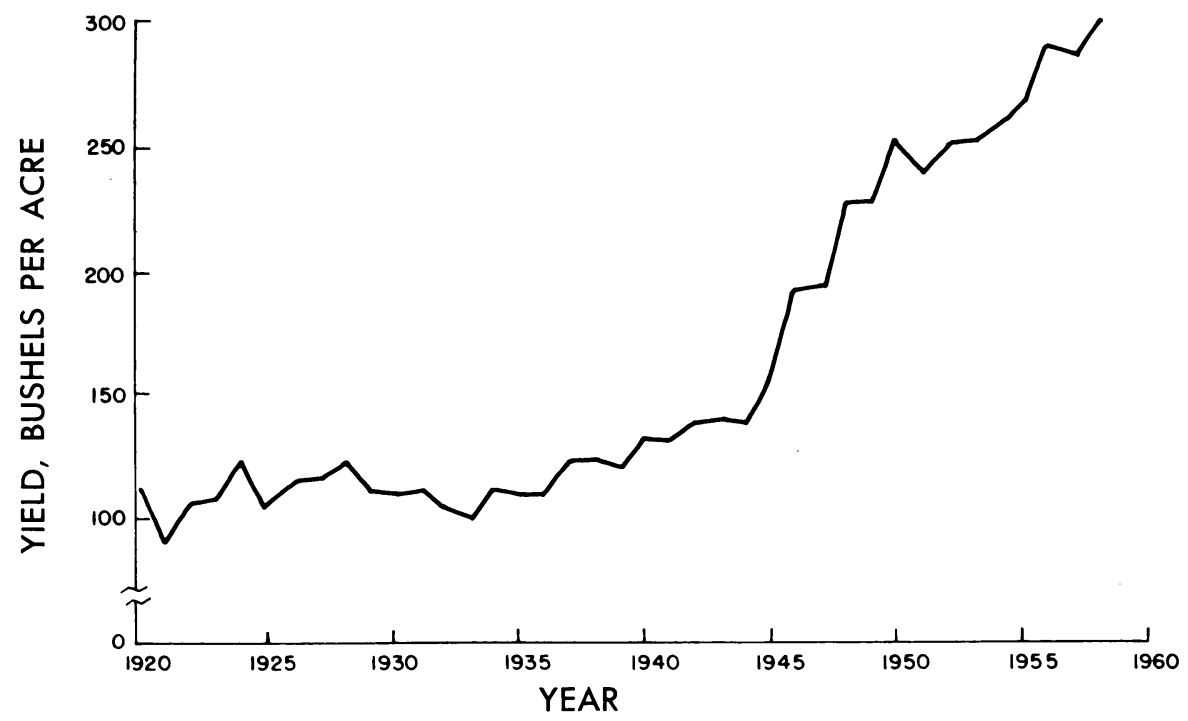

Fig. 2. Irish potatoes-average United States yields, 1920-1958. Sources: See fig. 3.

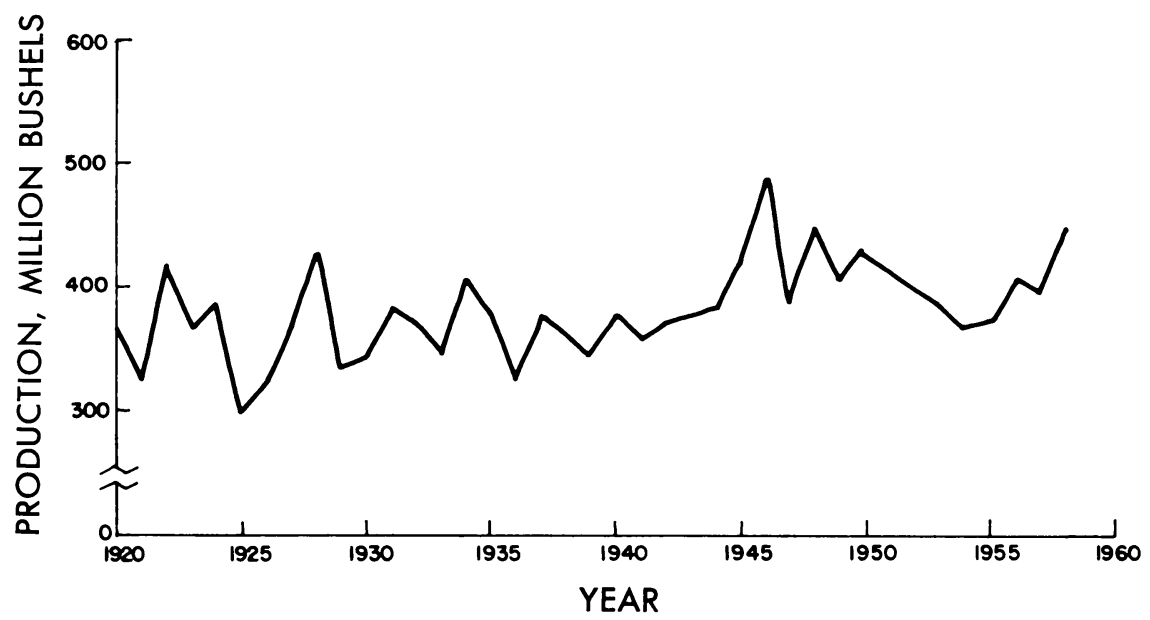

Fig. 3. Irish potatoes-total United States production, 1920-1958. Sources: USDA, Basic Potato Statistics, 1866-1950, Stat. Bul. 122 (Washington, 1953), p. 87. U. S. Agr. Marketing Serv.: Potatoes, Sweetpotatoes; Revised Estimates by States, 1949-1955, Stat. Bul. 190 (Washington, 1956), p. 2. Potatoes and Sweetpotatoes; Estimates by States and Seasonal Groups-Crops of 1956 and 1957 (Washington, 1958), p. 5. Potatoes and Sweetpotatoes; Estimates by States and Seasonal Groups-Crops of 1957 and 1958 (Washington, 1959$)$, p. 5. 


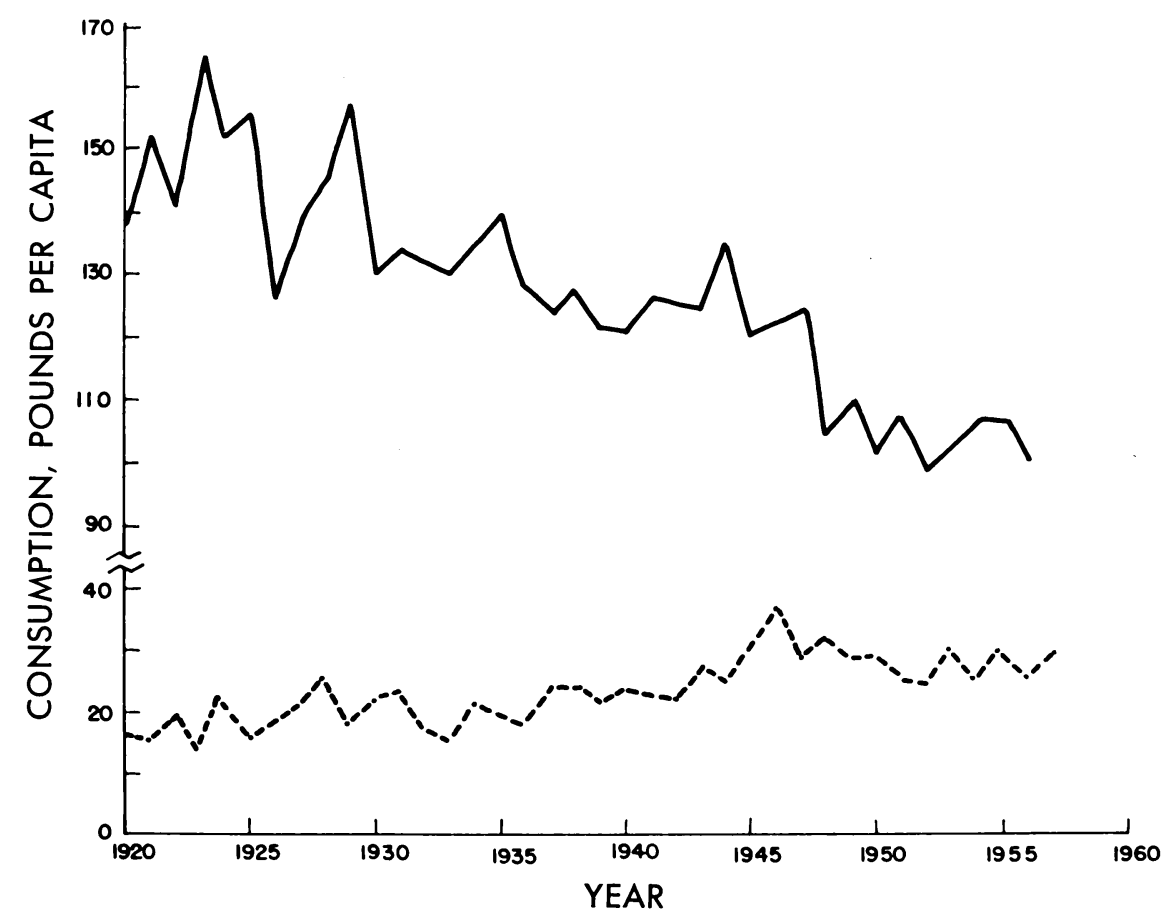

Fig. 4. Irish potatoes-per-capita consumption, 1920-1958. Upper curve indicates consumption of all potatoes, the lower that of early potatoes. Sources: U. S. Agr. Marketing Serv., Supplement for 1954 to the Consumption of Food in the United States, 19091952, Agr. Handbook 62 (Washington, 1955), p. 40. K. R. Farrell, California Early Potatoes; Statistical Report, University of California Agr. Ext. Serv. (Berkeley, 1958), table 19. Processed. 

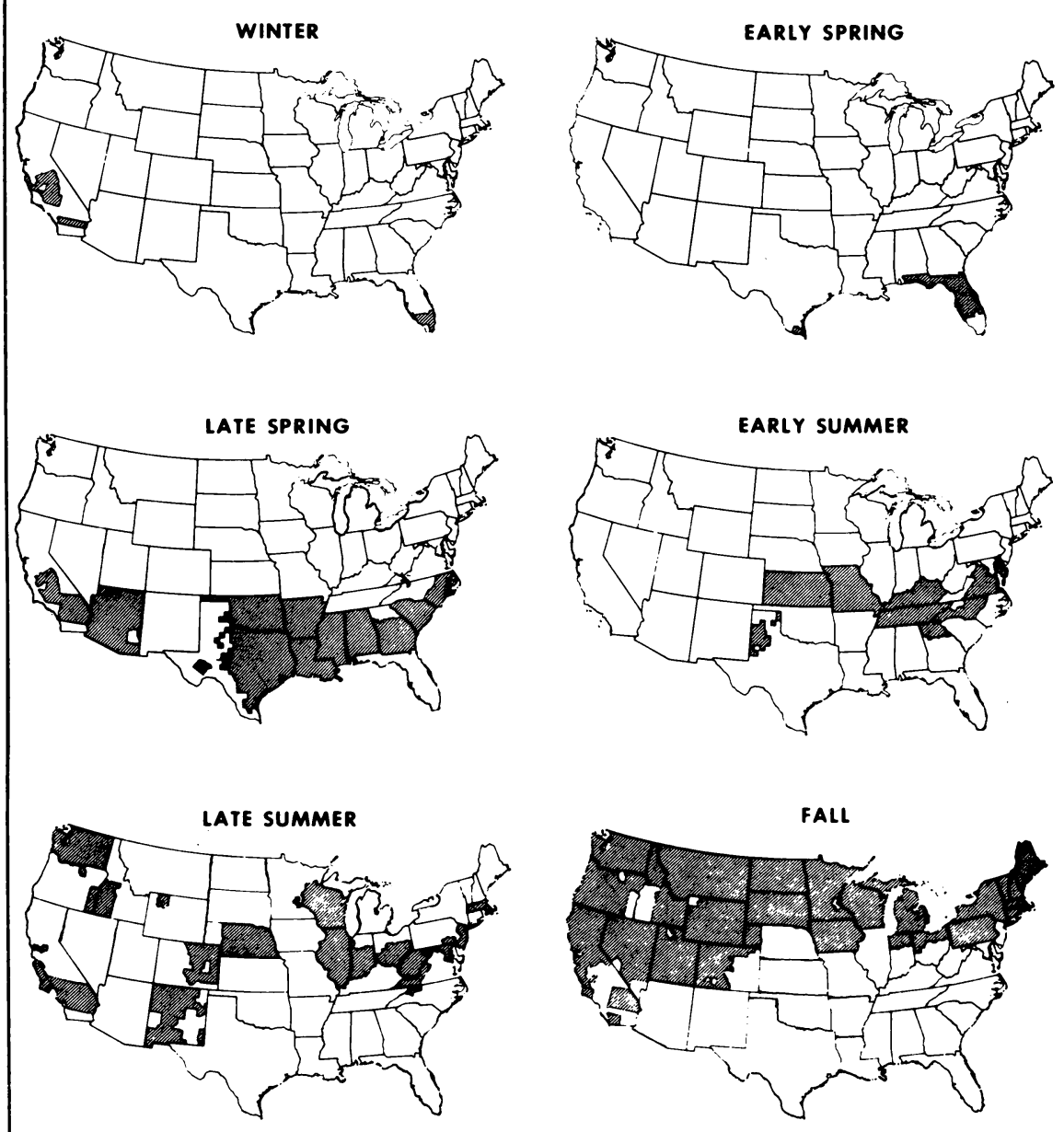

U.S. DEPARTMFNT OF ALRICULTURF

Fig. 5. Irish potatoes-principal producing areas by seasons. Source: U. S. Agr. Marketing Serv., Potatoes and Sweetpotatoes; Usual Dates for Planting, Harvesting and Marketing by Seasons, in Principal Areas, Agr. Handbook 127 (Washington, 1957), p. 2. 


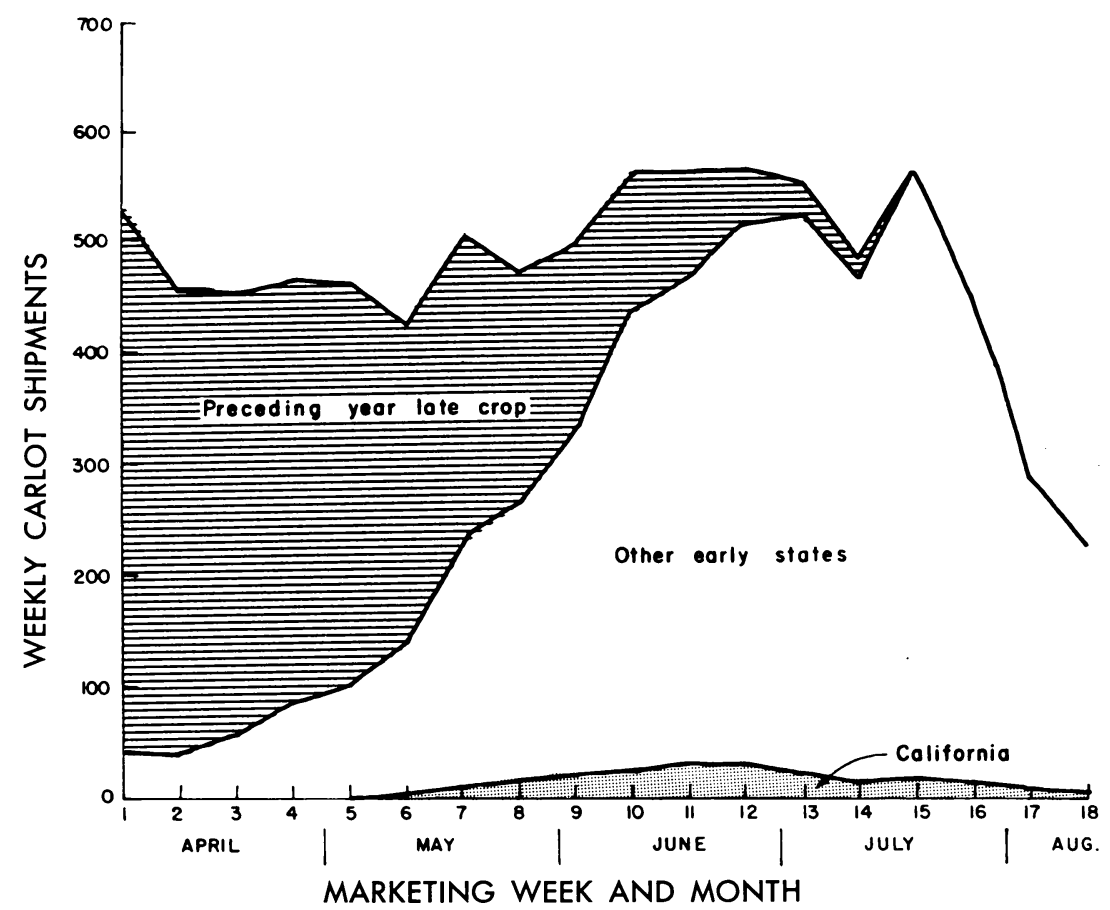

Fig. 6. Weekly carlot shipments of Irish potatoes in April-August, 1930-34. Sources: See fig. 7. 


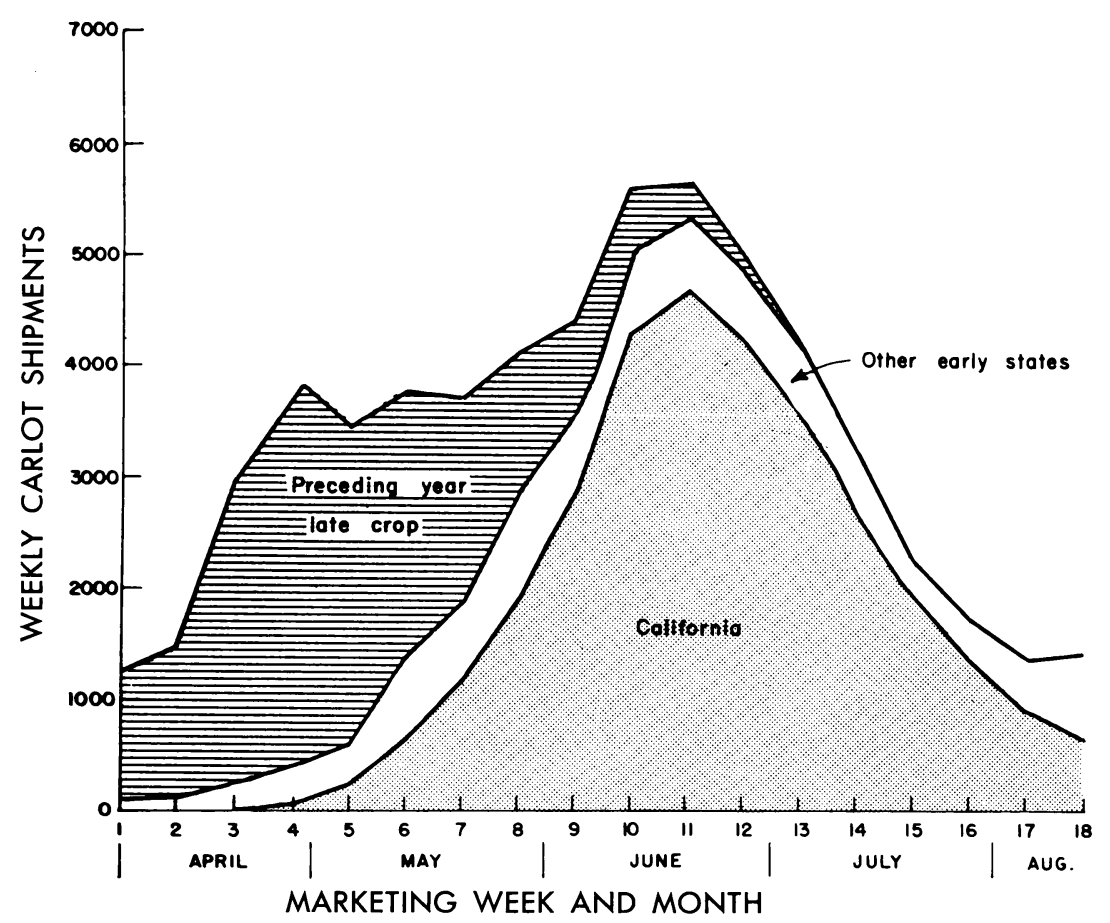

Fig. 7. Weekly carlot shipments of Irish potatoes in April-August, 1955-1957. Sources: U. S. Production and Marketing Adm., Weekly Summary of Carlot Shipments (Washington, weekly issues). U. S. Agr. Marketing Serv., Marketing Kern District Early Long White Potatoes (Bakersfield, Calif., annual summaries). 


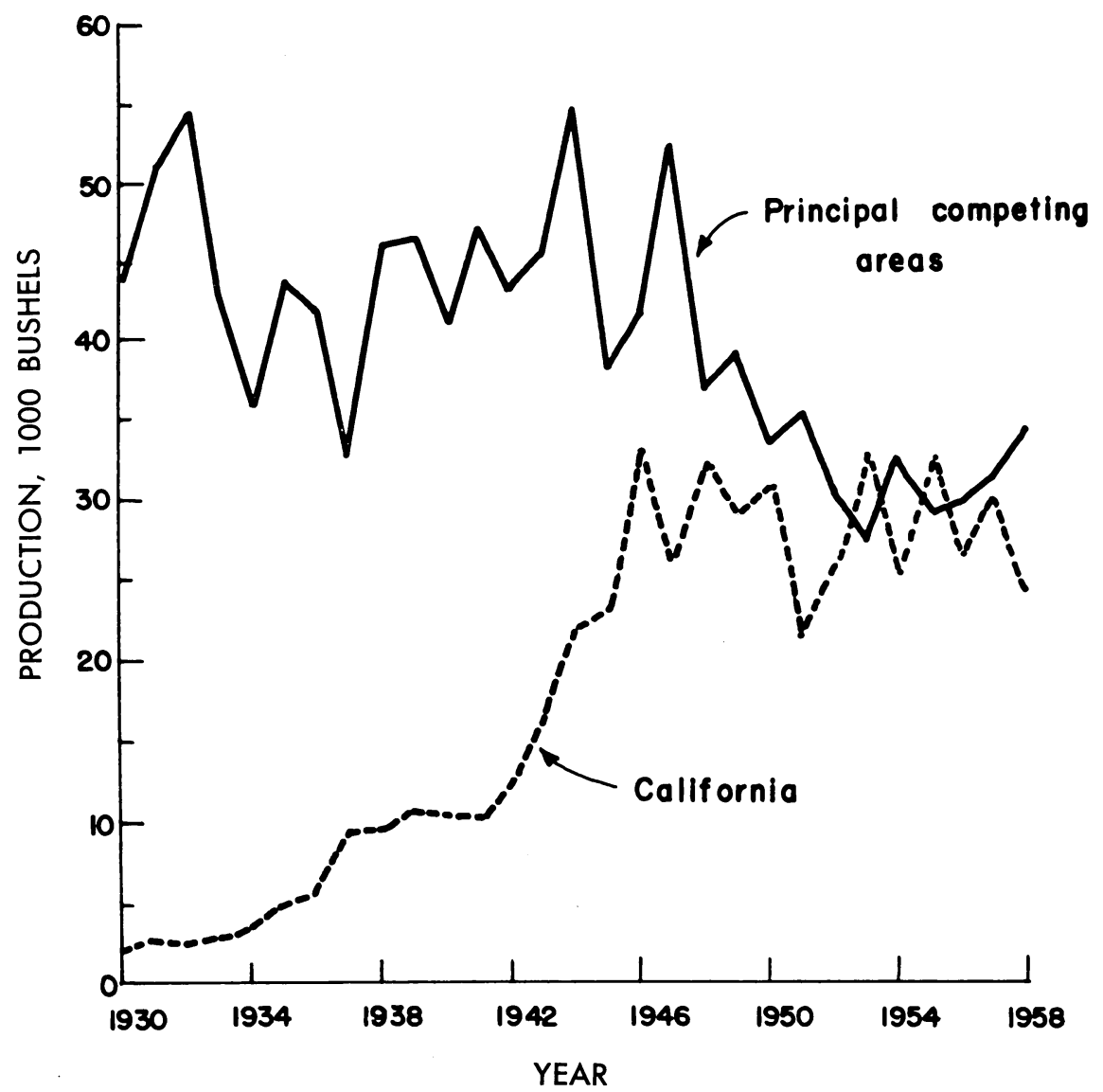

Fig. 8. Production of late spring potatoes-California and principal competing areas, 1930-1958. Sources: See fig. 10. 


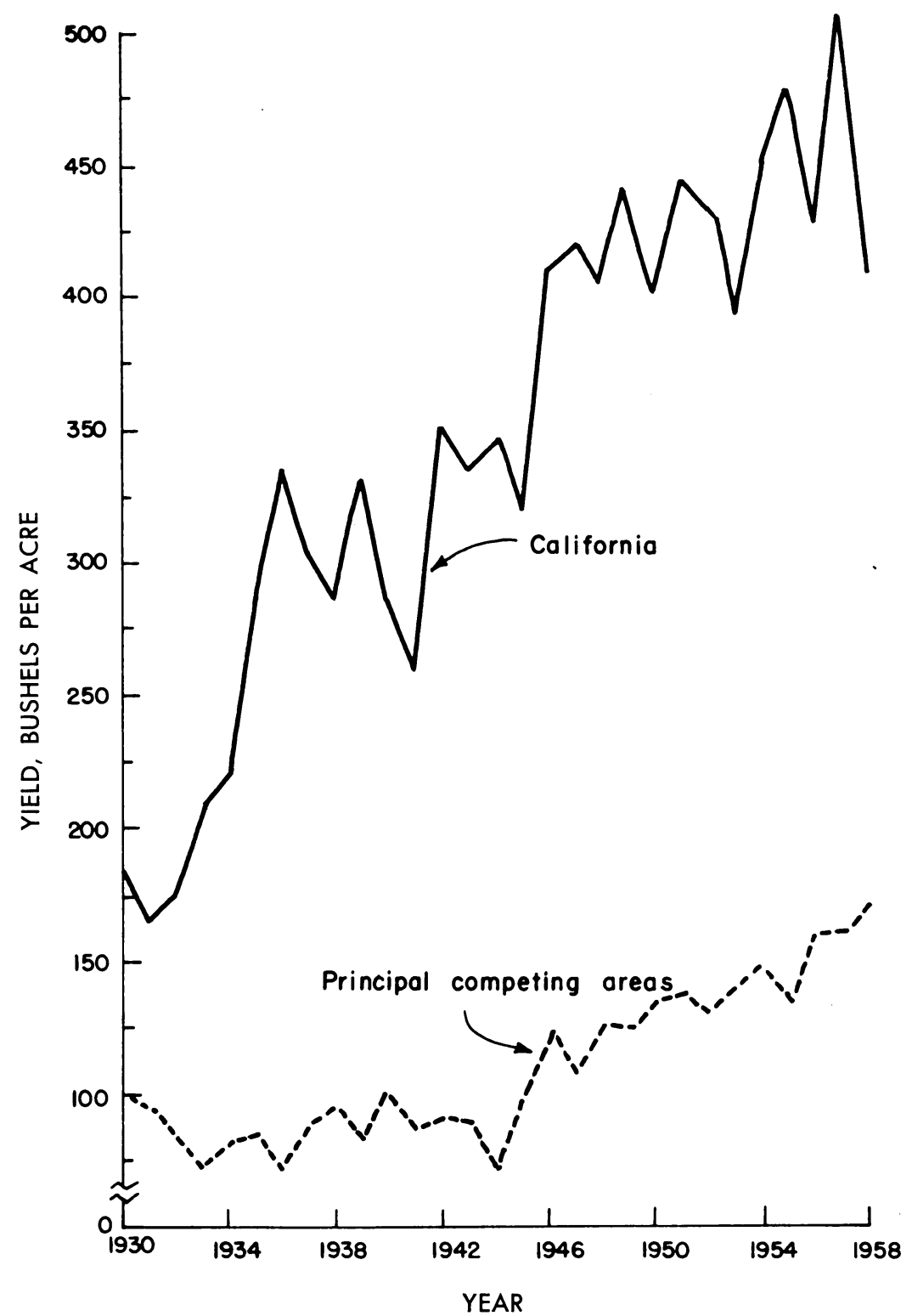

Fig. 9. Yields of late spring potatoes-California and principal competing areas, 19301958. Sources: See fig. 10. 


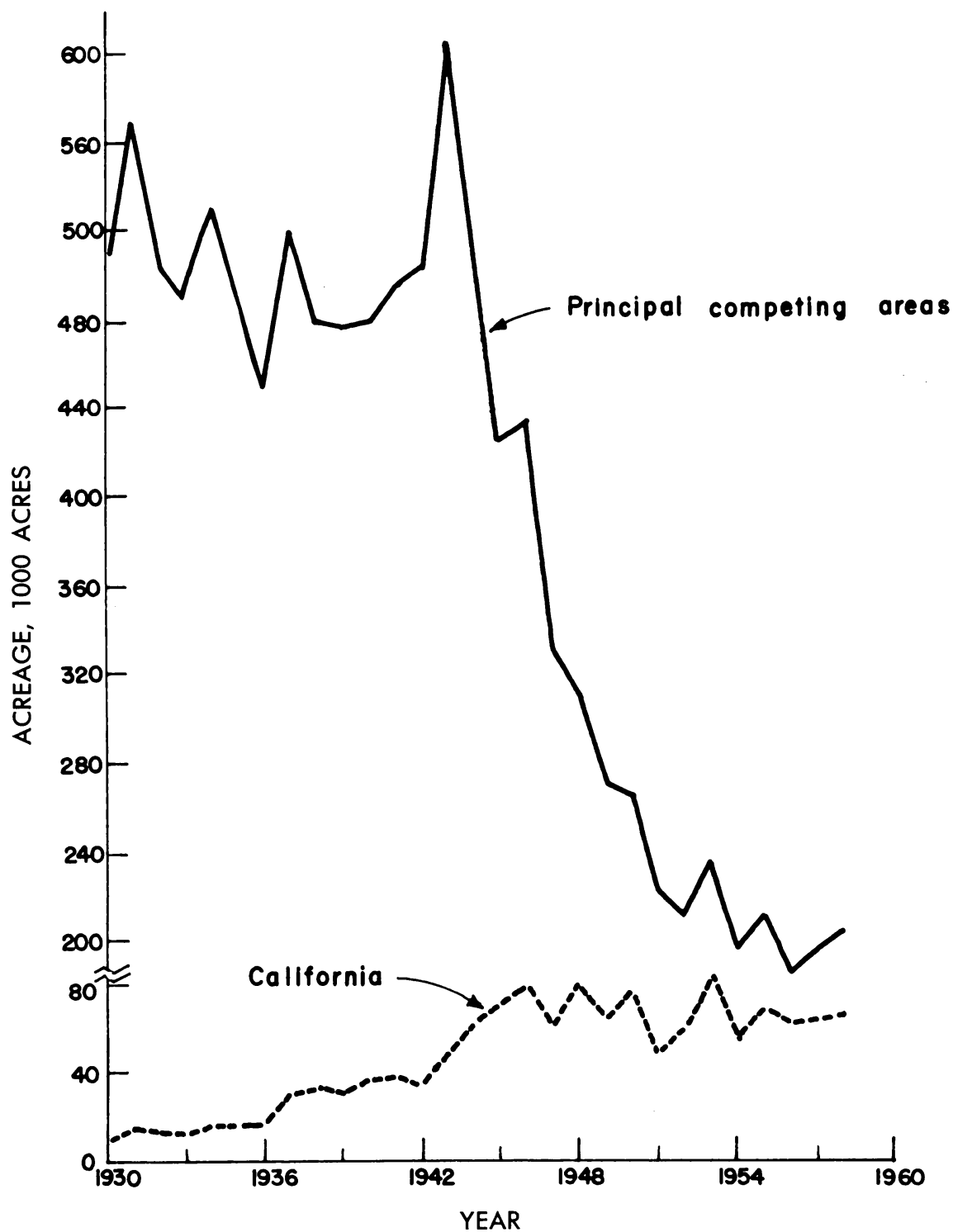

Fig. 10. Acreage of late spring potatoes-California and principal competing areas, 1930-1958. Sources: USDA, Basic Potato Statistics, 1866-1950, Dept. of Agr. Stat. Bul. 122 (Washington, 1953), pp. 73-86 and 92-108. U. S. Agr. Marketing Serv., Potatoes, Sweetpotatoes; Revised Estimates by States, 1949-1955, Stat. Bul. 190 (Washington, 1956), table 2. U. S. Agr. Marketing Serv., Potatoes and Sweetpotatoes; Estimates by States and Seasonal Groups-Crops of 1956 and 1957 (Washington, 1958), table 2. U. S. Agr. Marketing Serv., Potatoes and Sweetpotatoes; Estimates by States and Seasonal Groups-Crops of 1957 and 1958 (Washington, 1959), table 2. 


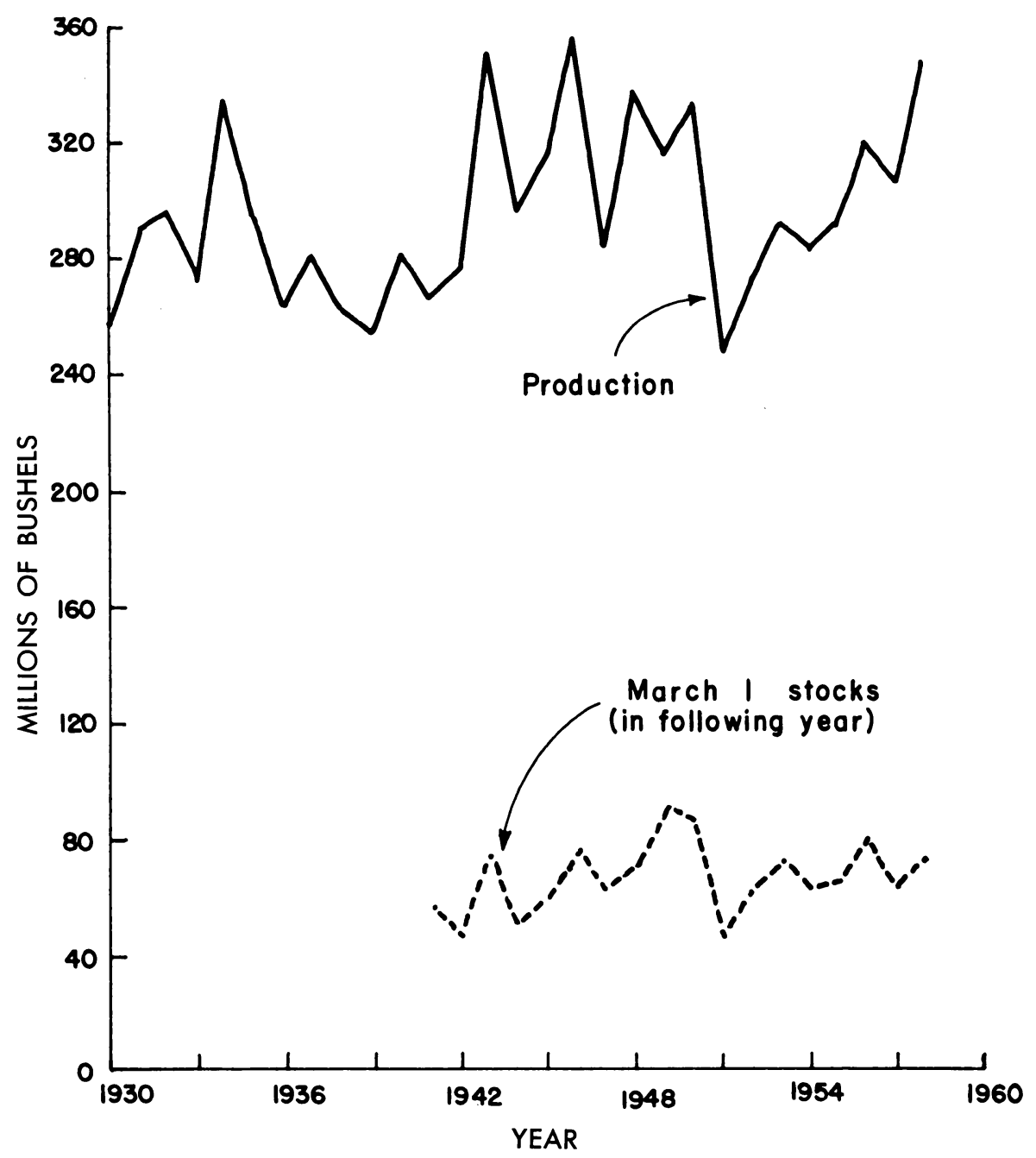

Fig. 11. Production of late Irish potatoes, 1930-1958 and March 1 stocks in following year, 1943-1958. Sources: USDA, Basic Potato Statistics, 1866-1950, Dept. of Agr. Stat. Bul. 122 (Washington, 1953), p. 64. U. S. Agr. Marketing Serv.: Potatoes, Sweetpotatoes; Revised Estimates by States, 1949-1955, Stat. Bul. 190 (Washington, 1956), table 2. Potatoes and Sweetpotatoes; Estimates by States and Seasonal Groups-Crops of 1956 and 1957 (Washington, 1958), table 2. Potatoes and Sweetpotatoes; Estimates by States and Seasonal Groups-Crops of 1957 and 1958 (Washington, 1959), table 2. Merchantable Potato Stocks, March 1 (Washington, annual reports). 


\section{THE ECONOMIC STRUCTURE OF THE POTATO INDUSTRY}

\section{General Importance and Trends}

The potato industry is one of the most important industries in United States agriculture. In terms of total value of production, it ranked in 1957 sixth among all crops and first among all vegetables. ${ }^{5}$ In 1958 , the total value of potatoes produced in the United States was $\$ 349.7$ million, out of which which $\$ 301.4$ million were sold and the rest consumed on farms where grown. ${ }^{6}$

General Trends. In the course of the last four decades, acreage planted, production, yields, and per-capita consumption of Irish potatoes have undergone considerable changes. Figures 1 to 4 illustrate the short-run variation, as well as the secular trend, of these important variables. The notable features of total production are its secular stability and short-run instability. During these four decades, population has increased by more than 50 per cent, percapita real income increased by a little less than 50 per cent, and the industry has undergone significant technological change; yet, the general level of production has shown but a slight increase. The reason for this phenomenon is, of course, the downsloping trend in per-capita consumption of Irish potatoes which marked this period. The second noticeable feature of total production is its strong short-run fluctuations. Variation of about 25 per cent of total production within a period of two to three years is not uncommon. The marked instability is mainly the outcome of variation in acreage and, to a lesser degree, of variation in yield. The trend in acreage (figure 1) is distinguished by a considerable reduction of the acreage planted and harvested. From a level of 3,300,000 acres in the early twenties, acreage has fallen to $1,400,000$ acres at present-almost a 60 per cent reduction. This decline of acreage was gradual until 1943, but very rapid since 1943, with a tendency to stabilize on a new low level during the last seven years. This substantial change in acreage has occurred with only slight changes in total production due to the great increase in yields during this period.

The trend in yield has been increasing at an increasing rate since the early 1920 's and up to 1950 . Since 1950 , yield has increased at more nearly a constant rate. The highest rate of increase in yields was during the years 1944 to 1950. During this period of six years, the United States average potato yield almost doubled. During the period 1920 to 1958, yields almost tripled. This unprecedented rise of yields has been brought about by a variety of factors. Most important among them are an increased use of fertilizers, improved varieties and seeds, better pest and disease control, general improvement in cultural methods and practices, and reallocation of production in accordance with comparative advantage.

${ }^{5}$ U. S. Dept. of Agr., Agricultural Statistics, 1958 (Washington, 1959), 473 p.

${ }^{6}$ U. S. Agr. Marketing Serv., Potatoes and Sweetpotatoes; Estimates by States and Seasonal Groups-Crops of 1957 and 1958 (Washington, 1959), p. 9. 


\section{Seasonal Categories, Major Producing Areas, and Growers Production Response}

Seasonal Categories and Major Producing Areas. Potatoes are grown for sale or for home use in practically every state, but the bulk of commercial production is highly localized. These concentrated areas have a comparative advantage in producing potatoes. The advantage is mainly due to climatic and soil conditions especially suited to the production of potatoes in some seasons and favorable geographical location with respect to the main markets.

Potatoes are harvested in some parts of the United States in every month of the year. In different seasons, different states are principal suppliers. For statistical purposes, the U. S. Department of Agriculture has classified the annual potato crop into seasonal categories according to the harvesting season. The present classification is as follows: ${ }^{7}$

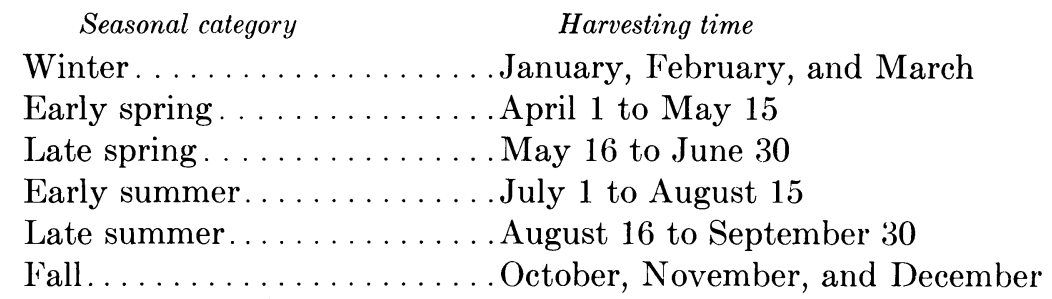

This classification has been employed since 1956. The earlier classification recognized only the following three major seasonal categories: (1) early, (2) intermediate, and (3) late.

The term "early Irish potatoes" is applied to the crop harvested during January through August in any given year. This category is further classified into the following subcategories:

Seasonal category Harvesting time

Winter January and February

Early spring. . . . . . . . . . . . . .

Late spring. . . . . . . . . . . . May and June

Summer. July and August

The intermediate crop is that portion of the crop which is harvested during September, and the late crop is harvested during October through December. In practice, of course, the beginning and end of seasons are not fixed calendar dates. There is typically some overlap in the marketing seasons, and weather frequently disturbs normal harvest schedules. States and, in some cases, counties within states are classified into seasonal groups in accordance with the period during which the bulk of the potato crop is harvested. Thus, some states may belong to more than one seasonal category. The major producing

${ }^{7}$ U. S. Agr. Marketing Serv., Potatoes and Sweetpotatoes; Usual Dates for Planting, Harvesting and Marketing by Seasons, in Principal Areas, Agr. Handbook 127 (Washington, 1957), $16 \mathrm{p}$. 
areas by seasons are presented graphically in figure 5. Their importance in the production of potatoes is indicated in table 1.

Winter Crop. The winter crop is produced in southern California and Florida. It accounts for 2.2 per cent of total United States production and is therefore a relatively unimportant component of total United States crop.

Early Spring Crop. This crop is produced mainly in Florida and to a lesser extent in Texas. The most active marketing period is during April and May and is therefore competing with the early part of the California late spring crop. Although the importance of the early spring crop in relation to total United States production is minor (2.3 per cent of total production), it is an

TABLE 1

UNITED STATES POTATO ACREAGE AND PRODUCTION, BY SEASONAL GROUPS, 1958

\begin{tabular}{|c|c|c|c|c|}
\hline \multirow[t]{2}{*}{ Seasonal group } & \multirow{2}{*}{$\begin{array}{c}\text { Acreage } \\
\begin{array}{c}\text { thousand } \\
\text { acres }\end{array}\end{array}$} & \multirow{2}{*}{$\begin{array}{c}\text { Harvested } \\
\begin{array}{c}\text { per cent } \\
\text { of total }\end{array}\end{array}$} & \multicolumn{2}{|c|}{ Production } \\
\hline & & & $\begin{array}{c}1,000 \text { hundred- } \\
\text { weight }\end{array}$ & $\begin{array}{c}\text { per cent } \\
\text { of total }\end{array}$ \\
\hline Winter........ & 34.5 & 2.5 & 4,971 & 2.2 \\
\hline Early spring....... & 31.2 & 2.3 & 4,703 & 2.1 \\
\hline Late spring. . & 166.2 & 12.0 & 24,152 & 10.3 \\
\hline Early summer. & 117.3 & 8.5 & 14,659 & 6.2 \\
\hline 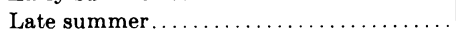 & 182.3 & 13.2 & 32,204 & 13.5 \\
\hline Fall ............ & 850.1 & 61.5 & 156.981 & 65.7 \\
\hline United States total. .................. & $1,382.6$ & 100.0 & 239,539 & 100.0 \\
\hline
\end{tabular}

Source: U. S. Agr. Marketing Serv., Potatoes and Sweetpotatoes; Estimates by States and Seasonal GroupsCrops of 1955 and 1956 (Washington, 1957), $15 \mathrm{p}$.

important component of the supply of new potatoes in the spring. Prices received by California growers are likely to be affected by the supply of early spring potatoes.

Late Spring and Early Summer Crop. The bulk of the California early crop, which is the focus of this study, belongs to these seasonal categories. Actually, the marketing of California early potatoes, exclusive of the winter crop, begins at about the third week of April and proceeds through May, June, July, and August. The peak of the marketing activity is in June. Thus, California's early season overlaps both the early spring and the early summer (figures 6 and 7).

Other late spring and early summer producers are concentrated in the South. The most important competing states are Alabama, Arizona, North Carolina, South Carolina, Texas, Virginia, Delaware, Kentucky, Missouri, and others.

The importance of California production relative to total production of early potatoes, as well as the absolute quantities produced, have increased very much during the last 30 years. These changes are well reflected in figures 6, 7, and 8. From a total of 2 million bushels produced in California in 1930, 
production increased to about 30 million bushels in the 1950's-an increase of 1500 per cent. In terms of relative importance, this is an increase from 4 per cent of total early production to about 50 per cent of total early production, winter crop excluded.

Figures 6 and 7 illustrate the corresponding change in total rail shipments. Since a higher percentage of California's crop was shipped by rail, the relative importance of California rail shipments shows even a greater change than total production. The greatest changes in California production took place during 1930 to 1946 , with the highest rate of increase during 1942 to 1946 . Since then, the general level of production has become stabilized at about 30 million bushels.

During the period under review, total production in principal competing areas has decreased markedly. The decrease in production in the principal competing areas, however, was much less than the gain in California, since total production of early potatoes has increased. It is interesting that during 1941 to 1947 - a period distinguished by the most rapid increase in California production-production of early potatoes in other states fluctuated about a constant level. On the other hand, in the following years, when California's production became stabilized, other states' production dropped markedly. That is to say-during 1941 to 1947, which was a period of relatively stable prices (due primarily to price control) and increasing demand, California producers made major gains in the potato market, whereas production of early potatoes in other states did not respond to these conditions. In the following period, during which total demand declined, the market position of California potatoes remained strong while other producers withdrew. The changes in production came about through changes in yields and changes in acreage (figures 9 and 10). Both California and other states have experienced increases in yields, but, in general, the rate of increase experienced by California has been greater than that of competing areas.

The increase in acreage planted to potatoes in California is the second component of the total increase in production. From figure 10 it appears that the general level of acreage in California has been relatively stable since 1946 .

The acreage planted to potatoes in principal competing areas has been reduced considerably. The decline in acreage has been much greater than the rise in yields. Consequently, total production has diminished considerably.

Production of spring potatoes in states other than California extends over a wide geographical area in the South. ${ }^{8}$ Variation in growing conditions, types

${ }^{8}$ Description of the production conditions of late crop potato and early crop produced in states other than California is based on:

U. S. Bur. of Agr. Econ., Generalized Types of Farming in the United States, Agr. Inf. Bul. 3 (Washington, 1950), $35 \mathrm{p}$.

Roger W. Gray, Vernon L. Sorenson, and Willard W. Cochrane, An Economic Analysis of the Impact of Government Programs on the Potato Industry of the United States, North Central Regional Publ. 42 and Minnesota Agr. Exp. Sta. Tech. Bul. 211 (St. Paul, 1954), pp. 52-87. 
of farming, and competing crops is great. In most of the area, the potato is a sideline crop, usually grown in small acreages per farm. The general types of farming are mainly cotton, tobacco, and general farming. In some areas, however, potato production is more concentrated, mainly on truck crop farms. Such is the case in parts of Florida, where potatoes are produced for the early spring market, and in parts of Alabama. Here, potatoes compete primarily with other truck crops, such as early vegetables.

Two-thirds to three-fourths of the California late spring potato acreage is found in Kern County. Tulare, Kings, and Kern counties in the southern San Joaquin Valley are the major producing counties. Late spring potatoes are produced on farms specializing in irrigated spring and summer field crops. In the major producing counties in California, cotton and alfalfa have been the other major enterprises, although acreage of small grains, beans, grapes, tree fruits, sugar beets, seed crops, or other vegetable crops is included in the organization of some of the farms. Expansion of potato acreage in Kern County began in the late 1920's and early 1930's. In the period 1930 to 1946 , the acreage planted increased from 1,500 acres to 65,000 acres, an increase made possible without compensating decline in acreage of other crops by the increase in irrigated cropland.

Late Crop-Late Summer and Fall. The late crop is the main component of the annual potato crop. In 1958, it accounted for approximately threefourths of the annual United States production. Areas producing late crop are located mostly in the northern part of the country. The states which ranked first in production in 1958 were:

\begin{tabular}{|c|c|}
\hline State & $\begin{array}{c}\text { Production } \\
\text { in 1,000 } \\
\text { hundredweight }\end{array}$ \\
\hline Idaho. . & 43,838 \\
\hline Maine. . & 37,250 \\
\hline New York. & 20,050 \\
\hline North Dakota. & 14,700 \\
\hline Colorado. & 13,505 \\
\hline Minnesota. & 11,346 \\
\hline Washington. & 11,040 \\
\hline Oregon. & 9,750 \\
\hline
\end{tabular}

The general level of production of late potatoes has increased but slightly during the last three decades. During the war and the immediate postwar years, it tended to be higher than in the preceding and subsequent periods. There were also marked fluctuations in the short run, which, curiously enough, seem to have been stronger during the years when the price support program was in operation (figure 11).

Description of the production conditions of late spring potatoes in California is based on: Chester O. McCorkle, Jr., and Yair Mundlak, "Statistical Analysis of Supply Response in Late Spring Potatoes in California," Hilgardia, 24 (16): 455-93, 1956.

Ivan M. Lee, California Early Potatoes; Situation and Outlook, 1948, Calif. Agr. Exp. Sta. Cir. 390 (Berkeley, 1948), 30 p. 
Late crop potatoes are characteristically more storable than early potatoes. In fact, they can be kept in storage for several months, often by relatively simple storage facilities. Since they are also produced in a season in which weather conditions are favorable to the majority of United States potato growers and are thus produced relatively in abundance, stocks of late potatoes are normally carried over through the winter and into the spring of the next calendar year.

Production of late potatoes extends over a wide and heterogeneous area. Variation in type of farming, soil and climatic conditions, and alternative enterprises is extreme. Aroostook County, Maine, is by far the most concentrated potato production area in the United States. Conditions for growing potatoes are ideal, while no comparable economic alternatives are available. Potatoes are a major cash crop in several of the western irrigated areas. They are the major crop in southern Oregon and northern California and in parts of Idaho, where they compete chiefly with sugar beets and dry beans. Other important irrigated areas are located in Washington and in Colorado. An important center of production in the Midwest is the Red River Valley (North Dakota and Minnesota). Here, the prevailing farm type is predominantly one of small grain farming. Potatoes serve as a cleaning crop in the rotation. The alternative is summer fallow. In the Lake states, potatoes are grown mainly as a side line on livestock and dairy farms. Here, potatoes serve as a cash crop. Such crops as dry beans, sugar beets, onions, and cabbage have come to substitute increasingly for potatoes. Also, an increasing demand for livestock products has generated a shift to more grains and hay production and fewer potatoes. Finally, as already mentioned, there has been an important shift of production from non-specialist to specialist states in the last two decades.

The Determinants of Growers' Production Response. In general, two phases can be distinguished in the supply of agricultural products to the market. In the first phase, the quantity to be produced is determined by the various producers. In the second phase, total production becomes a datum, and new decisions are made as to the quantity to be supplied out of the given output.

The relations considered in this chapter correspond to the first phase, that is, the relations describing the forces determining total output. As will be indicated in the subsequent discussion of the marketing process, the potato grower sells his output in a highly competitive market. He thus regards potato prices as given to him. This is, in general, true also for the prices of other crops which may compete with potatoes for the resources at the farmers' disposal.

The theory of producers' behavior and the derivation of the individual and aggregate production response functions have been treated extensively in the economic literature and will not be repeated here. ${ }^{9}$ The following discussion

${ }^{9}$ An extensive treatment of production theory can be found in:

J. R. Hicks, Value and Capital (Oxford: Clarendon Press, 1939), 328 p.

Sune Carlson, $A$ Study in the Pure Theory of Production (New York: Kelley \& Millman, Inc., 1956), $128 \mathrm{p}$.

Interesting application to farmers' production response is to be found in: Marc Nerlove, The Dynamics of Supply: Estimation of Farmers' Response to Price (Baltimore: Johns Hopkins Press, 1958), 268 p. 
will, therefore, consist of a few general remarks concerning production response of potato growers.

In the short run, total output (or input) will depend on the prices the farmer anticipates for the various outputs (potatoes and competing crops), the prices of the variable inputs, the amounts of fixed inputs at his disposal, and the production function. In the long run, all fixed factors become variable, and total output will depend on the prices of all inputs (including those which are fixed in the short run), as well as on the prices of all outputs. The production function itself varies over time due to technological changes and variation of weather conditions. Furthermore, output will depend not only on total resources under the farmer's control but also on the quality and degree of specialization of these resources. Thus, the know-how and managerial ability of the farmer in the production of potatoes may be expected to depend on his past experience in this line of production. Likewise, one would expect the amount of resources specialized to potato production to be greater following a prolonged period of expanding production. This may explain why the individual production response function may depend on past actual outputs. Risk is also an important element in potato production response. The experience gained during the price support program tends to indicate that potato growers have a "preference for certainty."

The industry production response function is a simple summation of the individual functions, provided no net external economies or diseconomies of large-scale production exist. In the case of the potato industry, net external economies of large-scale production are probably not important, although such may exist. External diseconomies may be important, if expanded potato output leads to higher prices of inputs. The actual situation with respect to this aspect is not clear, but it is believed that these diseconomies are relatively small. A simple summation of individual production response functions may therefore be a good approximation to the actual industry function. The implication of this statement is that the variation in output associated with given variation in prices is a simple sum of the individual variations. Accordingly, the direction of change in the industry output or input is suggested directly by the corresponding microtheory.

Thus, given the market and production structure of the potato industry in the United States as described above, economic theory suggests that an increase in potato prices will generate a positive production response. An increase in prices of other crops, however, may bring about an increase, decrease, or no change in the production of Irish potatoes, the actual response depending on the technical relation underlying the productive process.

Results of Previous Studies. Studies designed to obtain quantitative measures of potato growers' response to price date from the early 1920's. These, like other attempts to estimate supply functions, have since faced two basic diffculties: (1) supply functions are defined and analyzed by economic theory in terms of unobservable variables, that is, in terms of anticipated prices; and (2) production response is basically a dynamic process, in which formation of 
expectations and adjustments of the productive capacity play a central role. Unfortunately, these dynamic elements are extremely difficult to capture in quantitative analysis.

-A problem which usually arises, when the production response of a given crop is estimated, concerns the choice of the dependent variable. In most cases, better fits have been obtained by taking acreage rather than output as the dependent variable. The conventional argument is that farmers respond to price mainly by means of acreage variation, whereas the application of other inputs is varied but little. Evidence is not conclusive on this point. In the case of potatoes, $\mathrm{Hee}^{10}$ has found a significant yield response to price in late potatoes (table 2), whereas McCorkle and Mundlak ${ }^{11}$ were unable to find such a relation for California Spring potatoes.

Table 2 contains a summary of previous estimates of potato production response relations. United States aggregate, as well as certain regional estimates, are presented, and the time period on which each estimated relation is based is indicated in the Table.

The results obtained by Working, using a method of first differences, were reported by J. D. Black ${ }^{12}$ in 1924 . Details on the exact formulation are not available, so it is difficult to make any inferences.

In the $\mathrm{H}$. P. Hartkemeier ${ }^{13}$ results, it appears that for the period analyzed total production depended on July temperature in the current year and the preceding year. Hartkemeier suggests that the effect of the preceding-year temperature is through its effect on farmers' price expectation. B. H. Pubols and S. B. Klaman ${ }^{14}$ have related changes in acreage to price lagged one year and two years for the period 1922 to 1941 . Their formulation recognizes the dynamic aspect of the production response and allows the derivation of longrun elasticities. It is interesting that, whereas the long-run elasticities of acreage response are more or less equal for the United States, the 18 late states, and Idaho, the short-run elasticity is considerably greater for Idaho. That is, producers in this highly specialized state are more responsive to price variation in terms of short-run adjustment. Using a similar method, Gray, Sorenson, and Cochrane ${ }^{15}$ found similar results.

McCorkle and Mundlak ${ }^{16}$ attempted several formulations to estimate the acreage response of California late spring potatoes. All formulations gave high multiple correlation coefficients, but none of them included any variable for different points in time. Hence, the long-run elasticity cannot be derived.

${ }^{10}$ Olman Hee, "The Effect of Price on Acreage and Yield of Potatoes," Agr. Econ. Res., 10 (4): 131-40, 1958.

${ }^{11}$ McCorkle and Mundlak, op. cit.

${ }^{12}$ J. D. Black, "Elasticities of Supply of Farm Products," Journal of Farm Economics, 6 (2): 145-55, 1924.

${ }^{13}$ H. P. Hartkemeier, "The Supply Function for Agricultural Commodities," The University of Missouri Studies, 7 (4): 1-79, 1932.

${ }^{14}$ B. H. Pubols and S. B. Klaman, Farmers' Response to Price in the Production of Potatoes, 1922-1941, U. S. Bur. of Agr. Econ. (Washington, 1945), 10 p. Processed.

${ }^{15}$ Gray, Sorenson, and Cochrane, op. cit.

${ }^{16}$ McCorkle and Mundlak, op. cit. 


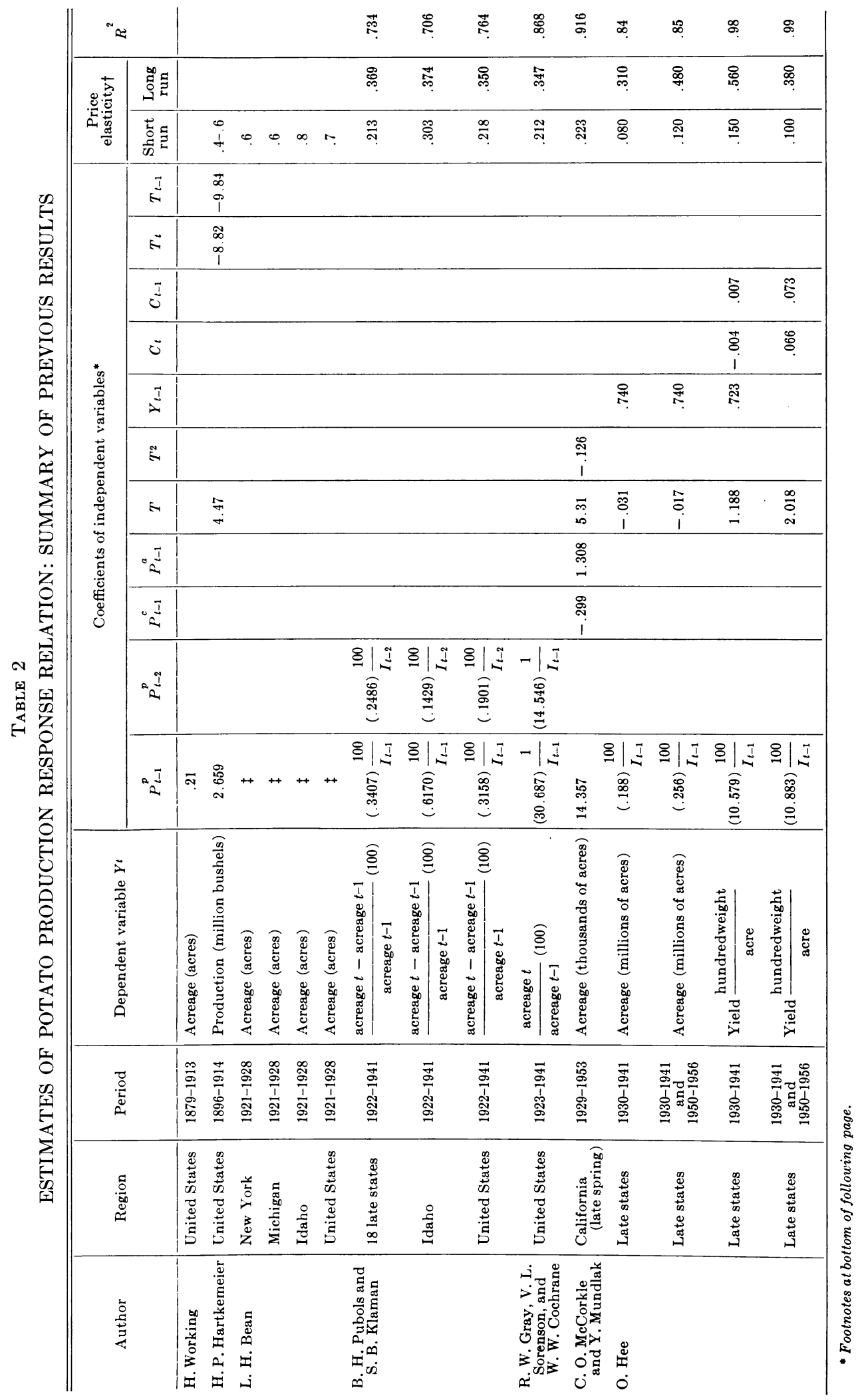


Only one of their formulations is cited in table 2. Using Nerlove's model, Hee ${ }^{17}$ derived estimates of the acreage response function for the late states. The short-run elasticities (that is, changes in acreage in response to changes in last year's price) estimated by Hee are smaller than those of Pubols and Klaman, but long-run elasticities are about the same or even greater.

The Econometric Approach Adopted. The econometric approach adopted for the purpose of estimating the supply relations of the various regions follows the development by Nerlove, ${ }^{18}$ allowing explicitly for an adjustment process. In the simple case, where no prices of particular competing crops are included explicitly in the formulation, the present formulation is analogous to his formulation derived from the expectation model. The "coefficient of adjustment" can then be interpreted as the "coefficient of expectation." In the case where prices of particular competing crops are included, the "expectation" approach has some statistical drawbacks. This is true since (1) it then becomes necessary to include lagged variables as explanatory variables, a form of specification which may lead to serious multicolinearity, and (2) the estimates of the "coefficients of expectation" are no longer unique.

The underlying model and the subsequent formulation derived by Nerlove is presented here for completeness.

Let $X_{t}=$ actual acreage in year $t$

$\bar{X}_{t}=$ acreage corresponding to conditions prevailing in year $t$ but after full adjustments are allowed

$P_{t}^{*}=$ the price expected by farmers to prevail in year $t$ and thereafter ("normal price")

$V_{t}=$ prices received by farmers for competing crops in year $t$

$t \quad=$ time

A linearized long-run acreage response function is:

$$
\bar{X}_{t}=c_{0}+c_{1} P_{t}^{*}+c_{2} V_{t}+c_{3} t
$$

${ }^{17}$ Hee, op. cit.

${ }_{18}$ Nerlove, op. cit., pp. 267-68.

M. Nerlove and W. Addison, "Statistical Estimation of Long-Run Elasticities of Supply and Demand," Journal of Farm Economics, 40 (4): 861-80, 1958.

${ }^{*} P_{t}^{p}=$ Average seasonal prices received by farmers for potatoes. In all but $\mathrm{O}$. Hee, analysis $P_{t}^{p}$ is in cents per bushel. In O. Hee, analysis is in dollars per bushel.

$P_{i}^{c}=$ Average seasonal price received by California growers for cotton lint; cents per pound.

$P_{t}^{a}=$ Average seasonal price received by California growers for alfalfa hay; dollars per ton.

$T_{t}=$ Temperature in July.

$T=$ Time.

$C_{t}=$ Cost of fertilizer, April 1 of each year deflated by wholesale price index.

$I_{t}=$ Index of prices received by farmers for all farm products.

t Elasticities are computed at the means of prices, quantities, and indices for the period analyzed. Long-run elasticities were computed on the assumption that in the long-run equilibrium "stationary" prices and quantities are constant over time.

$\ddagger$ No data_available. 
The explanatory variable $t$ is included to represent trends in the production function. The adjustment process is assumed to take place according to the following model:

$$
X_{t}-X_{t-1}=\gamma\left(\bar{X}_{t}-X_{t-1}\right)
$$

Substituting (1) into (2), we get:

$$
\begin{aligned}
X_{t} & =c_{0} \gamma+c_{1} \gamma P_{t}^{*}+c_{2} \gamma V_{t}+c_{3} \gamma t+(1-\gamma) X_{t-1} \\
& =\pi_{0}+\pi_{1} P_{t}^{*}+\pi_{2} V_{t}+\pi_{3} t+\pi_{4} X_{t-1}
\end{aligned}
$$

The parameters of (1) and the "coefficient of adjustment" are uniquely determined by the parameters of (3). Thus:

$$
\begin{aligned}
& \text { (a) } \gamma=1-\pi_{4} \\
& \text { (b) } c_{k}=\frac{k}{1-\pi_{4}} \quad k=0,1,2, \text { and } 3
\end{aligned}
$$

In the actual formulation, $P_{t}^{*}$ will be replaced by $P_{t-1}$. That is, the "adjustment" model is based on the assumption that farmers expect last year's price to be the "normal price." The estimated relations are presented in Section "Estimated Structure," pages 590 to 599.

\section{The Marketing Process, Temporal Structure, and Spatial Relation in the Potato Market}

The Marketing Process and Farm-Retail Price Relations. The market structure is distinguished by the variety of channels through which potatoes move from growers to consumers. ${ }^{19}$ Growers usually have the opportunity of making sales (referred to as cash, f.o.b., or local shipping point sales) to local dealers or to representatives of city wholesalers, jobbers, or chain stores. Growers may also consign their potatoes to shippers, who send them to wholesale markets, or they may consign them to receivers in the wholesale markets. Such transactions are called "delivered sales."

Wholesalers buy from the growers or local dealers through their agents in the producing areas and through the growers' agents in the wholesale markets. The wholesaler usually sells to jobbers, chain stores, and others. Usually, the retailer obtains his stock from a jobber. Individual growers and dealers control only very small proportions of the crop and are therefore unable to affect prices. This, combined with the existence of many alternative marketing channels, makes the system highly competitive.

${ }^{19}$ Description of the marketing process is based on:

F. E. Scott and Herbert W. Mumford, Jr., Problems in Marketing Potatces; Preliminary Results of Some Recent Research, U. S. Bur. of Agr. Econ. (Washington, 1949), 60 p. Processed.

F. E. Scott, An Analysis of the Factors Affecting the Price of California Early Potatoes (unpublished Master's thesis, University of California, 1942), $87 \mathrm{p}$. 
Marketing orders were instrumental in some instances in controlling quality of potatoes shipped to terminal markets. The quality is controlled by setting quality standards. Some control of quantities shipped may be achieved through changes in these standards. Thus, some reduction in quantities shipped may result from raising the quality standards.

The above suggests that at the farm and wholesale levels the potato market is highly competitive. On the retail level, however, this need not be true. At this level, products become differentiated by the mere fact that they are sold in different retail stores. That is, the same kind of potato is a different product when it is sold in a different retail store. ${ }^{20}$

To analyze the behavior of an individual retailer under such conditions it is assumed that (a) the retailer is a profit maximizer and (b) the demand function for his goods depends on the services, including advertising, that he provides in selling his goods.

Let:

$$
\begin{aligned}
& P_{r}=\text { retail price of the good } \\
& Q=\text { quantity sold } \\
& P_{w}=\text { wholesale price of the good } \\
& C_{r}=\text { total retail selling cost (excluding purchase price of the good) } \\
& S=\text { "quantity" of selling services. }
\end{aligned}
$$

Assume the demand function for his good is:

$$
\begin{aligned}
& Q=Q\left(P_{r}, S\right) \\
& \frac{\partial Q}{\partial P_{r}}<0 \quad \frac{\partial Q}{\partial S}>0
\end{aligned}
$$

and the retailer's cost function:

$$
\begin{array}{cc}
C_{r}=C_{r}(Q, S) \\
\frac{\partial C_{r}}{\partial Q}>0 & \frac{\partial C_{r}}{\partial S}>0
\end{array}
$$

Accordingly, the profit function is:

$$
R=P_{r} Q-P_{w} Q-C_{r}(Q, S)
$$

The necessary conditions for maximum $R$ with respect to $P_{r}$ and $S$ are:

$$
\begin{aligned}
& \text { (a) } \frac{\partial R}{\partial P_{r}}=P_{r} \frac{\partial Q}{\partial P_{r}}+Q-P_{w} \frac{\partial Q}{\partial P_{r}}-\frac{\partial C_{r}}{\partial Q} \frac{\partial Q}{\partial P_{r}}=0 \\
& \text { (b) } \frac{\partial R}{\partial S}=P_{r} \frac{\partial Q}{\partial S}-P_{w} \frac{\partial Q}{\partial S}-\frac{\partial C_{r}}{\partial Q} \frac{\partial Q}{\partial S}-\frac{\partial C_{r}}{\partial S}=0
\end{aligned}
$$

${ }^{20}$ E. H. Chamberlin, The Theory of Monopolistic Competition, a Reorientation of the Theory of Value (7th ed.; Cambridge: Harvard University Press, 1958), pp. 56-70. 
For any level of $S$ the relationship between the wholesale price and the retail price can be derived from equation (8a). It is:

$$
P_{w}=P_{r}\left(1+\frac{1}{\eta_{P}}\right)-\frac{\partial C_{r}}{\partial Q}
$$

where price elasticity

$$
\eta_{P}=\frac{\partial Q}{\partial P_{r}} \frac{P_{r}}{Q}<0
$$

Hence, the less elastic is demand at the retail level (for a given store), the smaller will be the coefficient associated with the retail price.

In deriving the retail to farm price relationship, it is assumed that at the farm and wholesale levels the system is perfectly competitive. Then profit maximizing behavior of the wholesaler will lead to the following relation:

$$
P_{w}=P_{f}+b d+\frac{\partial C_{w}}{\partial Q}
$$

where

$$
\begin{aligned}
& P_{f}=\text { farm price } \\
& d=\text { distance from farm to the terminal market } \\
& b=\text { transportation cost per unit product, per unit distance } \\
& C_{w}=\text { wholesale handling costs. }
\end{aligned}
$$

Substituting equation (10) into equation (9) gives:

$$
P_{f}=-\left(\frac{\partial C_{r}}{\partial Q}+\frac{\partial C_{w}}{\partial Q}\right)+\left(1+\frac{1}{\eta_{P}}\right) P_{r}-b d
$$

This represents the relationship between the retail price charged by an individual retailer and the potato farm price at a given location. In the present model, however, the retail price entering is a weighted aggregate. This complicates the derived relation somewhat, particularly since any individual demand function is not independent of prices charged by other retailers. Intuitively, however, one may expect the relationship in the aggregate to be similar to the individual relationship, at least with respect to the variables included and the signs of the coefficients.

From equation (11), it follows that the derived farm price depends on the marginal selling costs (retail and wholesale) and on transportation costs. The selling costs depend on the efficiency of the marketing system (mainly technological) and on the quantity of services provided. Generally speaking, the increased demand for services in the past has more than offset the improved efficiency. This is suggested by the farmers' declining relative share of consumers' expenditures on potatoes. The farmers' share decreased from about 
50-60 per cent at the beginning of the 1920's to approximately 35 per cent in 1957-58. ${ }^{21}$ Another characteristic of the farm-retail spread is its rigidity in the short run. ${ }^{22} \mathrm{~A}$ possible explanation for this rigidity is that wholesalers and retailers operate within the range of turnover such that the marginal cost terms in equation (11) are relatively stable.

The Temporal Structure and Spatial Relation in the Market. The temporal structure of the United States potato market is determined by the seasonality of production and the storage properties of the crop. The main features of this structure are illustrated in the flow chart presented in figure 12.

Temporally the market can be divided into two parts - the winter market, extending over the period September through February, and the spring market, extending over March through August. The first market is supplied mostly by late crop potatoes. The second market is supplied by two types of potatoes: (1) stocks of the preceding year's late potatoes carried over to the spring and (2) early potatoes produced in California and other early producing states. Because of their high perishability, only small stocks of early potatoes are ordinarily carried.

The carry-over of late potato stocks performs, therefore, a central role in connecting the two temporally separated markets.

The geographical pattern of production, the location of the heavily populated areas, and transportation costs are the major determinants of the spatial relationships in the potato market. Changes in these factors, and in particular the big shifts in production and the development of the transportation system, have changed the interregional relationships materially. The 1956 pattern of unloads of potatoes in various markets during the early season compared with the pattern of unloads in the same season in 1933 is graphically presented in figures 13 and 14. Several important conclusions can be drawn from an examination of these figures. From the historical point of view, the outstanding feature is the tremendous increase in the importance of California early potatoes in the eastern markets. In 1933 all markets east of the line ChicagoKansas City-New Orleans received relatively light shipments of potatoes from California and relied on early potatoes produced in the Southeast and on stocks of the preceding year's late crop as their main source of supply during the spring and early summer months. California early potatoes were marketed mostly in the West and Southwest.

In 1956 California early potatoes were an important component of the total April-July supply in every market in the country. In this year they constitute about 10-20 per cent of the total supply on the East Coast and in the Southeast, about 20 per cent to 40 per cent in the Northeast, and more than 70 per cent in Florida.

Another interesting observation is that all points in the market have been completely connected. This has come about by the fact that shipments from

${ }^{21}$ U. S. Agr. Marketing Serv., Farm-Retail Spreads for Food Products, Misc. Publ. 741 (Washington, 1957), p. 129.

${ }^{22}$ Ibid., pp. 3-4. 


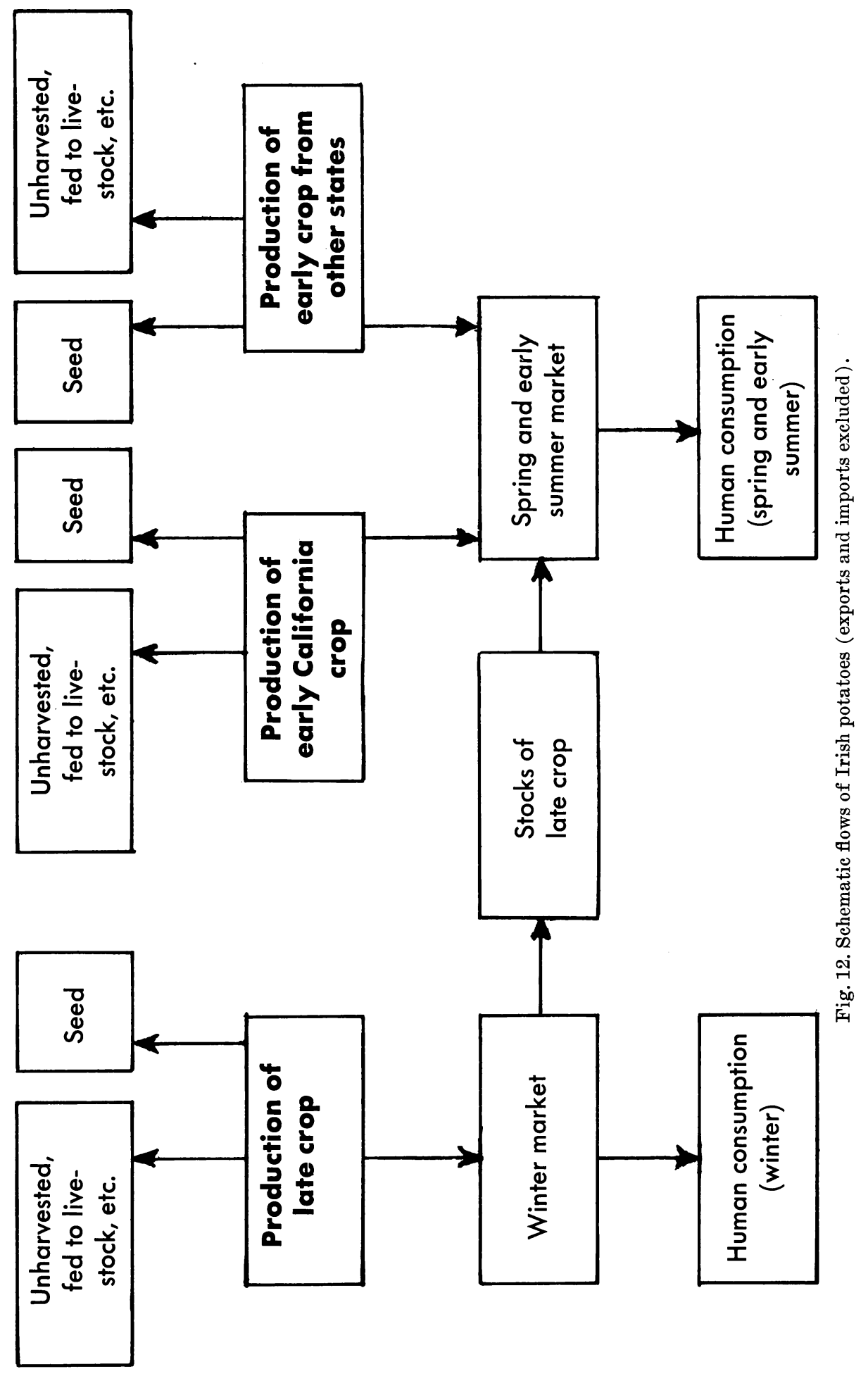


various surplus areas meet in many important markets. Thus, shipments of early potatoes from California meet with shipments of early potatoes from Alabama, Georgia, and other early states in the Southeast and with shipments of the preceding year's late crop from Idaho, Maine, and other late states in the eastern and northeastern markets.

This fact and the competitive nature of the market suggest treatment of the entire United States market as a single economic entity - as far as the geographical aspects are concerned. The geographical organization of the market for potatoes is distinguished by an extensive overlapping of marketing areas. This overlap has increased over time so that at present the market for California early potatoes extends over the entire country. This is clearly shown in figures 13 and $14 .{ }^{23}$ If potatoes produced at different locations would have been the same standardized commodity, this extensive overlap of marketing areas would hardly have been expected. Such an organization is, in fact, inefficient. ${ }^{24}$ In a competitive market such as the market for potatoes, inefficiencies of this type are not easily explained; that is, producers and wholesalers would be expected to exploit the profit possibilities that such market inefficiencies open and thus eliminate them. Hence, overlapping marketing areas are not strictly consistent with homogeneous commodities and a competitive market. The explanation for the overlap of marketing areas is presumably that potatoes produced in different regions are differentiated products. The extent of overlapping areas will depend on the demand relations, supply relations, geographical location of producers and consumers, and transportation costs. Intuitively, one may expect the overlapping area to be larger the lower the transportation costs, the smaller the cross elasticities of demand, the greater the supply, and the shorter the distance between producing regions and the markets.

\section{The Demand for Potatoes and Its Determinants}

Utilization of Irish Potatoes. The major types of utilization of Irish potatoes as reflected in disappearance data are: (1) potatoes consumed as food; (2) potatoes diverted to inferior industrial uses, such as starch and alcohol manufacturing; (3) potatoes used as seed; and (4) potatoes fed to livestock or lost.

The supply and disappearance of Irish potatoes during the period of 1930 1957 by source of supply and type of disappearance are presented in table 3 . It is evident that the first two categories, that is, potatoes used as food and potatoes diverted to industrial uses, together constitute the main component

${ }^{23}$ Figures 13 and 14, however, tend to exaggerate this overlap phenomenon because of the aggregation over time involved. It is the case, for instance, that during the earlier part of the season there are no shipments from California to Florida (in fact, there are some shipments from Florida to California), whereas in the latter part there are heavy shipments from California to Florida. That is to say, at any given point of time, there is only a limited overlap of marketing areas.

${ }^{24}$ In this case, it could be shown that transportation costs could be reduced by reorganizing the market in such a way that quantities supplied to every market would be as before but. without overlap of marketing areas. 


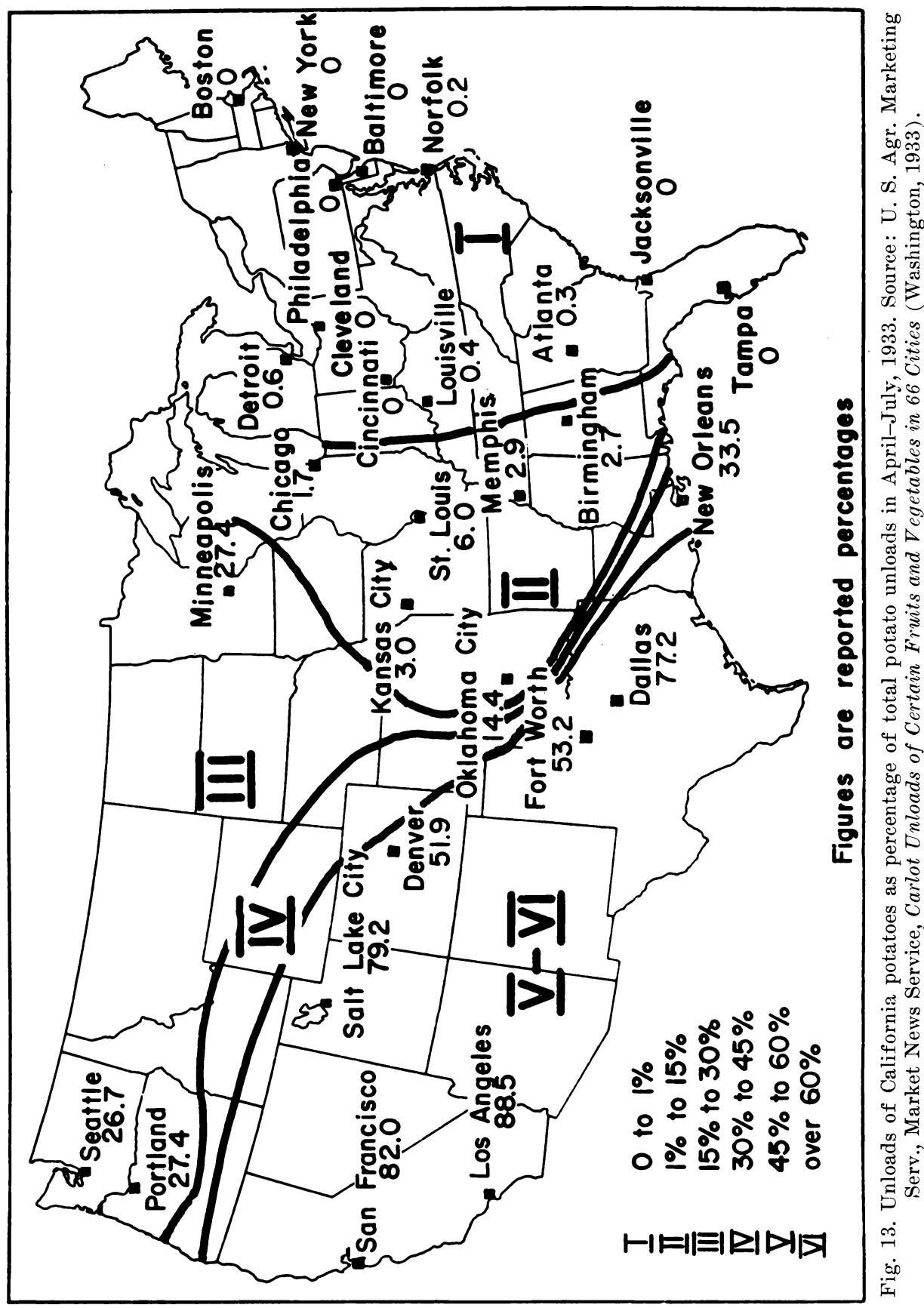




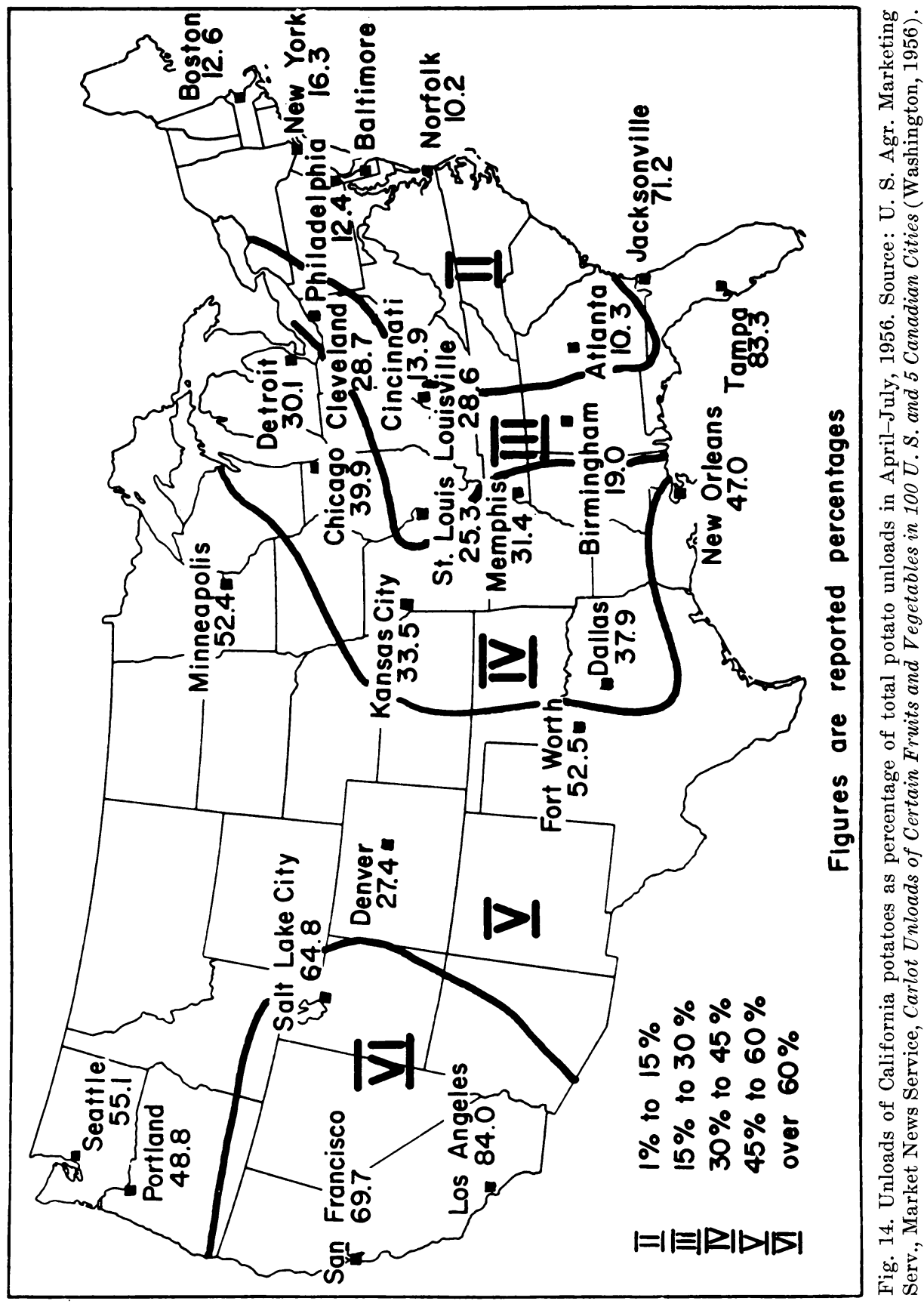


TABLE 3

POTATOES-SUPPLY AND DISAPPEARANCE, UNITED STATES TOTALS, 1930-1957

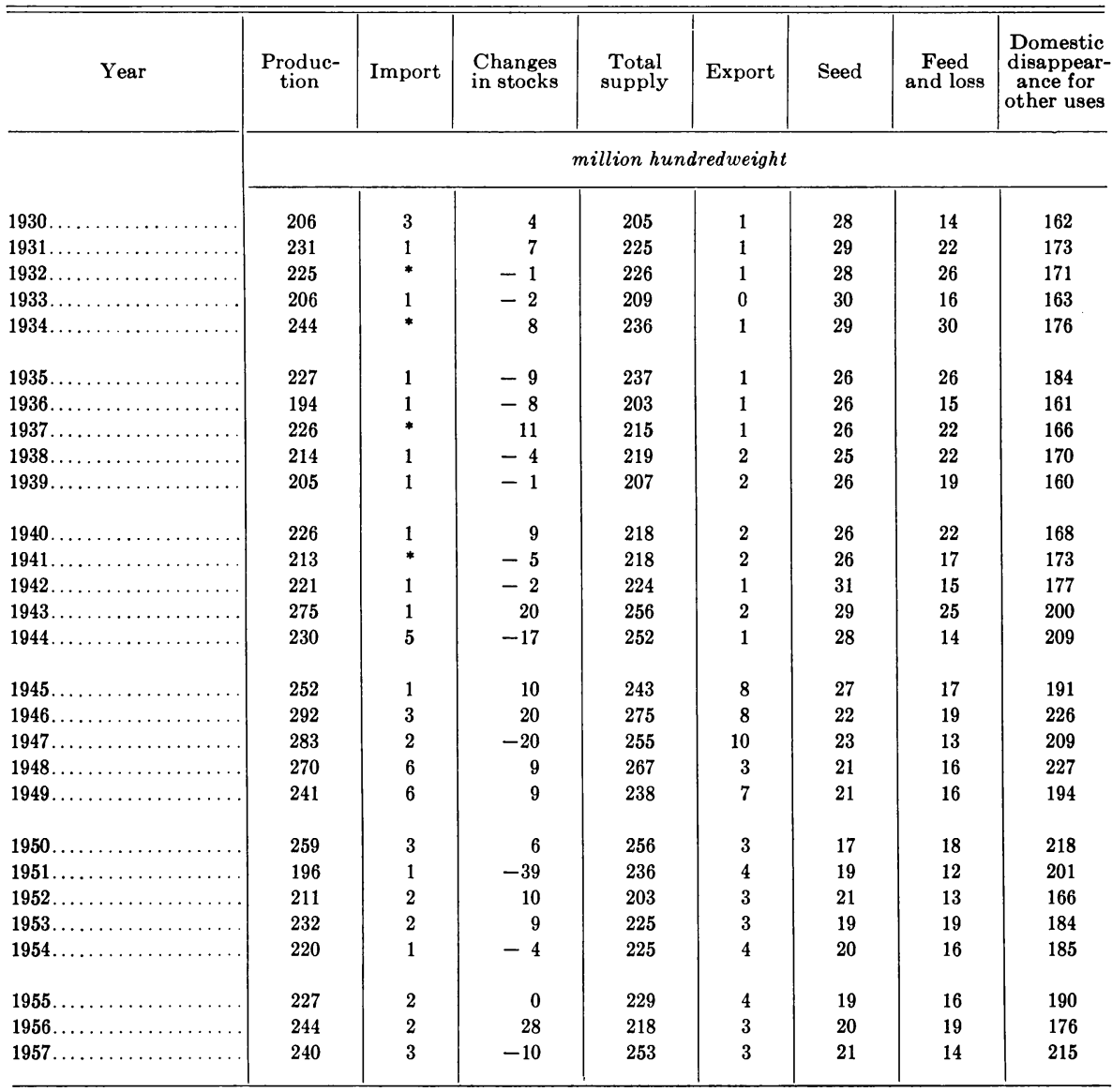

* Less than .5 million hundredweight. Sources:

U. S. Dept. of Agr., Agricultural Statistics, 1957 (Washington, 1958), p. 237.

U. S. Dept. of Agr., Agricultural Statistics, 1949 (Washington, 1950), p. 272.

U. S. Bur. of Agr. Econ., Potatoes-Acreage, Production, Value, Farm. Disposition, January 1 Stocks, 18661950 , by States, Dept. of Agr. Stat. Bul. 122 (Washington, 1953), 109 p.

U. S. Dept. of Agr., Potatoes-Sweetpotatoes, Revised Estimates, by States, 1949-55; Acreage, Yield, Production, Price and Value, Farm Disposition, and January 1 Stocks, Stat. Bul. 190 (Washington, 1956), 31 p. Processed.

U. S. Agr. Marketing Ser., Potatoes and Sweetpotatoes; Estimates by States and Seasonal Groups-Crops of 1955 and 1956 (Washington, 1957), $15 \mathrm{p}$.

of total disappearance. The relative amount of potatoes diverted to industrial uses, however, is practically negligible; and the "domestic disappearance for other uses" in table 3 consists mainly of potatoes consumed as food.

Considering now the "import" and "export" columns of table 3 , it becomes clear that foreign trade in Irish potatoes was relatively small during most years, and the net balance of trade was practically negligible. 
The Determinants of Demand for Potatoes as Food. On the basis of the general theory of demand, one would expect the quantity of Irish potatoes demanded at any given time to depend upon the price of potatoes, prices of potato substitutes, and consumers' income and preferences (tastes). Earlier studies on the demand for potatoes are suggestive in analyzing the determinants of demand qualitatively and quantitatively.

Consumers' Tastes. As stated before, per-capita consumption of potatoes has declined considerably in the last four decades. A decline of per-capita consumption, however, is not in itself an indication of a declining demand. Changes in consumption may be due to changes in demand, changes in supply, or a combination of both. Any analysis of this kind has, therefore, to consider the determinants of both supply and demand and their behavior over time. ${ }^{25}$ All statistical studies of the demand for potatoes indicate that demand has been falling continuously (table 4). An exception is probably the demand for early potatoes for which results suggest a positive time trend. ${ }^{26}$ Scott and

${ }^{25}$ This can be formulized as follows:

Let the supply function be:

where

$$
q=q_{s}\left(P, X_{1}, X_{2}, \cdots, X_{K}\right)
$$

$q=$ the quantity supplied

$P=$ price

$X_{1}, \cdots, X_{K}=$ other determinants of supply.

And let the demand function be:

where

$$
q=q_{D}\left(P, Y_{1}, \cdots, Y_{L}\right)
$$

$q=$ the quantity demanded

$P=$ price

$Y_{1}, \cdots, Y_{L}=$ other determinants of demand.

Assume that:

$\left\{X_{k}\right\}$ and $\left\{Y_{l}\right\}$ vary with time, then differentiating the two equations simultaneously and solving for $d q / d t$ and $d P / d t$ yields:

where

$$
\begin{aligned}
& \frac{d q}{d t}=\frac{-\frac{\partial q_{s}{ }^{*}}{\partial t} \frac{\partial q_{D}}{\partial P}+\frac{\partial q_{s}}{\partial P} \frac{\partial q_{D}{ }^{*}}{\partial t}}{\frac{\partial q_{s}}{\partial P}-\frac{\partial q_{D}}{\partial P}} \\
& \frac{d P}{d t}=\frac{\frac{\partial q_{D}{ }^{*}}{\partial t}-\frac{\partial q_{s}^{*}}{\partial t}}{\frac{\partial q_{s}}{\partial P}-\frac{\partial q_{D}}{\partial P}}
\end{aligned}
$$

$$
\frac{\partial q_{s}^{*}}{\partial t}=\sum_{k=1}^{K} \frac{\partial q_{s}}{\partial X_{k}} \frac{d X_{k}}{d t} \quad \text { and } \quad \frac{\partial q_{D}{ }^{*}}{\partial t}=\sum_{l=1}^{L} \frac{\partial q_{D}}{\partial Y_{l}} \frac{d Y_{l}}{d t}
$$

that is, the change in consumption and price depends upon the changes in supply and demand functions (through changes in their determinants) and the partial derivatives of $q_{*}$ and $q_{D}$ with respect to price.

${ }^{28}$ Since Equations (1) through (3) in table 4 were fitted with all variables expressed in terms of the first differences of their logarithms, the constant term in each equation is the trend coefficient in an equation with an undifferenced dependent variable. 


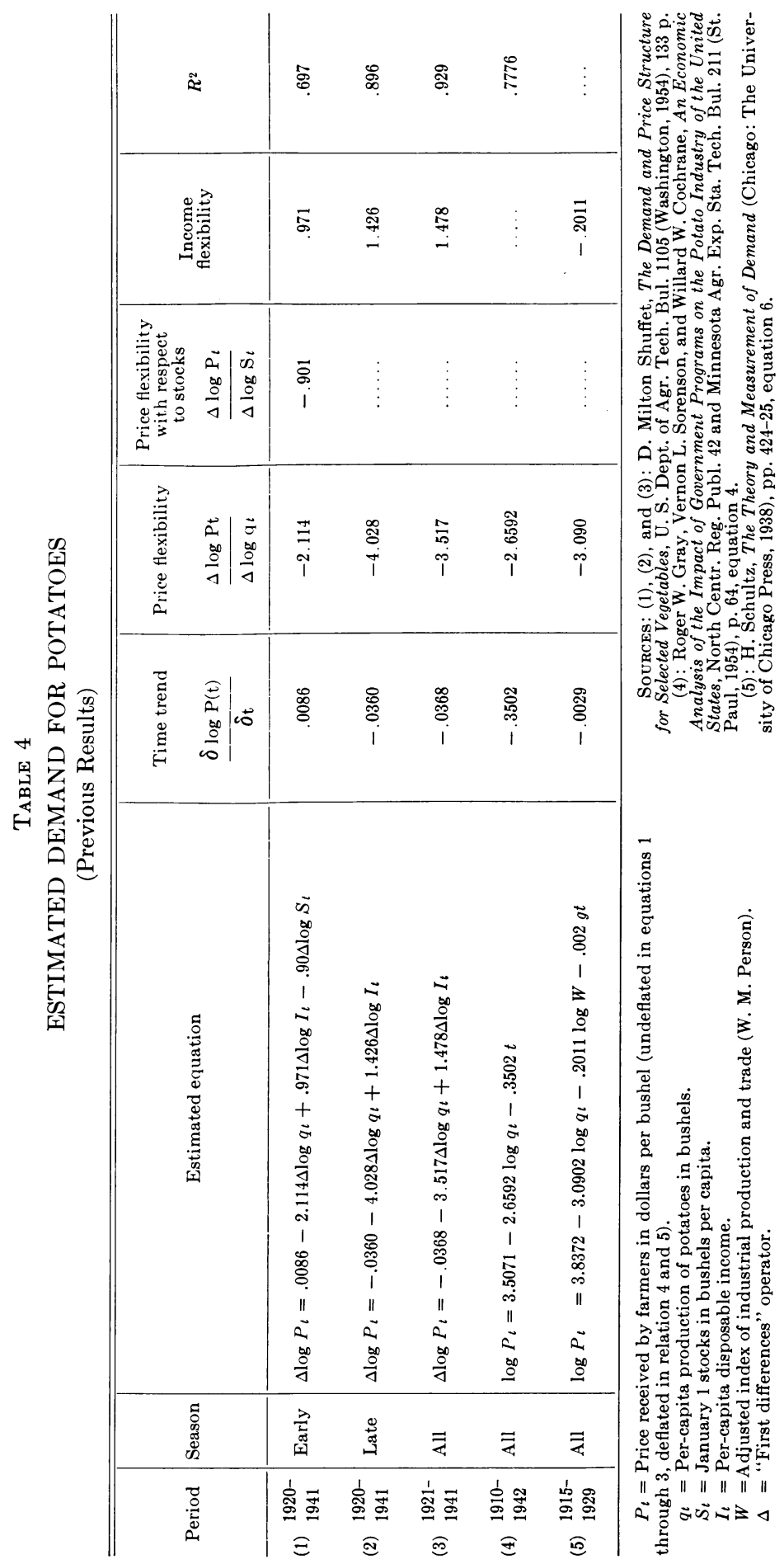


Mumford ${ }^{27}$ attribute the decline in demand to the following causes: (1) the increased availability of other vegetables geographically and throughout the year together with a strong desire for variety in the diet has brought about a substitution of vegetables for potatoes; (2) associated with the rising standard of living has been a shift away from potatoes and cereals as sources of energy in the diet; (3) the reduction in the number of persons engaged in hard work has reduced the total requirements for high-energy foods; and (4) the progressing urbanization of the United States population has had a similar effect.

Gray, Sorenson, and Cochrane ${ }^{28}$ attempt to explain the changes in consumption of Irish potatoes by analyzing the pattern of immigration and its possible effect on consumption of potatoes. The argument is that the over-all trend of consumption consists of a basic secular downward trend to which immigration has added the transitory effect of the newcomers' consumption habits. Since immigration has been mainly from European countries, where per-capita consumption of potatoes is high, per-capita consumption in the United States increased as long as immigration was of sizable dimensions. After 1910, immigration diminished considerably, and the downward trend in consumption since then reflects the secular trend in consumption plus the changes due to adaptation of the immigrants to their new environment.

Relative Prices. The demand for potatoes, as defined in the present study, consists of (1) demand of households on farms where potatoes are grown and (2) demand for all other consumers. The latter is, of course, more important.

Since statistical studies suggest that potatoes are not an inferior good, the income effect in the demand by nonproducers is in the same direction as the substitution effect. As this demand is the more important one, the price elasticity of demand for potatoes is negative; that is

$$
\frac{\partial q}{\partial P}<0
$$

Prices of substitutes may affect the demand for potatoes. A study of consumers' preference for potatoes ${ }^{29}$ suggests that the main substitutes are macaroni, spaghetti, noodles, and rice, and to a lesser extent other vegetables. However, none of the statistical analyses summarized include prices of substitutes as explanatory variables.

Consumers Income. The effects of changes in income are inconclusive. Time series studies generally suggest a positive relation with income (table 4). Cross-sectional studies, on the other hand, show a negative relation. Thus, for instance, it was found in the national preferences study already mentioned that the average weekly per-capita consumption in the United States was 2.8 pounds in the low-income group, 2.6 pounds in the middle-income group, and 2.5 pounds in the high-income group. The apparent differences in con-

\footnotetext{
${ }^{27}$ Scott and Mumford, op. cit.

${ }^{28}$ Gray, Sorenson, and Cochrane, op. cit., pp. 8-21.

${ }^{29}$ U. S. Dept. of Agr., Potato Preferences Among Household Consumers, Misc. Publ. 667 (Washington, 1948), $119 \mathrm{p}$.
} 
sumption may be due to the fact that each income group has a different scale of preference for potatoes. It may be, therefore, that each income group increases its demand for potatoes as income increases, while tastes remain unchanged. This, of course, is a short-run phenomenon, which is at least partially separated from changes in tastes in the time series analysis by the introduction of a trend variable but is not separable in the cross-sectional analysis.

Econometric Formulation of the Demand for Food Relations. The present model of the potato industry distinguishes two markets for potatoes. These are the "winter market," which extends over September through February, and the "spring market," which extends from April through the middle of August.

Disregarding the small quantities of winter potatoes supplied to the market, the sole source of supply in the winter is the preceding year's late crop. In the spring market, however, the supply consists of early crop produced in California, early crop produced in other states, and stocks of the preceding year's late crop. As already explained, differences between the various potatoes are probably sufficiently large to regard them as different products. Unfortunately, no separate series of retail prices for potatoes by seasonal categories are available. An attempt to estimate a set of simultaneous demand relations at the farm level, for which separate price series exist, failed to yield reasonable results. It also failed to recognize explicitly the locational aspects of the system. It was, therefore, decided to estimate the demand for potatoes as food at the retail level, using the weighted average retail price as a single price variable. With respect to winter demand for potatoes, this raises no special problems; but in the case of the spring demand, a problem of aggregation over products is involved. It was decided, therefore, to enter the supplies of the various potatoes as separate variables in the relations. If the products are undifferentiated, the coefficients associated with the separate supply variables should be approximately equal. ${ }^{30}$

${ }^{30}$ If products are differentiated and assuming linear demand relationships, the demand situation may be described by the structural set.

$$
q_{i t}=\gamma_{i}+\sum_{i^{\prime}=1}^{3} \lambda_{i i^{\prime}} P_{i^{\prime} t}+\delta_{i} Y_{t} \quad i=1,2,3
$$

where

$$
\begin{aligned}
& q_{i t}=\text { the quantity of } i \text {-th type of potato demanded at time } t \\
& P_{i^{\prime} t}=\text { the retail price of } i^{\prime} \text {-th type of potato at time } t \\
& Y_{t}=\text { consumers' income at time } t
\end{aligned}
$$

Assuming the $\left\{q_{i t}\right\}$ given, and expressing the $\left\{P_{i t}\right\}$ in terms of the $\left\{q_{i t}\right\}$

$$
P_{i t}=\alpha_{i}+\sum_{i^{\prime}=1}^{3} \beta_{i i^{\prime}} q^{{ }^{\prime}{ }^{\prime} t}+\eta_{i} Y_{t} \quad i, i^{\prime}=1,2,3
$$

The weighted average retail price $P_{t}$ is by definition

(c) $\quad \bar{P}_{t}=\frac{\sum_{i} q_{i t} P_{i t}}{\sum_{i} q_{i t}}$

Substituting (b) into (c) we get 
As subsequently specified, the spring demand relation includes the following variables: (1) average retail price in the spring, (2) per-capita quantity of preceding year's late potatoes carried over to the spring, (3) per-capita quantity of California spring crop supplied to the market, (4) per-capita quantity of other states' spring crop supplied to the market, (5) per-capita personal disposable income, (6) index of retail price of cereals and bakery products, and (7) time. All prices and income are deflated by the index of wholesale prices.

The winter demand relation includes similar variables, except that the average retail price is an average of the months September through February, and the three quantity variables are replaced by the single quantity of percapita consumption of late potatoes in the winter.

Potato Demand for Nonhuman Uses. Under this utilization are included quantities of potatoes which are reported by the U. S. Department of Agriculture as feed, shrinkage, and loss. In addition, quantities produced but not harvested because of low prices are also included in this category. Among the factors determining the quantity of potatoes diverted to these uses, the most important one is level of total production. This is regarded as plausible since a certain portion of the crop is ordinarily diverted because of low quality and small size, injuries during harvest, and deterioration in storage. Moreover, it is conceivable that during bumper crops a higher percentage of the crop is lost because of inadequate storage facilities.

Potato prices are another major determinant. As prices decline, the profitability of utilizing potatoes as feed increases. The quantity demanded as feed may, therefore, be expected to increase. Furthermore, prices may fall to such a level that the cost of harvesting is not covered and some of the acreage is actually abandoned.

The demand for potatoes as feed is probably the main component of demand for nonhuman use. Potatoes are usually fed to livestock on farms where grown or may be sold to nearby livestock farms. Hence, demand for potatoes as feed will depend on the degree of concentration and specialization of potato production. It is reasonable to expect a decline in this type of demand as specialization of production, regionally and within regions, progresses. Moreover, if production becomes highly concentrated in regions with relatively few livestock, it is conceivable that demand for nonhuman use could become price inelastic.

Since a high percentage of the early crop is produced in highly specialized regions (California, Florida, etc.), for the sake of simplicity the quantity of

$$
\bar{P}_{t}=\frac{\sum_{i} \alpha_{i} q_{i t}}{\sum_{i} q_{i t}}+\frac{\sum_{i} \beta_{i 1} q_{i t}}{\sum_{i} q_{i t}} q_{1 t}+\frac{\sum_{i} \beta_{i 2} q_{i t}}{\sum_{i} q_{i t}} q_{2 t}+\frac{\sum_{i} \beta_{i 3} q_{i t}}{\sum_{i} q_{i t}} q_{3 t}+\frac{\sum_{i} \eta_{i} q_{i t}}{\sum_{i} q_{i t}} Y_{t}
$$

That is, the coefficient associated with each quantity is a weighted average of the corresponding microparameters weighted by the relative quantities. It is obvious from (d) that, if products are undifferentiated, all quantity coefficients are_equal (since_all $\beta_{i i}{ }^{\prime}$ are equal). 
spring potatoes diverted to nonhuman use is regarded as an exogenous variable. In the winter market, however, quantity diverted to nonhuman uses is treated as an endogenous variable.

The Demand for Seed Potatoes. The demand for seed depends on farmers' intentions with respect to acreage in the next season as well as on technological factors, which determine the quantity of seed planted per acre. The changes in total demand for seed reflect the major trends in production and yields. Whereas during the early 1930's utilization for seed accounted for about 12 per cent of total production, this figure has fallen to about 8 per cent at present. Another interesting change in the use of potato seed which took place during this period was the increased proportion of certified seed used. This has had the effect of reducing the quantity of seed used on farms where grown. Though the demand for seed potatoes is partially endogenous to the system, it is regarded here as an exogenous factor. This is done, in part, to avoid a further increase in the complexity of the analysis.

\section{The Stock Relation}

Theoretical Considerations. In this section, a theory explaining the behavior of inventory holders is developed. No attempt will be made to deal with the inventory problem in its full generality. ${ }^{31}$ Instead, the scope of the analysis will be limited to the particular conditions and structure of the potato market. Similarly, the problem will be formulated in terms of our simplified conception of the potato market. The resulting theory will provide a basis for a subsequent econometric formulation, the parameters of which are estimable from available data.

In the general case, carrying stocks of goods involves both costs and returns. Carrying costs include storage costs, insurance, deterioration of the stored goods, etc. Carrying costs may be regarded as an increasing function of the size of stocks. Beyond some limit, the marginal carrying cost is also an increasing function of the stock size. Returns may be classified into convenience yields and speculative returns. In the case of a commodity such as potatoes, the latter type of returns is by far the more important.

Another relevant factor is the risk involved in carrying stocks. Although the type of risk considered here is ordinarily uninsurable and therefore not regarded as cost per se, any quantitative evaluation of the risk element must

${ }^{31}$ The "inventory problem" has been discussed extensively in economic literature. Among the discussions dealing with the individual inventory holder may be cited in:

K. Arrow, T. Harris, and J. Marschak, "Optimal Inventory Policy," Econometrica, 19 (3): 250-72, 1951.

A. Dvoretzky, J. Kiefer, and J. Wolfowitz, "The Inventory Problem: I. Case of Known Distributions of Demand," Econometrica, 20 (2): 187-222, 1952.

Among those dealing with industry equilibrium, reference is made to:

N. Kaldor, "Speculation and Economic Stability," Review of Economic Studies, 7 (1): 1-27, 1939.

H. Working, "The Theory of Price of Storage," American Economic Review, 39 (6): 1254-62, 1949.

M. J. Brennan, “A Model of Seasonal Inventories," Econometrica, 27 (2): 228-44, 1959. 
be formulated in monetary terms. The same is true for the evaluation of the convenience yields. It is possible therefore to add the risk element to carrying costs and subtract the convenience yields to get a net carrying cost function.

In analyzing the behavior of the individual decision maker, it is assumed that he aims at maximizing profits. From earlier descriptions of the marketing process, it is also clear that holders of potato stocks operate in a highly competitive market. ${ }^{32}$ Decision makers therefore regard potato prices as exogenously determined. Assuming further perfect foresight on the part of inventory holders (this unrealistic assumption will be relaxed subsequently), then in terms of the conceived temporal structure of the market, the net revenue function of inventory holders in year $t$ is:

where

$$
U_{t}=P_{t, 1} S_{t, 1}+\alpha P_{t, 2}\left(I_{t}-S_{t, 1}\right)-C_{s}\left(I_{t}-S_{t, 1}\right)
$$

$$
\begin{aligned}
U_{t} & =\text { net revenue } \\
P_{t, 1} & =\text { potato price in the winter market } \\
P_{t, 2} & =\text { potato price in the spring market } \\
S_{t, 1} & =\text { sales in the winter market } \\
I_{t} & =\text { initial stock of potatoes } \\
C_{s}\left(I_{t}-S_{t, 1}\right) & =\text { net carrying cost function } \\
\alpha & =\text { discounting factor }
\end{aligned}
$$

$C_{s}\left(I_{t}-S_{t, 1}\right)$ is assumed to be a twice differentiable, nondecreasing function, convex in at least some interval of its argument.

Then the necessary conditions for a maximum are:

$$
P_{t, 1}-\frac{d C_{s}\left(I_{t}-S_{t, 1}\right)}{d S_{t, 1}}=\alpha P_{t, 2}
$$

That is, the sales in the winter market are at such levels that the difference between the winter potato price and the marginal carrying cost of the remaining stocks is equal to the discounted spring price. ${ }^{33}$

The second-order conditions for a maximum are:

$$
\frac{d^{2} U_{t}}{d S_{t, 1}^{2}}=-\frac{d^{2} C_{s}\left(I_{t}-S_{t, 1}\right)}{d S_{t, 1}^{2}}<0
$$

${ }^{32}$ In fact, a great many of the stock holding decisions and transactions take place in a highly competitive futures' market.

${ }^{33}$ In reality, the decision process is continuous and levels of potato stocks can be varied at any point in time. The inventory problem then consists of finding a function $\hat{I}(v)$ of inventory levels such that:

$$
U_{t}=\boldsymbol{S}_{v_{0}^{1}}^{v_{1}} e^{-\rho v}\left[S_{t}(v) P_{t}(v)-c_{s t}(I(v)] d v\right.
$$

is maximized with respect to $I(v)$ in the interval $\left(v_{0}, v_{1}\right)$, where $S(v)=-d I(v) / d v$ and $\rho$ is the discounting coefficient.

The necessary conditions for $\hat{I}(v)$ are described by the corresponding Euler equation:

$$
\frac{d C_{s}[I(v)]}{d I(v)}+\rho P(v)=\frac{d P(v)}{d v}
$$

Our model involves, therefore, a great deal of aggregation over time. 
which implies $\left[d^{2} C_{s}\left(I_{t}-S_{t, 1}\right)\right] /\left[d\left(I_{t}-S_{t, 1}\right)^{2}\right]>0$; that is, for a maximum, operations must be at inventory levels where marginal net carrying costs are increasing. To derive the effects of an increase in $P_{t, 1}$ on sales in the winter market, differentiate equation (14) with respect to $P_{t, 1}$ and rearrange. We get:

$$
\frac{d S_{t, 1}}{d P_{t, 1}}=\frac{1}{\frac{d^{2} C_{s}\left(I_{t}-S_{t, 1}\right)}{d\left(I_{t}-S_{t, 1}\right)^{2}}}>0
$$

Similarly, the effect of an increase in $P_{t, 2}$ is:

$$
\frac{d S_{t, 1}}{d P_{t, 2}}=--\frac{\alpha}{\frac{d^{2} C_{s}\left(I_{t}-S_{t, 1}\right)}{d\left(I_{t}-S_{t, 1}\right)^{2}}}<0
$$

The assumption of perfect knowledge is now relaxed. This is done by (a) replacing "known" future prices by "anticipated" future prices ${ }^{34}$ and (b) formulating an "expectation model" which relates price expectations to actual past prices.

The choice of any "expectation model" is inevitably somewhat arbitrary. For the purpose of this study, an "expectation model" similar to the one introduced by Nerlove ${ }^{35}$ was first contemplated. It was later rejected, since it led to a substantial increase in the number of variables, some of which were highly intercorrelated. Instead, the highly simplified model introduced by L. A. Metzler ${ }^{36}$ was adopted in a somewhat modified form.

The modified Metzler expectation model is:

where

$$
P_{t, 2}^{*}=P_{t, 1}+\eta\left(P_{t-1,2}-P_{t-1,1}\right)
$$

$$
\begin{aligned}
& P_{t, 2}^{*}=\text { the anticipated value of } P_{t, 2} \\
& P_{t, j}=\text { actual price in } t, j \quad(j=1,2) \\
& \eta \quad=\text { coefficient of expectations }
\end{aligned}
$$

That is, inventory holders are assumed to expect the change in price from $t, 1$ to $t, 2$ to depend on its actual change from $t-1,1$ to $t-1,2$.

Condition (14) now becomes:

$$
(1-\alpha) P_{t, 1}-\frac{d C_{s}\left(I_{t}-S_{t, 1}\right)}{d\left(I_{t}-S_{t, 1}\right)}=\alpha \eta\left(P_{t-1,2}-P_{t-1,1}\right)
$$

${ }^{34}$ The effect of imperfect knowledge is, of course, not restricted to substitution of anticipated prices for certain prices in the decision functions. In fact, there is a fundamental change in the functions themselves due to uncertainty. In the present context, this is the risk element already mentioned. Risk does not exist under perfect knowledge, but it is regarded as a cost once the perfect knowledge assumption is relaxed.

${ }^{35}$ Nerlove, op. cit.

${ }^{36}$ L. A. Metzler, "The Nature and Stability of Inventory Cycles," Review of Economic Statistics, 23 (3): 113-29, 1941. 
The effect of a change in $P_{t, 1}$ (holding $P_{t-1,2}-P_{t-1,1}$ constant) is:

$$
\frac{d S_{t, 1}}{d P_{t, 1}}=\frac{1-\alpha}{\frac{d^{2} C_{s}\left(I_{t}-S_{t, 1}\right)}{d\left(I_{t}-S_{t, 1}\right)^{2}}}>0 \quad \text { since } \quad \alpha<1
$$

and the effect of a change in $\left(P_{t-1,2}-P_{t-1,1}\right)$ on $S_{t, 1}$, holding $P_{t, 1}$ constant, is:

$$
\frac{d S_{t, 1}}{d\left(P_{t-1,2}-P_{t-1,1}\right)}=-\frac{\alpha \eta}{\frac{d^{2} C_{s}\left(I_{t}-S_{t, 1}\right)}{d\left(I_{t}-S_{t, 1}\right)^{2}}}<0 \quad \text { for } \quad \eta>0
$$

Since $\alpha=(1+r)^{-1}$, where $r$ equals interest rate, this implies that the effect of a change in $P_{t, 1}$ on $S_{t, 1}$ under the assumed mode of expectation is much smaller than its effect under perfect knowledge.

In the present study, the main interest is the supply out of a given stock. To this effect, we solve equation (14) for $S_{t, 1}$, obtaining:

$$
S_{t, 1}=I_{t}-C_{s}^{\prime-1}\left(P_{t, 1}-\alpha P_{t, 2}\right)
$$

where $C^{\prime-1}\left(P_{t, 1}-\alpha P_{t, 2}\right)$ is the inverse function of

$$
\frac{d C_{s}\left(I_{t}-S_{t, 1}\right)}{d\left(I_{t}-S_{t, 1}\right)} .
$$

Provided no net external economies or diseconomies exist, the industry supply function is a simple sum of the individual functions. Hence, all derivatives of the industry functions are simple sums of the corresponding individual derivatives.

An Econometric Formulation. The objective is an estimable formulation which will describe the supply of potatoes to the "winter" market out of a given production.

From equation (22), it is apparent that the relevant variables are: (1) "winter" retail price $\left(P_{t, 1}\right),(2)$ the retail price expected to prevail in the following spring $\left(P_{t, 2}^{*}\right),(3)$ the initial stock of potatoes $\left(I_{0 t}\right)$, and (4) interest rate $\left(r_{t}\right)$.

Assuming a linear function to be a good approximation to the industry supply function within the range of interest, we get:

$$
S_{t, 1}=\alpha_{0}+\alpha_{1} I_{0 t}+\alpha_{2} P_{t, 1}+\alpha_{3} P_{t, 2}^{*}+\alpha_{4} r_{t}
$$

Since $P_{t, 2}^{*}$ is unobservable, it is replaced by a function of past actual prices. In accordance with the expectation model already presented, we obtain:

$$
S_{t, 1}=\pi_{0}+\pi_{1} I_{0 t}+\pi_{2} P_{t, 1}+\pi_{3}\left[P_{t-1,2}-P_{t-1,1}\right]+\pi_{4} r_{t}
$$

where

$$
\pi_{0}=\alpha_{0} \quad \pi_{1}=\alpha_{1} \quad \pi_{2}=\alpha_{2}+\alpha_{3} \quad \pi_{3}=\eta \alpha_{3} \quad \pi_{4}=\alpha_{4}
$$




\section{Government Programs}

The importance of government programs and their impact on the potato industry has varied considerably in the past 25 years. Objectives, means, and extent of government intervention in the economic processes of the industry have changed over the period. In general, government policy aimed at increasing and stabilizing growers' income although during 1942-1945 the assurance of an adequate supply of potatoes to the population was its prime objective.

The means adopted for attaining these objectives were different in different periods, and in some periods a variety of programs were in operation simultaneously. The various programs included operations intended to expand the market and remove surplus supplies, measures of production control, programs for regulating quality and quantities of potatoes moved into terminal markets, and direct price support operations, such as nonrecourse loans and government purchases.

Historically, three main periods, during which government programs differed markedly, are to be distinguished. These are: (1) the period 1934-1942, during which the first programs were initiated with an objective of raising and stabilizing growers' income; (2) the period 1943-1950, during which the first full-scale price-support program for potatoes was undertaken; and (3) the period 1951 to present, during which government programs were limited to marketing agreements and orders alone.

Government Programs During 1934-1942. The Potato Control Act of 1935 was the first federal legislation to deal directly with potato price support. The objective of this legislation was to achieve parity price for potato growers. To this effect the Secretary of Agriculture was given the power and required to control excess supply. Due to the Supreme Court decision of 1936, this act never became operative. Limited diversion operations were carried out, however, through the use of Section 32 funds. Diversions were mainly to school lunch programs and relief consumption. No producer in any area was guaranteed a given percentage of parity or had any knowledge of how government operations were to affect his price for the prospective crop. The first marketing agreement became effective in some southeastern states in 1934 under the Agricultural Adjustment Act of 1933. Following this attempt, producers in some late producing areas adopted marketing agreements in 1937. In general, the orders which became effective provided for federal-state inspection of all shipments. They prohibited interstate shipments of cull potatoes produced in the areas where the orders were adopted. After a year of operation, the orders expired and were not reactivated.

${ }^{37}$ Government programs are a subject of several studies. The present section draws heavily from:

Gray, Sorenson, and Cochrane, op. cit.

M. R. Benedict and O. C. Stine, The Agricultural Commodity Programs. Two Decades of Experience (New York: The Twentieth Century Fund, 1956), chap. 10. 
In 1938 following a referendum, potatoes were placed under the acreage allotment program. This action was taken under the Soil Conservation and Domestic Allotment Act of 1936 which defined potatoes as a soil-depleting crop. The main objective of this program, besides soil conservation, was to support price through control of production.

Some quantitative measures of the importance of government programs during 1933 through 1942 are presented in table 5. The largest quantities purchased and diverted by the government were during 1937 and 1940, years of

TABLE 5

SUMMARY OF PURCHASES, DIVERSIONS, AND SOIL CONSERVATION PAYMENTS ON POTATOES, 1934-1943

\begin{tabular}{|c|c|c|c|c|c|c|}
\hline \multirow[b]{2}{*}{ Crop year } & \multicolumn{2}{|c|}{ Quantity } & \multicolumn{4}{|c|}{ Expenditures } \\
\hline & Purchase & Diversion & Purchases & $\begin{array}{l}\text { Diversion } \\
\text { payments }\end{array}$ & $\begin{array}{c}\text { Soil con- } \\
\text { servation } \\
\text { payments }\end{array}$ & $\begin{array}{c}\text { Total } \\
\text { expenditures }\end{array}$ \\
\hline & \multicolumn{2}{|c|}{ thousand bushels } & \multicolumn{4}{|c|}{ thousand dollars } \\
\hline $1934 \ldots$ & 3,278 & $-^{*}$ & 1,041 & - & - & 1,041 \\
\hline $1935 \ldots$ & 460 & - & 208 & - & - & 208 \\
\hline 1936. & - & - & - & - & - & - \\
\hline 1937. & 5,276 & 8,751 & 3,576 & 1,302 & - & 4,878 \\
\hline 1938. & 2,264 & - & 1,418 & - & 6,095 & 7,513 \\
\hline $1939 \ldots$ & - & - & - & - & 5,632 & 5,632 \\
\hline $1940 \ldots$ & 6,240 & 14,946 & 4,581 & 2,226 & 5,491 & 12,298 \\
\hline 1941. & 1,280 & 3,282 & 1,143 & 347 & 4,697 & 6,187 \\
\hline 1942 . & 6 & - & 7 & - & 4,130 & 4,137 \\
\hline Total. & 18,804 & 26,979 & 11,974 & 3,875 & 26,045 & 41,894 \\
\hline
\end{tabular}

* Dashes indicate zero.

Source: U. S. Congress, House, Potato Surpluses and Prevention of Wastage; Hearings Before the Subcommittee on Food Shortages of the Committee of Agriculture, 8th Cong., 1st Sess., 1947.

low potato prices. Even in these years, the value of the crop removed by the government amounted to only 2.33 per cent and 3.35 per cent of the total crop values, respectively.

In their analysis of the impact of government programs on the potato industry, Gray, Sorenson, and Cochrane ${ }^{38}$ conclude that: "It is doubtful, therefore, that purchases and diversions in any one year during the prewar period had any appreciable effect on supplies of the following year." They also estimate the price-increasing effect in the years of the greatest government intervention to be at about 3 cents per bushel. As to the effectiveness of the soil conservation programs in reducing supplies, they conclude that evidence available casts doubt on the effectiveness of the program in reducing supplies. The fact that never during this period were prices guaranteed is considered by them crucial in its effect on producers' response. Similar conclusions are offered by Benedict and Stine. ${ }^{39}$

${ }^{38}$ Gray, Sorenson, and Cochrane, op. cit., pp. 34-39.

${ }^{39}$ Benedict and Stine, op. cit., pp. 420-22. 
The Period 1943-1950. In the early part of the war period, the demand for potatoes increased and prices rose sharply. Adjustments of acreage and production were slow, and some shortages developed during 1942. In anticipation of a higher level of demand and fearing that supplies would continue low (because of a general rise of agricultural prices, higher costs, and labor shortages), the objectives of the government policy were redefined. The new objective was to assure adequate supply of potatoes for consumption. In July, 1942, Congress passed the Steagall amendment which provided price support at 85

TABLE 6

SUMMARY OF LOANS, DIVERSION, AND PURCHASES, UNITED STATES, 1943-1950

\begin{tabular}{|c|c|c|c|c|c|c|c|}
\hline \multirow{2}{*}{ Year } & \multicolumn{2}{|c|}{ Loans } & \multicolumn{2}{|c|}{ Diversion and subsidization } & \multicolumn{2}{|c|}{ Purchases } & \multirow{2}{*}{ Production } \\
\hline & Quantity & $\begin{array}{l}\text { Net value of } \\
\text { operation }\end{array}$ & Quantity & $\begin{array}{l}\text { Net value of } \\
\text { operation }\end{array}$ & Quantity & $\begin{array}{l}\text { Net value of } \\
\text { operation }\end{array}$ & \\
\hline & $\begin{array}{c}1,000 \text { hundred }- \\
\text { weight }\end{array}$ & $\begin{array}{l}\text { thousand } \\
\text { dollars }\end{array}$ & $\begin{array}{c}1,000 \text { hundred- } \\
\text { weight }\end{array}$ & $\begin{array}{l}\text { thousand } \\
\text { dollars }\end{array}$ & $\begin{array}{c}1,000 \text { hundred- } \\
\text { weight }\end{array}$ & $\begin{array}{l}\text { thousand } \\
\text { dollars }\end{array}$ & $\begin{array}{c}1,000 \text { hundred- } \\
\text { weight }\end{array}$ \\
\hline 1943. & 4,367 & 6,895 & 11,645 & 7,068 & 10,194 & 13,916 & 275,332 \\
\hline 1944. & 5,949 & 7,504 & 510 & 243 & 2,062 & 3,103 & 230,356 \\
\hline 1945. & 33,958 & 38,915 & 5,661 & 1,742 & 7,138 & 11,482 & 251,639 \\
\hline $1946 \ldots$ & 68,981 & 63,873 & 5,439 & 5,625 & 43,754 & 67,227 & 292,389 \\
\hline 1947. & 8,669 & 10,229 & 1,439 & 1,373 & 19,079 & 52,510 & 233,391 \\
\hline 1948 . & 21,722 & 29,553 & -* & - & 81,624 & 223,089 & 269,937 \\
\hline 1949. & 12,529 & 8,598 & - & - & 45,193 & 80,532 & 240,950 \\
\hline 1950 . & - & - & - & - & 60,715 & 64,810 & 259,112 \\
\hline
\end{tabular}

* Dashes indicate zero.

SOURCES:

1943-1948: U. S. Production and Marketing Administration, Irish Potatoes: Price Support and Reloted Operations, Commodity Credit Corporation and Section 32 Funds, January 1, 1948-December \$1, 1949 (Washington, 1950), 29 p. Processed.

1949-1950: U. S. Production and Marketing Administration, Report of the Administrator of the Production and Marketing Administration (Washington, 1950 and 1951).

U. S. Dept. of Agr., Potatoes-Sweetpotatoes, Revised Estimates, by States, 1949-55; Acreage, Yield Production, Price and Value, Farm Disposition, and January 1 Stocks, Stat. Bul. 190 (Washington, 1956), 31 p. Processed.

per cent of parity to nonbasic agricultural commodities which farmers were asked by the Secretary of Agriculture to produce in larger quantities. In November, 1942, potatoes were included in the list of Steagall commodities. In 1943 potato prices were supported at 92 per cent of parity. From 1944 through 1948, prices were supported at 90 per cent of parity. Support under the Steagall amendment lasted through December, 1948. In 1949 and 1950, support operations were authorized by the agricultural acts of 1948 and 1949 . Support operations were discontinued after the 1950 crop.

In general, farmers responded to the incentive provided to the program by increasing production through the expansion of acreage and increasing yields. This involved the government in heavy support and surplus disposal operations. A summary of the scale of price support operation is presented in table 6 . The relatively great importance of government programs is quite evident. In a number of years, these operations involved more than one-third of the annual production. 
These wide-scale programs no doubt had significant impact on the potato industry. Certain effects must have been of a temporary nature, but permanent structural changes were probably also generated. Perhaps the most important changes were the increased concentration of production in specialized farms and in regions having comparative advantage in the production and marketing of potatoes. The reduction in price risk is believed by some authors ${ }^{40}$ to have had a catalytic effect in speeding up this process. As a result of the increased specialization and the wide adoption of new technologies, yields have increased substantially thus changing the structural supply relations.

The Period 1951 to Present. During this last period, government programs have been of a limited scope. Governmental action has been mainly through marketing orders, both state and federal. These instruments are of a much more restricted scope. In fact, the objectives of marketing agreements and orders are to regulate the marketing of potatoes. Marketing orders, although once issued are compulsory on producers and handlers in the particular region, must be first approved by the majority of producers. And there are many instances where proposals for orders were repealed. The administration of the orders is highly decentralized. In a nationwide industry, such as the potato industry, this places bounds on the range of policy measures that any producers' group can employ effectively. The regulation of marketing has therefore been confined to setting quality standards such as grades, maturity requirement, packing, etc. Through these requirements the administrative committee has some control over quantity, but this type of supply control has been of little importance. The questions that arise in this connection are: To what extent is production control feasible? And if it is feasible, is it also desirable? Other questions of interest are: In what way could production and prices be stabilized for the benefit of both consumers and producers? Are there any other ways of raising producers' returns, such as for instance sales promotion?

${ }^{40}$ Gray, Sorenson, and Cochrane, op. cit. 


\section{AN ECONOMETRIC MODEL OF THE POTATO INDUSTRY}

\section{The Model}

The focus of this study is on the market for California early potatoes. From the preceding chapter it is evident, however, that this market is highly dependent on the behavior of all factors operating in the potato industry. Hence, a complete model embracing the entire industry is indispensable.

The Structural Relations. The review of forces operating in the industry suggests that the retail price for California early crop is determined by the demand conditions for early potatoes, by the quantities supplied by California and other early producing states, and by the quantity of preceding year's late crop carried over to the spring. The quantities supplied by California and other producers of early crop depend on the production conditions in these states and the price expectations of growers with respect to the prospective early potato crop and other competing crops. ${ }^{41}$

The quantity of the preceding year's late crop carried over to the spring depends on the quantities of the late crop produced in the preceding year and on the demand and supply conditions during the time period between the harvest of the late crop and the harvest of the early crop. In particular, the supply relation during this period is characteristically a supply out of a given stock. As such, one may expect this supply relation to depend on current potato prices as well as on anticipated prices for the following spring.

The production of late crop potatoes depends, of course, on the production conditions in the states producing the late crop and on the price expectations of growers in these states. The prices which enter the producers' decision functions are prices received at the farm level. On the other hand, consumers' decision functions are in terms of retail prices. ${ }^{42}$ Hence, it becomes necessary to consider relations which determine price spread between the price received by growers and the retail price.

The over-all demand for potatoes consists of demand for various uses, some of which are negligible. Some are more or less exogenously determined, but the bulk of the quantity demanded is endogenously determined. The demand for human consumption is the most important component of total demand. The demand for other uses (excluding demand for seed) is of appreciable dimensions only during the fall and the winter. The inclusion of the demand for nonhuman consumption as a separate relation may therefore shed some light on its role in the functioning of the potato market.

${ }_{41}$ The price expectations are probably functions of past prices. They are unobservable economic magnitudes, and their introduction into the model (which is completely in terms of observable variables) requires the adoption of some expectation model. This subject will be discussed in the sections on the production relations and the winter supply relation.

${ }^{42}$ It is possible, of course, to formulate a model in which all demand relations would be defined at the farm level. This formulation was attempted but failed to give acceptable results when actually fitted. 
The above considerations suggest:

(a) Production relations for California spring crop, other spring crop, and preceding year's late crop.

(b) Demand relations for the winter and for the spring.

(c) Supply-out-of-stock relations for preceding year's late crop and supply out of current production for spring potatoes.

(d) Farm-to-retail transfer relations describing the relationship between retail price and prices received by the various growers groups.

(e) Identities.

The relations mentioned under (a) through (d) are, in general, behavioral relations. In some cases, however, they were reduced to identities through the adoption of certain simplifying assumptions which are believed to be good approximations to reality.

The model presented in this study differs in many respects from the one originally formulated. Certain modifications were forced by lack of suitable data. Others were suggested by results of exploratory analyses based on the original formulation. Among the criteria influencing final choice of model was a measure of degree of fit; that is, from a class of formulations equally acceptable on theoretical economic grounds the one with highest adjusted multiple correlation coefficient was accepted.$^{43}$ Certain formulations were rejected because the signs of particular estimated coefficients were in contradiction to accepted economic theory.

The result is a model consisting of 14 equations in 14 endogenous variables. Eight of the endogenous variables occur also as lagged variables. In addition, there are 15 exogenous variables, some of which appear both in their current and lagged values. For a given set of values assumed by the exogenous variables, the model is linear. It is, however, nonlinear in some of the exogenous variables.

${ }^{43}$ It seems that, in general, the set of possible formulations, as determined by economic theory, admits of a large number of formulations. It is a common practice to choose among the various formulations in accordance with the highest adjusted multiple correlation coefficient $\left(\bar{R}^{2}\right)$. Some support for this approach is given by Theil's demonstration that:

$$
E\left\{\bar{R}_{c}^{2}\right\} \geqq E\left\{\bar{R}_{I}^{2}\right\}
$$

where $\bar{R}_{c}{ }^{2}$ is the coefficient corresponding to the correct formulation and $\bar{R}_{I}{ }^{2}$ to the incorrect one.

H. Theil, Economic Forecasts and Policy ("Contributions to Economic Analysis," No. 15; Amsterdam: North-Holland Publishing Co., 1958), pp. 210-13. 
The relations and the variables involved are as follows:

Structural relations

Production response, late crop.... $\quad Y_{1 t}, Y_{2, t-1}, Y_{1, t-1}, Z_{2, t-1}, Z_{1, t-2}$

Transfer farm-retail, late crop.... $Y_{2 t}, Y_{3 t}, Z_{5, t-1}, Z_{2, t-1}$

Demand for potatoes as food in

September-February......... $Y_{3 t}, Y_{6 t}, Z_{6, t-1}, Z_{7, t-1}, Z_{2, t-1}$

Demand for potatoes for nonhuman use............. $Y_{2 t}, Y_{4 t}, Y_{1 t}, Z_{2, t-1}$

Supply of late potatoes in

September-February ......... $Y_{3 t}, Y_{5 t}, Y_{1 t}\left(Y_{8, t-1}-Y_{3, t-1}\right), Z_{8 t}$

Late crop supply identity I . . . . . $Y_{6 t}-Y_{5 t}+Y_{4 t} \equiv 0$

Late crop supply identity II .... $-Y_{1 t}+Y_{5 t}+Y_{7 t} \equiv-Z_{9 t}$

Demand for potatoes as food in the spring................ $Y_{8 t}, Y_{7 t}, Y_{9 t}, Y_{10 t}, Z_{2 t}, Z_{6 t}, Z_{7 t}$

California supply identity....... $-Y_{11 t}+Y_{9 t} \equiv-Z_{10 t}$

Other spring potatoes supply identity ................... $-Y_{12 t}+Y_{10 t} \equiv-Z_{11 t}$

Production response, California spring crop..................

Production response, other states

$$
\begin{aligned}
& Y_{11 t}, Y_{11, t-1}, Y_{13, t-1}, Z_{12, t-1}, Z_{2 t}, \\
& \quad Z_{1, t-1}, Z_{13, t-1}
\end{aligned}
$$

spring crop.............. $Y_{12 t}, Y_{12, t-1}, Y_{14, t-1}, Z_{2 t}, Z_{1, t-1}$

Transfer farm-retail, California crop $Y_{13 t}, Y_{8 t}, Z_{5 t}, Z_{2 t}$

Transfer farm-retail, other states spring crop.............. $Y_{14 t}, Y_{8 t}, Z_{5 t}, Z_{2 t}$

The variables entering each relation are those suggested by the economic theory discussed in preceding sections.

\section{Endogenous Variables}

$Y_{1 t}$ Per-capita production of late potatoes (bushels per capita).

$Y_{2 t}$ Real average price received by growers of late crop in SeptemberFebruary (dollars per bushel).

$Y_{3 i}$ Real retail price of potatoes in September-February (dollars per bushel).

$Y_{4 t}$ Quantity per capita of late potatoes fed to livestock, lost, etc. (bushels per capita).

$Y_{5 t}$ Total per-capita supply of late potatoes in September-February (bushels per capita). 
$Y_{\mathbf{c} t}$ Quantity per capita of late potatoes consumed as food in SeptemberFebruary (bushels per capita).

$Y_{7 t}$ Quantity per capita of late potatoes carried over to the spring (bushels per capita).

$Y_{8 t}$ Real retail price of potatoes in the spring (dollars per bushel).

$Y_{9 t}$ Per-capita consumption of California spring potatoes (bushels per capita).

$Y_{10 t}$ Per-capita consumption of other states spring potatoes (bushels per acre).

$Y_{11 t}$ Per-capita production of California spring crop (bushels per capita).

$Y_{12 t}$ Per-capita production of other spring potatoes (bushels per capita).

$Y_{13 t}$ Real seasonal average price received by California growers (dollars per bushel).

$Y_{14 t}$ Real seasonal average price received by other spring crop producers (dollars per bushel).

\section{Exogenous Variables}

$Z_{1 t}$ Real index. of prices received by farmers for all farm products.

$Z_{2 t}$ Time (calendar year $1925=1$ ).

$Z_{3 t}$ Average yield of late crop (bushels per acre).

$Z_{4 t}$ United States population (in thousands).

$Z_{5 t}$ Real index of railroad freight rates (fruits and vegetables).

$Z_{6 t}$ Real United States per-capita disposable income (dollars per capita).

$Z_{7 t}$ Real index of retail prices of cereals and bakery products.

$Z_{8 t}$ Bank rate of interest on business loans.

$Z_{9 t}$ Quantity (per capita) of late potatoes used as seed (bushels per capita).

$Z_{10 t}$ Quantity (per capita) of California spring potatoes used as seed, fed to livestock, or lost (bushels per capita).

$Z_{11 t}$ Quantity (per capita) of other spring potatoes used as seed, fed to livestock, or lost (bushels per capita).

$Z_{12 t}$ Real average price received by California growers for cotton lint (cents per pound).

$Z_{13 t}$ Real average price received by California growers for alfalfa hay (dollars per ton).

$Z_{14 t}$ Average yield of California spring potatoes (bushels per acre).

$Z_{15 t}$ Average yield of spring potatoes in other states (bushels per acre).

Real prices were used in all relations, since all behavioral relations involved were assumed to be of zero degree in all prices and in income. This assumption implies that there is no "money illusion" in the demand functions. It has also some statistical advantage inasmuch as it may reduce intercorrelation between prices, income, and time and thereby lead to greater precision in estimated coefficients. 
Since it was considered desirable to use a common deflator for all variables and since both retail prices and farm prices were involved, the index of wholesale prices was used as the general deflator.

The subscript $t$ refers to a "model year" as distinguished from a calendar year. A "model year" is defined to be the year beginning September 1 of the preceding year and ending August 31 of the current calendar year. Thus, the late crop of the preceding calendar year belongs to the current "model year." The "spring" period is defined to be the period beginning March 1 and ending August 15 of the current calendar year. ${ }^{44}$

In the process of estimating the parameters of the structural relations, it was found that per-capita quantity measures gave stronger results from the statistical point of view; hence, all quantities were defined in per-capita terms. Although in some cases such a definition seems irrelevant (for example, quantity per capita of potatoes used as seed), no loss of information is involved, and the relation can always be translated to absolute quantities on multiplication by population size.

The Sample Period. The central role of California potatoes in the early market is a rather recent development. As already mentioned, California production was not important in the 1920's and earlier. California's growth in importance in the potato industry began in the early 1930's; hence, earlier years are of little interest in this study. The period under study includes, therefore, the years 1930 through 1958. Another reason for excluding earlier years is that certain time series used in this study were not available for years prior to 1929. To estimate the structural relations, the years 1942 through 1950 were excluded from the analysis, since it was felt that during these years the war conditions, combined with heavy support programs, altered the structure materially.

In fact, most empirical studies of real economic structures which are based on time series face the difficulty that the structures are not stable. By stability of a structure is meant, of course, the constancy of the relations (for example, of coefficients) over time. It is likely that the structure of the potato industry has not been stable over time. Some change in structure due to changing technology, changing tastes, reallocation of production, and so forth, has occurred. In a limited sense, stability of the structure can be maintained by introducing a trend variable, since the trend variable allows for continuous shifts of the relations over time. Trend may also be regarded as replacing unobservable variables such as technology, tastes, and so forth, that are assumed to be linear functions of time.

${ }^{44}$ Let $Y_{i:^{c}}$ denote the value assumed by the $i$-th endogenous variable in calendar year $t$, then:

and

$$
Y_{i t}=\left\{\begin{array}{lll}
Y_{i, t-1}^{c} & \text { for } & i=1,2, \cdots, 6 \\
Y_{i, t}^{c} & \text { for } & i=7,8, \cdots, 14
\end{array}\right.
$$

$$
Z_{k t} \equiv Z_{k t}^{c}
$$


Clearly, the trend variable cannot account for structural variations such as those experienced during 1942-1950. It seemed desirable, therefore, to exclude these years from the sample.

The Estimation Procedure. ${ }^{45}$ An important property of the model is that various relations or groups of relations are defined for different intraseasonal time intervals. The late crop production relation is defined for the earlier part of the "model year." The quantity of late crop produced is determined by some exogenous and lagged endogenous variables. It is therefore recursive with respect to the rest of the system.

TABLE 7

SUBSYSTEMS IN ESTIMATION

\begin{tabular}{|c|c|c|}
\hline Subsystem & $\begin{array}{l}\text { Relations in } \\
\text { subsystem }\end{array}$ & $\begin{array}{c}\text { Variables } \\
\text { determined }\end{array}$ \\
\hline & equations & \\
\hline I. & (25) & $Y_{1}$ \\
\hline II. & (26), (27), (28) & $Y_{2}, Y_{3}, Y_{4}$ \\
\hline & $(29),(30),(31)$ & $Y_{5}, Y_{6}, Y_{7}$ \\
\hline III. & $(32)$ & $Y_{8}$ \\
\hline IV.. & (33) & $Y_{9}$ \\
\hline v. & (34) & $Y_{10}$ \\
\hline VI.. & (35) & $Y_{11}$ \\
\hline VII.. & (36) & $Y_{12}$ \\
\hline VIII $\ldots \ldots \ldots \ldots \ldots$ & (37) & $Y_{13}$ \\
\hline IX... & (38) & $Y_{14}$ \\
\hline
\end{tabular}

The United States potato market during September-February is described by a set of behavioral relations and identities. This set includes a supply-outof-stock relation (29); two demand equations: for food (27), and for nonhuman use (28); a farm-to-retail transfer relation (26); and two identities (30) and (31). Total production, which is identical with the total stock at the beginning of the period, enters these relations as a predetermined variable. This group of relations jointly determine the real average farm price of late potatoes in September-February $\left(Y_{2 t}\right)$; the real average retail price $\left(Y_{3 t}\right)$; per-capita quantity of late crop fed to livestock, lost, and so forth $\left(Y_{4 t}\right)$; and per-capita consumption of late crop in this period $\left(Y_{6 t}\right)$. Total per-capita supply during September-February $\left(Y_{5 t}\right)$ and the quantity carried over (per capita) are therefore determined also. The quantity of preceding year's late crop supplied to the early market is thus predetermined with respect to this market.

Since production of spring potatoes in California and other states is assumed

${ }_{45}$ The general approach and techniques adopted in this section are due to H. Wold and L. Jureen, Demand Analysis; a Study in Econometrics (New York: John Wiley and Sons, 1953), 358 p.; William C. Hood and T. C. Koopmans (eds.), Studies in Econometric Methods, Cowles Comm. for Res. in Econ. Mono. 14 (New York: John Wiley and Sons, 1953), 323 p.; and Theil, op. cit. 
to depend on exogenous and lagged endogenous variables alone, the system of equations pertaining to the early market is completely recursive. Table 7 summarizes the interdependence specified among the relations in the model. Under the specifications, all behavioral equations not included in subsystem II may be estimated by direct least squares. ${ }^{46}$ Subsystem II calls for methods of estimation appropriate for multiequational models.

The number of predetermined variables in subsystem II is eight. The largest number of predetermined variables included in any one equation is three, while the largest number of endogenous variables included in any one equation is three. Hence, by the order criterion, all equations are over-identified.

The two-stage least-squares (TSLS) method of estimation was chosen for the present analysis. The considerations leading to this choice were:

(1) Two-stage least squares yields estimates which are consistent and asymptotically unbiased.

(2) The asymptotic efficiency of estimates derived by this method is the same as the asymptotic efficiency of estimates derived by the limited information single equation (maximum likelihood) method. ${ }^{47}$

(3) Computations are simpler than for LISE.

The recursiveness of the system as a whole made it possible to adopt various econometric approaches for the various subsystems. Thus, for instance, the production response relations were fitted in terms of acreage response and then transformed into quantities per capita by multiplying the relation by the yield and dividing by the population size. The demand relations, on the other hand, were fitted directly in terms of per-capita quantities.

\section{The Estimated Structure}

Before presenting the estimated structure of the United States potato industry in its final form, two sets of estimated relations, derived as intermediate phases in the estimation procedure, are given. These sets of relations, that is, the "acreage response relations" and "reduced form of the winter market subsystem" are interesting and useful independent of other relations in the system. Since these sets of relations were transformed upon their incorporation into the final model, it was considered desirable to present separately the original direct results.

The Acreage Response Relations. In accordance with the econometric formulation developed on pages 561 and 562, the production response relations were estimated in terms of acreage response. From the corresponding description

${ }^{46}$ Strictly speaking, this is permissible only if the nonzero coefficients associated with the endogenous variables in these equations can be arranged in a triangular matrix and if the random disturbances associated with the various equations are statistically independent. The analysis was carried out under such assumptions. These assumptions were considered acceptable inasmuch as the various relations are defined for different points in time.

47 Theil, op. cit., pp. 193-378. 
of production conditions, it is evident that it is difficult to single out competing crops in the late crop area and in the spring crop areas, other than California. In the case of California, however, alfalfa and cotton are recognized as competing crops. It was therefore decided to include alternative enterprises in the production relations of the late crop and spring crop of other states only in a general way by using the ratio of potato prices to the index of prices received by farmers for all farm products as the price variable. In the California production relation, prices of cotton and alfalfa were included explicitly. The general effect of prices received by farmers for other crops was included, again by using the ratios of potato, cotton, and alfalfa prices to the index of prices received by farmers for all farm products as price variables.

The estimated relations are:

Relation

(1) Late crop

$$
\begin{array}{cc}
X_{t}=570.137+401.31419 P_{t-1}^{p}+ & .7307308 X_{t-1} \\
(154.6) & (.1329) \\
& -15.45295 t \\
& (10.388) \\
X_{t}=156.10831+83.398771 P_{t-1}^{p}+ & .6576533 X_{t-1} \\
(27.05) & (.154) \\
& -4.5518052 t
\end{array}
$$

(2) Other spring crop

(3) California spring crop

$$
\begin{aligned}
& X_{t}=-6.415828+4.065137 P_{t-1}^{p}-1.537773 P_{t-1}^{c} \\
& \text { (6.558) } \\
& +1.2500035 P_{t-1}^{a}-.11489547 X_{t-1} \\
& \text { (1.640) } \\
& \text { (.1928) } \\
& +2.8118546 t \\
& \text { (.4617) }
\end{aligned}
$$

$R^{2}$

Figures in parentheses are standard errors of estimates.

$X_{t}=$ Acreage planted to potatoes (1,000 acres).

$P_{t}^{p}=$ Average prices received by farmers for potatoes deflated by the index of prices received by farmers for all farm products (dollars per bushel).

$P_{t}^{c}=$ Average price received by California farmers for cotton lint deflated by the index of prices received for all farm products (cents per pounds).

$P_{t}^{a}=$ Average price received by California farmers for alfalfa hay deflated by the index of prices received for all farm products (dollars per ton).

$t=$ Time $(1925=1)$.

$R^{2}=$ Multiple correlation coefficient.

The Reduced Form for the Winter Market Subsystem. The assumption that the random disturbances are independent over time, even within a "model year," implies a substantial degree of recursiveness in the model. Because of 


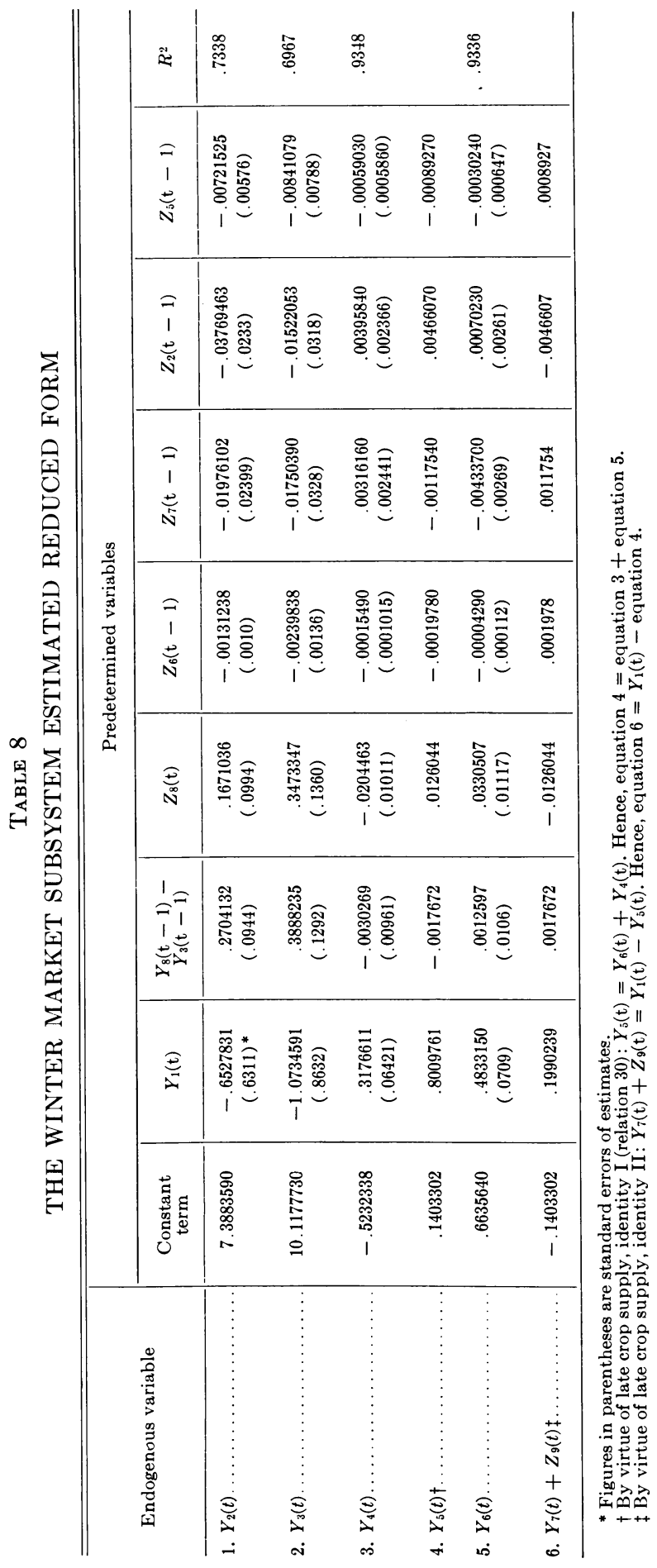


this type of relationship, it was possible to estimate relation (25) and relations (32) through (38) as individual relations by direct least-squares method. Relations (26) through (31), however, form a jointly determined subsystem. This set of relations determines for a given production of late crop potatoes the quantities that are consumed as food; quantities fed to livestock and lost; quantities carried over to the following spring; retail price of potatoes; and prices received by farmers during the months September-February. As indicated earlier, ${ }^{48}$ the structural relations were estimated by two-stage least squares. Accordingly, the first step in the estimation procedure was to obtain estimates of the reduced form relations by direct least squares. The prede-

TABLE 8A

THE WINTER MARKET SUBSYSTEM-THE VARIANCE-COVARIANCE MATRIX OF THE REDUCED FORM $\boldsymbol{\Sigma}_{\mathrm{v}}{ }^{*}$

\begin{tabular}{|c|c|c|c|c|c|c|}
\hline & $V_{2}$ & $V_{3}$ & $V_{4}$ & $V_{\mathrm{s}} \dagger$ & $V_{6}$ & $V_{7} \ddagger$ \\
\hline $\mathrm{V}_{2}$. & .087892 & .106786 & .000450 & -.001576 & -.002026 & .001576 \\
\hline$V_{3}$. & .106786 & .164417 & -.004046 & -.003333 & .000713 & .003333 \\
\hline$V_{4}$ & .000450 & -.004046 & .000910 & .000317 & -.000593 & -.000317 \\
\hline$V_{5}$. & -.001576 & -.003333 & .000317 & .074048 & .073731 & -.074048 \\
\hline$V_{6} \ldots$ & -.002026 & .000713 & -.000593 & .073731 & .074324 & -.073731 \\
\hline$V_{7} \ldots \ldots \ldots \ldots$ & .001576 & .003333 & -.000317 & -.074048 & -.073731 & .074048 \\
\hline
\end{tabular}

† Since $V_{5} \equiv V_{4}+V_{6}$ by late crop supply identity I:

$$
\begin{array}{lll}
\sigma_{5 j}=\sigma_{44}+\sigma_{66}+2 \sigma_{46} & \sigma_{45}=\sigma_{44}+\sigma_{46} & \sigma_{35}=\sigma_{34}+\sigma_{36} \\
\sigma_{25}=\sigma_{24}+\sigma_{26} & \sigma_{56}=\sigma_{46}+\sigma_{66} &
\end{array}
$$

‡ Since $V_{7} \equiv-V_{5}$ by late crop supply identity II:

for $j=2,3,4,5$, and 6 ; and $\sigma_{77}=\sigma_{55}$

termined variables are all strictly exogenous variables and lagged endogenous variables entering the structural equations (26) through (31) and the current per-capita production of the late potato crop.

Table 8 presents the estimated reduced form equations. Actually, only the relation involving $Y_{2}(t), Y_{3}(t), Y_{4}(t)$, and $Y_{6}(t)$ as dependent variables were estimated directly. The relations involving $Y_{5}(t)$ and $Y_{7}(t)+Z_{9}(t)$ as dependent variables were derived from the corresponding estimated relations through the use of the appropriate late crop supply identities. It should also be noted that as an intermediate step in the analysis, a new endogenous variable $X_{7}(t)+Z_{9}(t)$ was defined. This variable consists of the total carryover of late crop potatoes to the spring; that is, it comprises both stocks to be used as food and stocks to be used as seed. In a later stage, this variable is decomposed into $Y_{7}(t)$ and $Z_{9}(t)$, respectively. The elements of the estimated variance-covariance matrix presented in table $8 \mathrm{~A}$ have been derived by use of the formula:

$$
\hat{\sigma}_{i i^{\prime}}=\frac{1}{T-k} \sum_{t=1}^{T} \hat{v}_{i t} \hat{v}_{i^{\prime} t}
$$

${ }^{48}$ See "The Estimation Procedure," page 589. 
where

$$
\begin{aligned}
\hat{v}_{i t} & =\text { computed residual }=Y_{i t}-\hat{Y}_{i t} \\
T-k & =\text { number of degrees of freedom. }
\end{aligned}
$$

The elements corresponding to $Y_{5}(t)$ and $Y_{7}(t)$ were derived by using late crop supply identities I and II.

The Complete Estimated Structure. Having estimated separately all parameters of the various subsystems, a unified and complete set of estimated relations is formed which serves as an estimate of the unknown economic structure. In this unification, corresponding variables must be defined in comparable units for all equations in the set. Accordingly, all quantities were converted to bushels per capita and all prices to real prices. Since all production response relations were formulated and estimated in terms of acreage rather than quantities, they were multiplied by yield per acre and divided by population size to get the relations in terms of bushels per capita. Since the price variables entering these relations were ratios of the prices received by farmers for the particular products to the index of prices received for all farm products, the coefficients associated with these variables were divided by the real index of prices received, so that real prices alone serve as price variables. No change was required in any other relation. Consequently, a set of 14 equations is obtained. All equations are linear in all current and lagged endogenous variables and in all exogenous variables except population size, yields of the various crops, and the index of prices received by farmers for all farm products. Using the notation on page 586, the system may be written in matrix form as follows:

$$
\mathrm{B} Y(t)+\Gamma_{1}(t) Y(t-1)+\Gamma_{2}(t) Z(t)=U(t)
$$

where

B is a $14 \times 14$ matrix of constant coefficients.

$\Gamma_{1}(t)$ is a $14 \times 14$ matrix of coefficients, some of which depend on certain exogenous variables.

$\Gamma_{2}(t)$ is a $14 \times 15$ matrix of coefficients, some of which depend on certain exogenous variables.

$Y(t)$ is a $14 \times 1$ vector of current endogenous variables.

$Z(t)$ is a $15 \times 1$ vector of exogenous variables entering the system linearly.

$U(t)$ is a $14 \times 1$ vector of random disturbances, with the following properties:

$$
\begin{aligned}
E\{U(t)\} & =0 \\
E\left\{U(t) U^{\prime}(t-\tau)\right\} & =\left\{\begin{array}{l}
0 \text { for } \tau \neq 0 \\
\boldsymbol{\Sigma}_{u} \text { for } \tau=0
\end{array}\right.
\end{aligned}
$$

In tables 9,10 , and 11 the estimated relations of the complete structure are presented. 


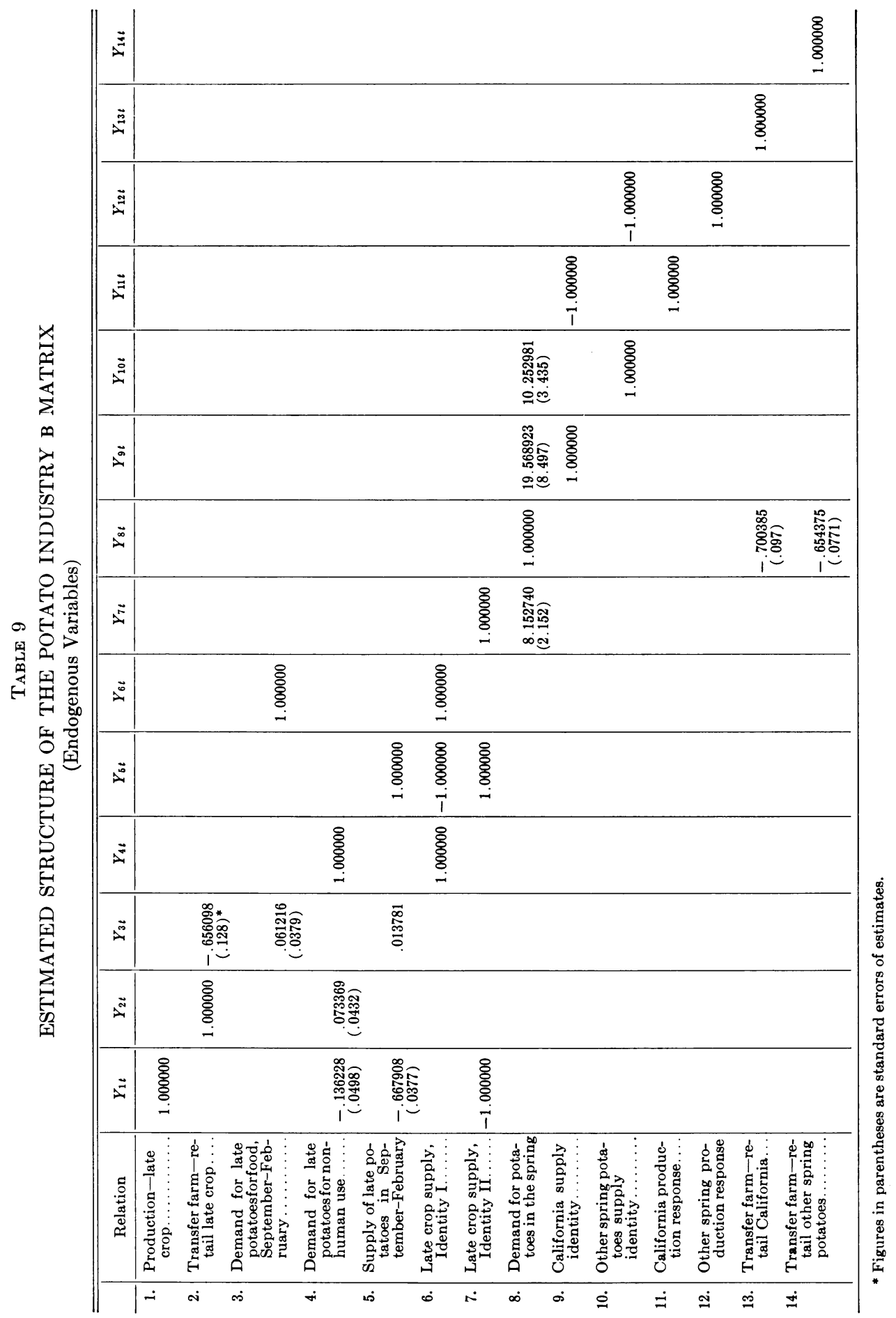




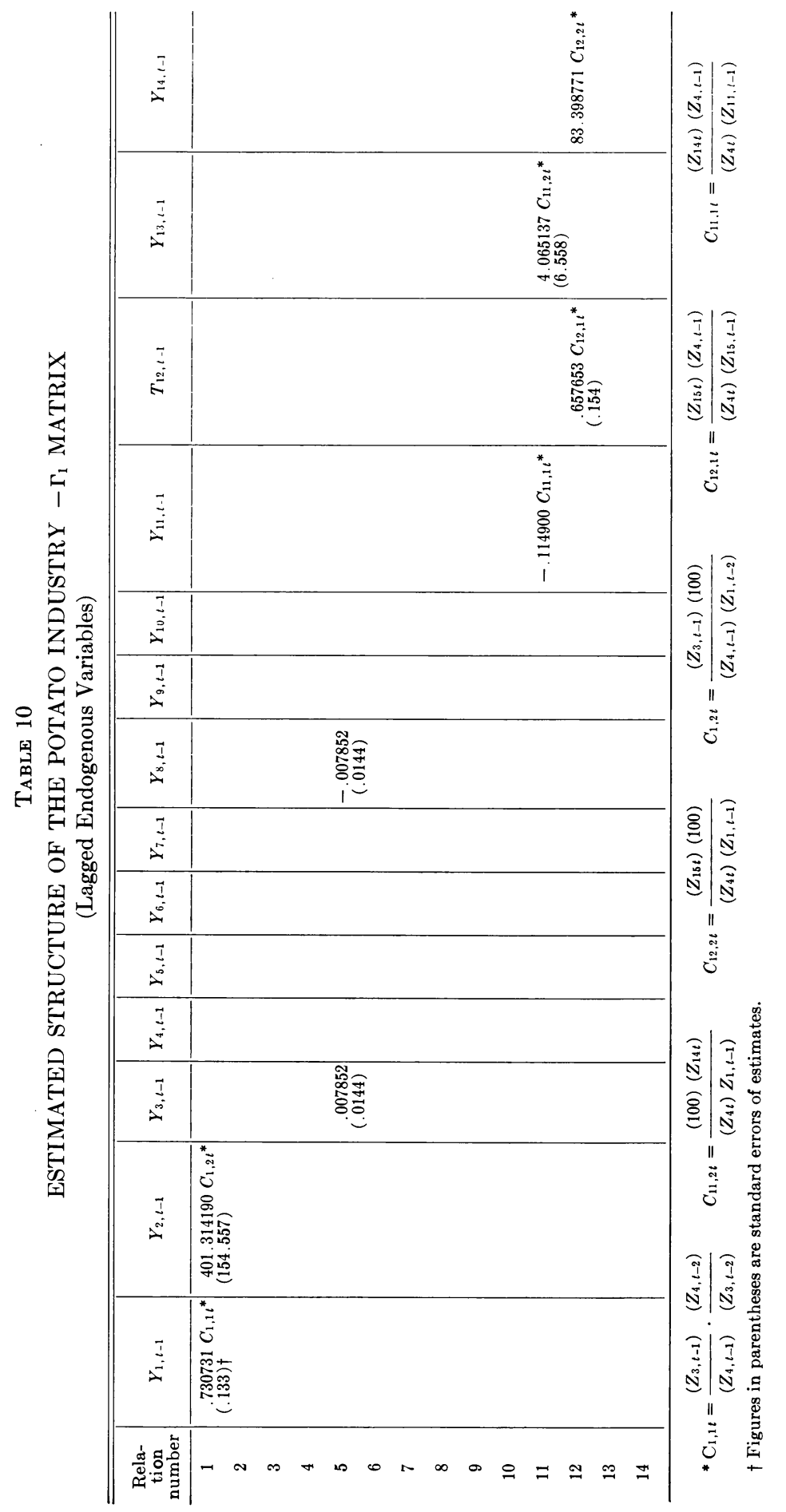




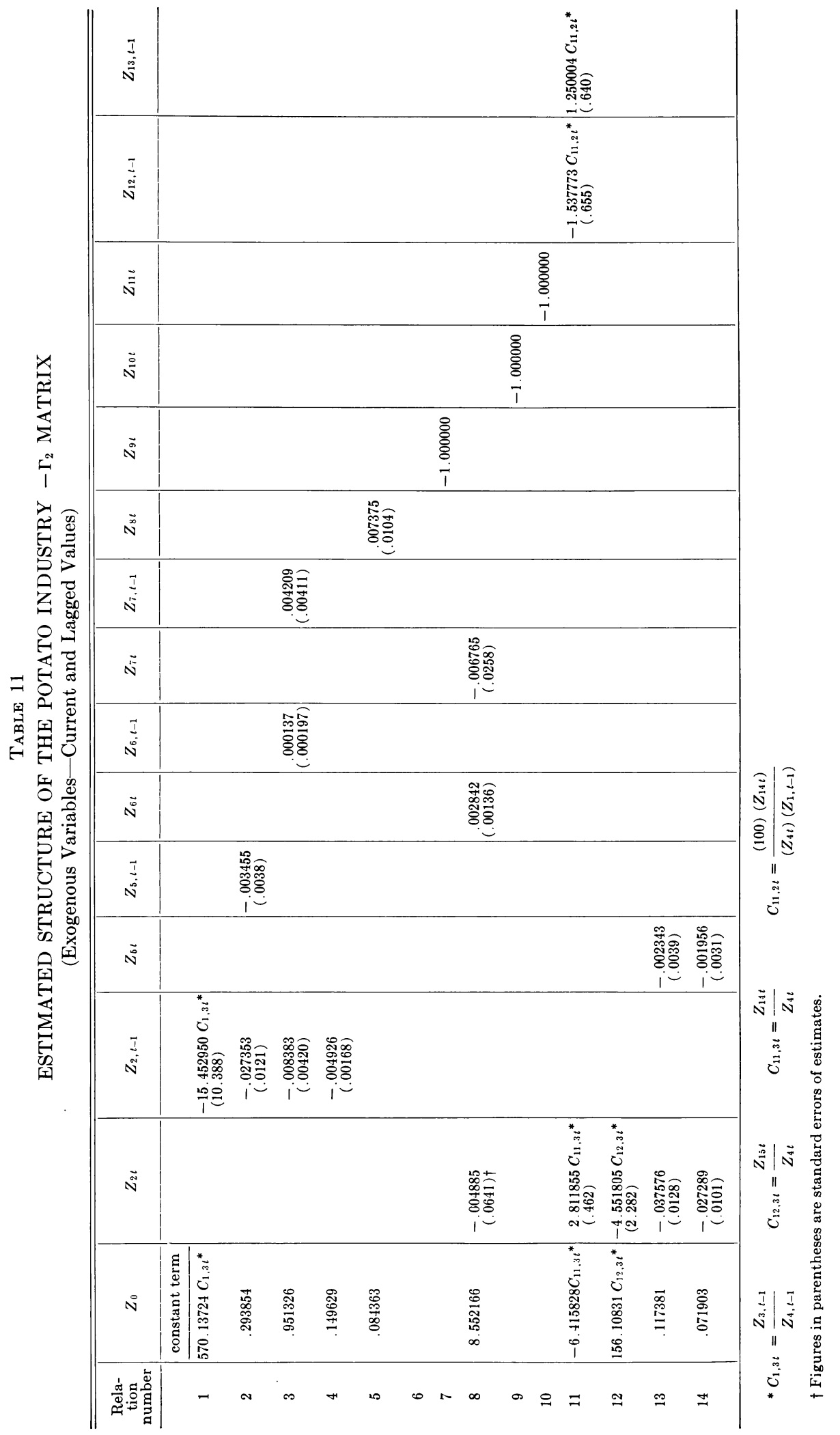




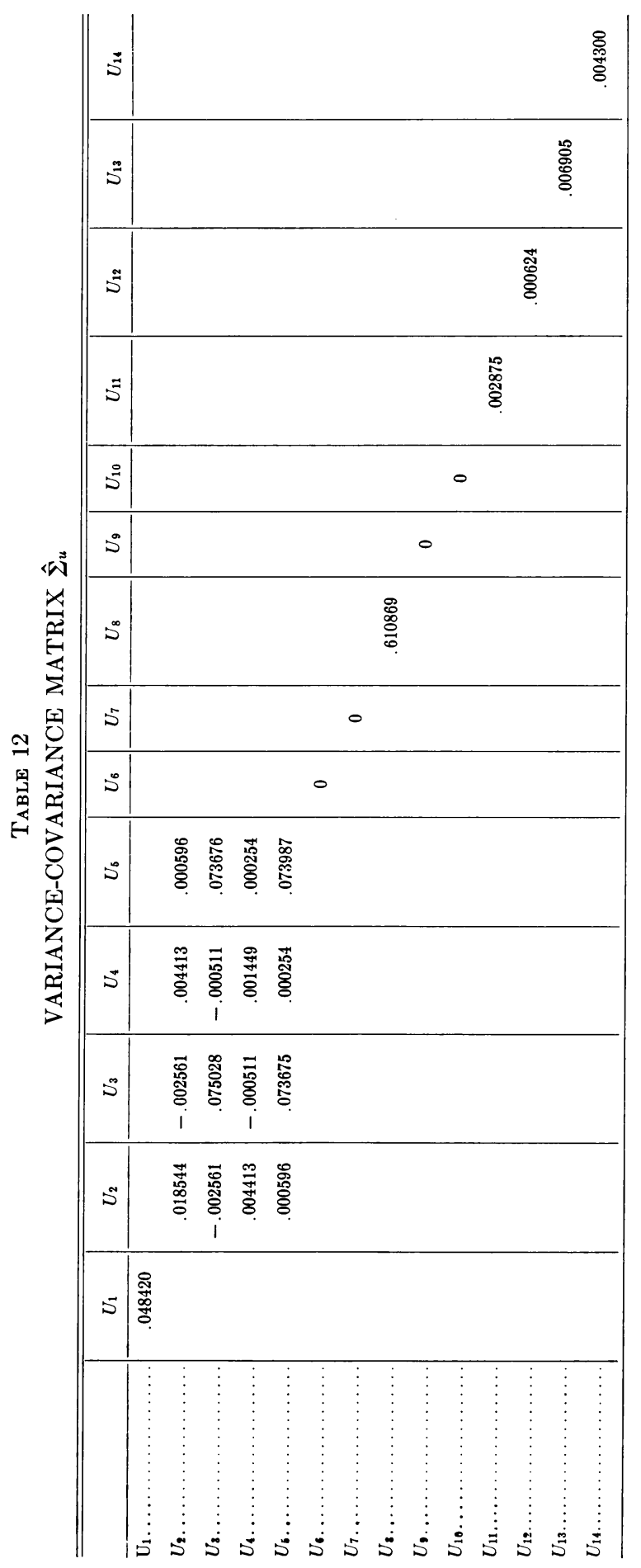


For the definition of the various variables, see pages 586 to 587 . Notice that in $\Gamma_{1}$ and $\Gamma_{2}$ some coefficients are actually functions of the exogenous variables which enter the system nonlinearly. Table 12 contains the estimated variancecovariance matrix $\boldsymbol{\Sigma}_{u}$. The nonzero diagonal elements $\sigma_{1,1}, \sigma_{8,8}, \sigma_{11,11}, \sigma_{12,12}$, $\sigma_{13,13}, \sigma_{14,14}$ are estimates of $\sigma_{u_{i}}^{2}$ from the estimated equations (25), (32), (35), (36), (37), and (38), respectively; that is:

$$
\hat{\sigma}_{i i}=\frac{1}{T-k_{i}} \sum_{t=1}^{T} \hat{u}_{i t}^{2}
$$

The submatrix $\hat{\boldsymbol{\Sigma}}_{u}{ }^{*}$ involving variances and covariances of $u_{2}(t)$ through $u_{5}(t)$ were obtained from the variance-covariance matrix $\hat{\boldsymbol{\Sigma}}_{v}{ }^{*}$ of the reduced form system of the winter market from:

$$
\hat{\mathbf{\Sigma}}_{u}^{*}=\hat{\mathbf{B}}^{*} \hat{\boldsymbol{\Sigma}}_{v}^{*} \hat{\mathbf{B}}^{*+}
$$

where $\mathrm{B}^{*}$ is the matrix associated with the endogenous variables in the structural system of the winter markets. Zero diagonal elements correspond to identities in the model.

"Goodness of Fit." The multiple correlation coefficients associated with the various equations estimated by means of least squares is of some interest, as they provide some measure of the explanatory power of the individual equations with respect to the sample period. The coefficients associated with the production response relations and with the "winter" market subsystem were presented on page 591 and table 8 , respectively. The multiple correlation coefficients associated with the other relations in the model are presented below.

\section{Equation}

(32) Demand for potatoes in the spring

(37) California, farm-to-retail transfer relation

(38) Other early states, farm-to-retail transfer relation

\section{$R^{2}$}

.6867

.7870

.8230

\section{Some Remarks and Comparisons}

Though the full implication of the estimated relations will be pursued in the next two chapters, it seems desirable to derive at this point certain measures of performance from the present estimates and compare them with corresponding measures based on earlier studies. Such comparisons are summarized in the present section.

The Acreage Response Relation. The major price-acreage relationships for the three regions are summarized in terms of elasticities in table 13.

Comparing these results with earlier studies, ${ }^{49}$ it appears that there is good agreement with the $\mathrm{O}$. Hee findings with respect to acreage response of late crop. In the case of California acreage response, however, results are quite different from those reported by McCorkle and Mundlak. It is believed that this difference is partly due to the different formulation and partly due to the

\footnotetext{
${ }^{49}$ See table 2, page 560.
} 
fact that McCorkle and Mundlak used undeflated prices as explanatory variables. The present results suggest that the behavior of California producers does not conform to expected behavior. A relatively inelastic price elasticity is associated with a very high coefficient of adjustment (ordinarily, it is expected that $0 \leqq \gamma \leqq 1$ ). That is, California production and price relationship are such that a large price change generates a small acreage change, but this change is carried out in the immediate season with a tendency to overadjust. One may doubt, however, whether the coefficient of adjustment is really larger than unity. The standard error of estimate associated with the coefficient of lagged acreage is such that the hypothesis that

TABLE 13

ELASTICITIES OF ACREAGE RESPONSE*

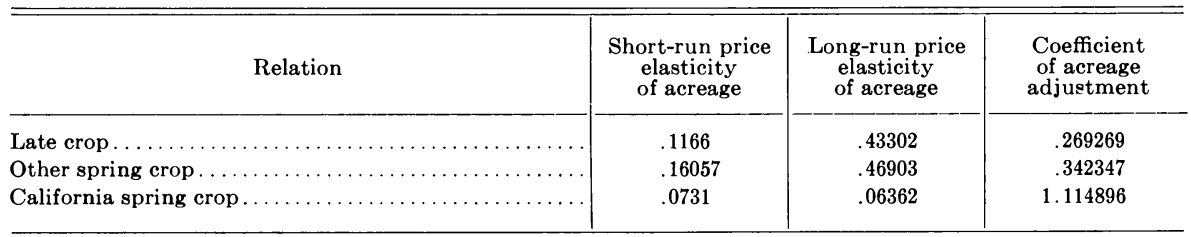

* Elasticities are evaluated at the mean. Short-run price elasticities are defined by:

$$
\eta_{s r}=\frac{\partial X_{t}}{\partial P_{t-1}^{p}} \frac{\bar{P}^{p}}{\bar{X}}
$$

long-run price elasticities by:

$$
\eta_{l r}=\frac{\partial X_{t}}{\partial P_{t-1}^{p}} \frac{\bar{P}_{-1}^{p}}{\left(1-\frac{\partial \bar{X}_{t}}{\partial \bar{X}_{t-1}}\right) \bar{X}}
$$

where all derivatives are defined for the estimated relations on page 591 .

$\gamma=1$ can hardly be rejected. On the other hand, the manifested behavior of California growers may well be compatible with accepted economic theory. In fact, this type of behavior is expected if production conditions are such that the marginal cost of production rises rapidly when acreage is increased and at the same time (1) price expectations are such that producers expect the observed price change to continue in the same direction and (2) acreage adjustments are easily made.

Acreage of late crop and of other states' spring crop is relatively more elastic with respect to price, but adjustment is much slower than in California. This would be expected in view of the differences in production conditions. California production is highly commercialized, so that higher price responsiveness and speculative behavior is not surprising. On the other hand, potato production is probably carried to the limit so that the marginal cost of production increases rapidly with changes in acreage. These factors may be less important and acute in the other regions. Hence, adjustment is slower in these regions, but cost conditions are such that there is plenty of room for acreage change without changing the marginal costs considerably. 
The negative elasticity of potato acreage with respect to cotton in California is not unexpected and reflects competitive relations between the two crops. A positive elasticity of potato acreage with respect to alfalfa price indicates a complementary relation. McCorkle and Mundlak ${ }^{50}$ found similar results, and they suggest the following explanation: Alfalfa and cotton compete for midsummer water supply. An expansion of 1 acre of alfalfa will typically replace two acres of cotton. The acreage freed from cotton has to be replaced by a crop which does not require midsummer water supply. The potato is the most important crop which satisfies this restriction. Thus, an increase in alfalfa price will lead to an increase in potato acreage through the replacement of cotton.

The time trends in all equations reflect trends in relevant variables not included explicitly in the equation. The expansion of irrigated cropland in California is an example of such trend; technological changes are another.

The Demand Relation. The estimated demand relation presented in the complete estimated structure (tables $9,10,11$ ) are in per-capita terms. Price flexibilities can thus be derived directly. In terms of the model's relation, the following price flexibilities evaluated at the sample means are obtained.

$$
\text { "Winter" Demand }
$$

Quantity:

$$
\frac{\partial Y_{3 t}}{\partial Y_{6 t}} \frac{\bar{Y}_{6}}{\bar{Y}_{3}}=-7.2249
$$

Income:

$$
\frac{\partial Y_{3 t}}{\partial Z_{6, t-1}} \frac{\bar{Z}_{6}}{\bar{Y}_{3}}=.9093
$$

Price of substitutes:

$$
\begin{gathered}
\frac{\partial Y_{3 t}}{\partial Z_{7, t-1}} \frac{\bar{Z}_{7}}{\bar{Y}_{3}}=2.71665 \\
\text { "Spring" Demand }
\end{gathered}
$$

Quantity of preceding year's crop carried over:51

$$
\frac{\partial Y_{8 t}}{\partial Y_{7 t}} \cdot \frac{\left(\bar{Y}_{7}+\bar{Y}_{9}+\bar{Y}_{10}\right)}{\bar{Y}_{8}}=-1.4151
$$

Quantity of California spring potatoes:

$$
\frac{\partial Y_{8 t}}{\partial Y_{9 t}} \cdot \frac{\left(\bar{Y}_{7}+\bar{Y}_{9}+\bar{Y}_{10}\right)}{\bar{Y}_{8}}=-3.3968
$$

\footnotetext{
${ }^{50}$ McCorkle and Mundlak, op. cit., p. 468.

${ }^{51}$ Individual price flexibilities were defined relative to total supply in order to permit comparison with results of earlier studies.
} 
Quantity of other states' early potatoes:

$$
\frac{\partial Y_{8 t}}{\partial Y_{10 t}} \cdot \frac{\left(\bar{Y}_{7}+\bar{Y}_{9}+\bar{Y}_{10}\right)}{18}=-1.7800
$$

Income:

$$
\frac{\partial Y_{8 t}}{\partial Z_{6 t}} \cdot \frac{\bar{Z}_{6}}{\bar{Y}_{8}}=.988761
$$

Price of substitutes:

$$
\frac{\partial Y_{8 t}}{\partial Z_{7 t}} \cdot \frac{\bar{Z}_{7}}{\bar{Y}_{8}}=-.22425
$$

The price flexibility of demand for potatoes in the winter, as estimated in this study, is much higher than that found in earlier studies ${ }^{52}$ for the total annual crop. This may be due to the fact that only potatoes utilized as food are considered in this relation. Previous studies have considered all types of potatoes, and demand for nonfood uses may be much more elastic. An additional explanation is provided by the estimated price flexibility in the spring, which is generally lower than the annual price flexibility found in earlier studies. Thus, the price flexibility estimated by earlier studies is a weighted average of the flexibilities in the various seasons of the year.

The income flexibility is about the same in both seasons and agrees well with that estimated by Karl Fox.

The effect of a change in the prices of substitutes on retail potato price is different in the two seasons; that is, the cross flexibility is positive (as one expects it to be) in the winter but negative in the spring. Nevertheless, the $t$ ratio in the latter case is .262 , and the hypothesis that the cross flexibility is, in fact, zero can hardly be rejected.

It is interesting to note that the trend coefficient is negative in both demand relations, although in the spring the associated standard error of estimate is rather large. This agrees with earlier findings on total annual demand but not with Shuffett's finding on the demand for the early crop. The fact that percapita consumption of early potatoes was also rising during the sample period cannot serve as evidence to support Shuffett's results. It is suggested that the increasing per-capita consumption of early potatoes is mainly due to the rapid expansion of California production response and occurs even though the demand for early potatoes is declining.

The Demand for Nonhuman Use. Similar to the demand for potatoes as food, the various elasticities and coefficient for nonhuman use can be derived directly from tables 9,10 , and 11 . The price elasticity of demand for nonhuman use is .32455 (a price flexibility of 3.0812). This suggests that this type of demand is considerably more elastic than the demand for potatoes as food.

An increase in production of 1 unit, all other factors constant, leads to an increase of approximately .14 units of potatoes diverted to nonhuman uses.

${ }^{52}$ See table 4 , page 572 . 
The trend coefficient is -.0049255 . It is suggested that the negative time trend may result from (1) a diminishing demand for potatoes as feed due to increased specialization of production and (2) improved storage methods which lead to a smaller loss and shrinkage.

The Farm-to-Retail Transfer Relations. Rows 2, 13, and 14 of tables 9, 10, and 11 represent the farm-to-retail transfer relation corresponding to the late crop, California early crop, and other states' early crop, respectively. On the basis of the theoretical derivation on pages 563 and 564 and disregarding complications due to aggregation, the above-mentioned estimates of the farm-toretail transfer relation suggest the following price flexibilities of demand for potatoes at individual stores (compared with industry flexibilities).

\begin{tabular}{lcc} 
& \multicolumn{2}{c}{ Price flexibilities of demand } \\
& Individual stores ${ }^{53}$ & Industry \\
Late potatoes_"winter market” & -.3439 & -7.2249 \\
California spring potatoes & -.2996 & -3.3968 \\
Other spring potatoes & -.3456 & -1.7800
\end{tabular}

The individual demand functions are much more elastic than the industry demand functions. The average individual elasticities are very similar for the various types of potatoes and seasons, whereas the industry elasticities differ materially. This presumably is a result of the individual demand functions being determined by a market organization which does not vary for various types of potatoes and seasons.

The negative trend coefficients are another indication of the general tendency for the farm-retail spread to increase over time due to an increasing demand for marketing services.

The coefficients associated with the index of railroad freight rates may be interpreted as measures of the relative distance of potato producers from the main markets. However, the relatively large standard errors of estimate of these coefficients do not permit a reliable comparison of locational advantages and disadvantages of the various producer groups.

${ }^{53}$ The price flexibility of demand at an individual store is estimated by $1 / \eta_{p}=1-$ (coefficient of retail potato price). This formula is derived from equation (11), page 564 .

${ }^{54}$ See tables $9,10,11$. 


\section{ANALYSIS OF THE STATIC AND DYNAMIC CHARACTERISTICS OF THE INDUSTRY}

\section{Objectives and Theoretical Background}

Objectives and Outlines. Having estimated the parameters of all relations in the model, we are in a position to analyze the static and dynamic characteristics of the potato industry.

The static analysis will be a comparative one; that is, an attempt will be made to evaluate the effect of changes in certain predetermined variables on the values assumed by the endogenous variables in equilibrium, short run and long run (stationary).

The analysis of the system dynamics will be concerned with the time path taken by the system under various environmental conditions. In particular, an attempt will be made to determine the stability of the system and its movement in a changing economy.

The analysis of the stationary state is important inasmuch as it represents the point toward which the system gravitates (providing it is stable). The stability of the system is of interest, since it has a direct effect on the dynamic efficiency of the system. Where "efficiency" is to be interpreted in terms of welfare economics, the analysis of the system evolution in a changing economy is perhaps the most interesting, since it represents the closest approximation to reality. This analysis will also shed light on the adjustment process of the potato industry to everchanging exogenous conditions.

The method of analysis will be a "period equilibrium analysis"; ;5 that is, the time path is divided into discrete "periods." In every such period, each variable assumes a unique value that is its equilibrium value. The set of equilibrating variables includes all endogenous variables.

The analysis is in terms of the estimated relations. Of course, the estimated parameters are subject to sampling error, and it would have been desirable to develop conclusions reflecting this explicitly. Accordingly, the best procedure would have been to present conclusions as confidence statements to which probability measures can be attached. This, however, calls for much more elaborate methods and computations, some of which are yet to be developed. All quantitative statements will therefore be presented as single numbers (point estimates) rather than intervals.

Theoretical Background and Definitions. The terms "statics," "dynamics," "stationary states," etc., are frequently used in the economic literature in a rather vague fashion, having different meanings when used by different authors and for different purposes. It therefore seems desirable to define certain concepts before a detailed analysis is undertaken. No generality is claimed for these definitions, but they will serve to indicate how these concepts are understood in the present analysis.

${ }^{55}$ Cf. W. J. Baumol, Economic Dynamics (2d ed.; New York: Macmillan Co., 1959), chap. 8 . 
In defining a "dynamical system," reference is made to the following statement by P. A. Samuelson:

Conceived broadly, a dynamical system might be regarded as any set of functional equations which together with initial conditions (in the most general sense) determine as solutions certain unknowns in function of time..$^{56}$

According to R. Frisch, in such systems "variables at different points of time" are involved in an "essential" way ${ }^{57}$ Formalizing the above definition, a dynamical system is described by the set of functionals:

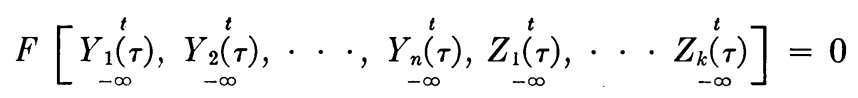

where $\{Y(t)\}$ are endogenous variables and $\{Z(t)\}$ are exogenous variables. The present structure is, in fact, a set of stochastic linear difference equations that may be written in matrix form as in Equation (39), that is:

$$
\mathrm{B} Y(t)+\Gamma_{1}(t) Y(t-1)+\Gamma_{2}(t) Z(t)-U(t)=0
$$

It thus represents a dynamical system.

The term "statical system" will refer to a set of relations that does not satisfy the above definition; that is, a system that does not involve variables at different points of time in an essential way. Such systems may be derived from a dynamic one in two general ways: (1) We consider a single period alone, treating all exogenous and lagged endogenous variables as given. The equilibrium thus determined will be referred to as the short-run equilibrium. ${ }^{58}$ (2) We consider only stationary states of the system (corresponding to given values of exogenous variables)..$^{59}$ This implies that each variable is constant over time. Equation (42) then becomes:

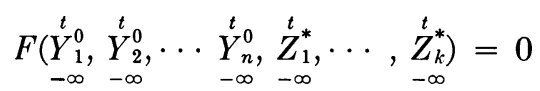

The dynamic system is thereby reduced to a static set of relations describing the equilibrium values of the endogenous variables as functions of the exogenous variables. ${ }^{60}$

\footnotetext{
${ }^{56}$ P. A. Samuelson, Foundations of Economic Analysis (Cambridge: Harvard University Press, 1947), p. 284.

${ }^{57}$ R. Frisch, "On the Notion of Equilibrium and Disequilibrium," Review of Economic Studies, 3 (2): 100-06, 1936. Such systems include sets of difference equations, sets of differential equations, integral equations, and combinations of the three.

${ }^{58}$ This type of static equilibrium is the one referred to by Baumol as the "time slice" equilibrium in Economic Dynamics, op. cit.

${ }^{59}$ Stationary values of $Y^{\prime}(t)$ corresponding to varying values of $Z(t)$ are conceivable but are rather unusual.

${ }^{60}$ Static systems are not necessarily derived from dynamic systems. They may be derived directly from static theory. Although some relations of the present model were developed in this way, the model as a whole represents a dynamic system. The analysis of its static properties will therefore include reduction of the broader dynamic model to a static system by the above-mentioned methods.
} 
From equation (43), it follows that the present structure is stochastic and historical ${ }^{61}$ that is, the existence of stochastic disturbances is recognized in formulating the system. The historical nature of the system follows from the introduction of the exogenous variables.

In the following analysis, however, it will be helpful in many instances to treat the structure as a deterministic set of relations, disregarding the role of the random disturbances. The justification for such a procedure rests on the a priori specification of the model. According to specifications, the unconditional expectations of the values taken by endogenous variables are identical with those generated by the nonstochastic components of the system. ${ }^{62}$

Similarly, it will prove helpful in some cases to analyze the system as if it were purely causal. This will be done by "freezing" all historical changes; that is, by treating the exogenous variables as fixed constants.

Mathematical Methods. The analysis of the dynamic properties of the system is in terms of the estimated structure. It consists of finding the solution to equation (43), where $U(t)$ is set equal to zero identically for all $t$ and $\mathrm{B}, \Gamma_{1}$, and $\Gamma_{2}$ are replaced by their estimates. ${ }^{63}$ The solutions $Y(t)$ are explicit functions of time such that the estimated set, equation (43), is satisfied identically in all values of $t$ over which the system is defined.

To simplify the solution, it is first necessary to obtain matrices of constant coefficients. This is achieved by either one of the following methods: (1) the exogenous variables that determine the values of coefficients in $\Gamma_{1}$ and $\Gamma_{2}$ are assumed constant over time, or (2) the system is "linearized." ${ }_{64}$ The reduced form of the estimate of equation (43) is:

$$
Y(t)=\Pi_{1} Y(t-1)+\Pi_{2} Z(t)
$$

where

$$
\Pi_{1}=-\mathrm{B}^{-1} \Gamma_{1} \quad \text { and } \quad \Pi_{2}=-\mathrm{B}^{-1} \Gamma_{2}
$$

It happens that the relations in the present model are, at most, first-order difference equations. Hence, no further translation into a set of first-order equations is necessary.

The general solution to the set of first-order difference equations is the sum of (1) a particular solution $Y^{*}(t)$ to equation (45) for given $Z(t)$ and (2) a general solution $y(t)$ to the homogenous set:

$$
y(t)-\Pi_{1} y(t-1)=0
$$

${ }^{61}$ Cf. Samuelson, op. cit., chap. XI.

${ }^{62}$ For a more detailed discussion, see the section starting page 616 .

${ }^{63}$ In the forthcoming analysis, the same relation will be used as in equation (43), but B, $\Gamma_{1}$, and $\Gamma_{2}$ will refer to the estimates of the true parameters.

${ }^{64}$ For a detailed explanation of the "linearization" method, see the section starting page 608 . 
The general solution to equation (45) is therefore:

$$
Y(t)=Y^{*}(t)+y(t)^{65}
$$

If $Z(t) \equiv Z^{*}$ and $I-\Pi_{1}$ is nonsingular, then

$$
Y^{*}=\left(I-\Pi_{1}\right)^{-1} \Pi_{2} Z^{*}
$$

is a particular solution to equation (43) ; in fact, $Y^{*}$ is the stationary (equilibrium) value of $Y(t) . y(t)=Y(t)-Y^{*}$ is then interpreted as the deviation from the stationary value.

If $Z(t)$ varies over time, $Y^{*}(t)$ will also vary over time. The movement of $Y^{*}(t)$ will now depend on the particular movement of $Z(t)$. This case will be discussed in more detail in the section starting page 636 .

To solve equation (46), we first translate the set, equation (46), of firstorder difference equations in $G$ variables to $G$ independent linear difference equations of order $K \leqq G$ each in the single variables $Y_{g}(t)$. To this effect, we notice that:

$$
y(t+i)=\Pi_{1}^{i} y(t)
$$

satisfies equation (46).

Now let

$$
P_{\Pi_{1}}(\lambda)=\sum_{i=0}^{k} a_{i} \lambda_{k}^{i}
$$

be the characteristic polynomial of $\Pi_{1}$. By the Cayley-Hamilton theorem,

$$
P_{\Pi_{1}}\left(\Pi_{1}\right)=\sum_{i=0}^{k} a_{i} \Pi_{1}^{i}=0
$$

Multiplying equation (49) by $a_{i}$ and sum over $i=0,1, \cdots, k$, we get:

$$
\begin{aligned}
\sum_{i=0}^{k} a_{i} y(t+i) & =\sum_{i=0}^{k} a_{i} \Pi_{1}^{i} y(t) \\
& =P_{\Pi_{1}}\left(\Pi_{1}\right) y(t) \\
& =0
\end{aligned}
$$

and, hence,

$$
\begin{gathered}
\sum_{i=0}^{k} a_{i} y_{g}(t+i)=0 \\
g=1, \cdots, G
\end{gathered}
$$

${ }_{65}$ The rest of this section consists of a general description of the method of solving sets of linear difference equations. A more detailed treatment of the subject can be found in Samuelson, op. cit., Mathematical Appendix B, pp. 380-439; R. G. D. Allen, Mathematical Economics (Iondon: Macmillan Co., 1956), chap. 6; and Baumol, op. cit., pp. 169-373. 
The solution to equation (51) is then of the form: ${ }^{66}$

$$
y_{g}(t)=\sum_{i=1}^{k} A_{g i} \lambda_{i}^{t}
$$

where the $\left\{A_{g i}\right\}$ depends on initial conditions and the $\left\{\lambda_{i}\right\}$ are roots of the characteristic polynomial.

Since, in the present analysis, all $\lambda_{i}$ were actually found to be distinct, the case of multiple roots is of no concern. If some $\lambda_{i}$ are complex, a cyclical element is introduced into the solution. Suppose $\lambda_{i} \cdots \lambda_{m}(m \leqq k / 2)$ are $m$ conjugated (pairs) of the form:

$$
\lambda_{j}=a_{j}+b_{j} i \quad j=1, \cdots, m,
$$

then it can be shown that the general solution to equation (51) is of the form:

$$
y_{o}(t)=\sum_{j=1}^{m} A_{g j} r_{j}^{t} \cos \left(\theta_{j} t-\epsilon_{j}\right)+\sum_{i=2 m+1}^{k} A_{g i} \lambda_{i}^{t}
$$

where

$$
r_{j}=\sqrt{a_{j}^{2}+b_{j}^{2}} \quad \text { and } \quad \theta_{j}=\tan ^{-1}\left(\frac{b_{j}}{a_{j}}\right)
$$

and $\left\{A_{g j}\right\},\left\{\boldsymbol{\epsilon}_{j}\right\}$, and $\left\{A_{g i}\right\}$ depend on initial conditions.

\section{Impact Multiplier}

The General Concept of Multipliers. The concept of the multiplier, although originally developed in connection with the effect of a change in autonomous investment on income, is used at present in a much more general way. Thus, the "multiplier" is broadly defined as the change in an endogenous variable that is associated with a unit change in an exogenous variable. The number of multipliers in a system will be equal to the number of exogenous variables times the number of endogenous variables. ${ }^{67}$ Multipliers are classified in accordance with their mode of operation over time. Thus, two general types of multipliers are ordinarily distinguished: (1) static multipliers and (2) dynamic multipliers. The difference between these types follows from the nature of the economic system in which the changes take place. If the system is statical, then all multipliers are statical. If the system is dynamic, the multipliers are dynamic.

Corresponding to the two types of static analysis described in the previous section, there are two types of static multipliers. The first corresponds to the

\footnotetext{
${ }^{66}$ The form obtained was referred to by J. Tinbergen as the "final equation." Cf. Tinbergen, op. cit., pp. 16-18. J. Marschak has named it as the "separated form." Cf. J. Marschak, "Statistical Inference in Economics: An Introduction," Statistical Inference in Dynamic Economic Models, ed. T. C. Koopmans, Cowles Comm. for Res. in Econ. Mono.10 (New York: John Wiley and Sons, 1950), p. 34.

${ }^{67}$ Quite often, multipliers are defined for autonomous changes in endogenous variables. Such autonomous changes are really analogous to exogenous variables; hence, the definition of the multiplier will include these also.
} 
short-run statical system where values of exogenous and lagged endogenous variables are given as data. Such short-run static multipliers describe the changes in current endogenous variables associated with unit changes in current exogenous and lagged endogenous variables. These are instantaneous multipliers, and the name "impact multipliers" was given to them by Goldberger. ${ }^{68}$

The second type of static multiplier corresponds to the system of equations describing the stationary state. Accordingly, they will be referred to as "stationary multipliers" or "long-run multipliers." A stationary multiplier

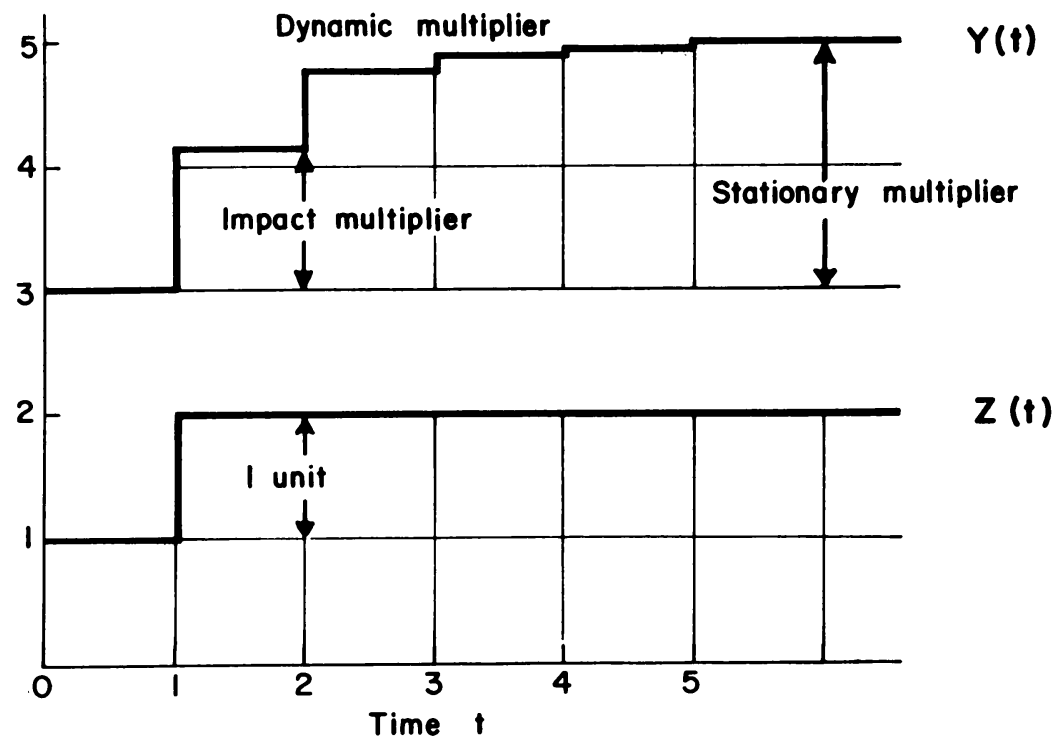

Fig. 15. Static and dynamic multipliers.

describes the change in the level of an endogenous variable between two stationary states, the difference in the two stationary states being generated by a unit change in the level of one exogenous variable. Stationary multipliers are derived from the set of equations describing the steady state as functions of exogenous variables.

Dynamic multipliers describe the change in the endogenous variables following unit changes in exogenous variables as functions of time. The change in an exogenous variable may be transitory in the sense that in subsequent periods the exogenous variable returns to its original level, or it may be maintained at its new level--"maintained change."

In stable systems, transitory changes lead to transient disturbances of the system, the system eventually returning to its original equilibrium. Maintained changes lead to a movement of the system to a new steady state. The

${ }^{68}$ Goldberger: op. cit. 
change in an endogenous variable associated with $t$ periods of a "maintained change" of one unit in an exogenous variable is referred to by P. A. Samuelson as the "truncated multiplier." ${ }^{69}$ If the endogenous variable was in equilibrium before the change and provided the system is stable, then after a sufficiently long time has elapsed, the "truncated multiplier" becomes equal to the "stationary multiplier." In figure 15, the various multipliers are demonstrated for a monotone convergent system.

Here a change of 1 unit in the exogenous variable $Z(t)$ that occurred at $t=1$ is associated with a change of 1.10 units in $Y(t)$-an impact multiplier of 1.10. At the new equilibrium level, the corresponding change is 2 units; that is, a stationary multiplier of 2.00 . The value of the truncated multiplier (dynamic multiplier) depends on $t$; thus, at $t=2$ it equals 1.7 and at $t=3$ it equals 1.9 .

Empirical Results. To derive the impact multiplier, we first write our system implicitly as follows:

$$
F[Y(t), Y(t-1), \tilde{Z}(t)]=0
$$

where $F$ is a vector valued function.

$Y(t)$ and $Y(t-1)$ are defined as before as vector functions of $t$, and $\tilde{Z}(t)$ is the vector function of all exogenous variables, including those which enter the relation in a nonlinear form (population size, yields, index of prices received by farmers, etc.).

Differentiating equation (54) with respect to $t$, we get:

$$
\frac{d F}{d t}=\frac{\partial F}{\partial Y(t)} \dot{Y}(t)+\frac{\partial F}{\partial Y(t-1)} \dot{Y}(t-1)+\frac{\partial F}{\partial \widetilde{Z}(t)} \dot{Z}(t)=0
$$

where

$$
\begin{gathered}
\frac{\partial F}{\partial Y(t)} \text { is a } G \times G \text { matrix of partial derivatives }\left[\frac{\partial F_{i}}{\partial Y_{j}(t)}\right] \\
i, j=1, \cdots, G \\
\frac{\partial F}{\partial Y(t-1)} \text { is a } G \times G \text { matrix of partial derivatives }\left[\frac{\partial F_{i}}{\partial Y_{j}(t-1)}\right] \\
\frac{\partial F}{\partial \widetilde{Z}(t)} \text { is a } G \times K \text { matrix of partial derivatives }\left[\frac{\partial F_{i}}{\partial \widetilde{Z}_{k}(t)}\right] \\
k=1,2, \cdots, K
\end{gathered}
$$

$\dot{Y}(t), \dot{Y}(t-1)$, and $\dot{Z}(t)$ are vectors of derivatives of $Y(t), Y(t-1)$, and $\tilde{Z}(t)$ with respect to time.

${ }^{69}$ P. A. Samuelson, "A Fundamental Multiplier Identity," Econometrica, 11 (3 and 4): 221-26, 1943. 
Assuming $\partial F / \partial Y(t)$ is nonsingular, premultiplying equation (55) by $[\partial F / \partial Y(t)]^{-1}$ and solving for $\dot{Y}(t)$, we get:

$$
\begin{aligned}
\dot{Y}(t) & =-\left(\frac{\partial F}{\partial Y(t)}\right)^{-1} \frac{\partial F}{\partial Y(t-1)} \dot{Y}(t-1)-\left(\frac{\partial F}{\partial Y(t)}\right)^{-1} \frac{\partial F}{\partial \tilde{Z}(t)} \dot{Z}(t) \\
& =\tilde{\Pi}_{1} \dot{Y}(t-1)+\tilde{\Pi}_{2} \dot{Z}(t)
\end{aligned}
$$

$\tilde{\Pi}_{1}$ and $\tilde{\Pi}_{2}$ are therefore matrices of impact multipliers. ${ }^{70}$ In a purely linear system, these are simply the reduced form matrices. In the present use, $\partial F / \partial Y(t)$ is equal to $\mathrm{B}$, and $\partial F / \partial Y(t-1)$ is equal to $\Gamma_{1}$, but $\partial F / \partial Z(t)$ is not equal to $\Gamma_{2}$, since certain components of $\tilde{Z}(t)$ enter some of the coefficients of $\Gamma_{1}$ and $\Gamma_{2}$ and are not elements of $Z(t)$. To get actual numerical values, it is necessary to evaluate the various partial derivatives at the current values of $Y(t-1)$ and $Z(t)$. Instead of evaluating at current values, the impact multipliers were evaluated at the means of these variables for the years 1948-1958. They should therefore be regarded as valid only for values of exogenous variables in the neighborhood of these means. Actually, this is not a serious drawback in the present case. Most variables have undergone compensatory changes so that the values of the coefficients in $\Gamma_{1}$ and $\Gamma_{2}$ were relatively stable. For instance, population size usually enters in the denominator of a coefficient and yield in the numerator. Since secular changes in both were typically in the same direction, there was a compensatory effect on the coefficients. This, however, is not necessarily always so. Moreover, multipliers are defined as partial derivatives; that is, only ceteris paribus changes in exogenous variables are considered. In this case, compensatory changes are excluded by definition, and the multipliers are stable only for sufficiently small variations in $\tilde{Z}(t)$. In pure linear systems, the multipliers are, of course, constant. The greater the departure from linearity, the greater will be the changes in the multiplier for a given change of the exogenous variable. Hence, if the system is approximately linear, the computed multipliers will tend to be stable. Tables $14 \mathrm{a}$ and $\mathrm{b}$ present the matrices $\tilde{\Pi}_{1}$ and $\tilde{\Pi}_{2}$ of impact multipliers. These tables were derived by evaluating equation (56) at the mean values of $Y(t-1)$ and $\tilde{Z}(t)$ for the period 1948-1958.

Before evaluating equation (56), however, the trend coefficient in the California production response relation was adjusted to approximate more closely the trend relation in 1948-1958. In the original equation, time entered linearly and the trend coefficient was estimated for the period 1930-1958 as a whole. During the earlier part of this period, there was a very rapid increase in the acreage of California early potatoes. Since 1950, however, the rate of increase has diminished considerably. As a result, the average trend coefficient for 1930-1958 overestimates the rate of growth in the last decade. To overcome this shortcoming, a new acreage response equation was estimated for

\footnotetext{
${ }^{70}$ The method employed above to get impact multipliers is due to Goldberger, op. cit.,
} pp. 14-20. 


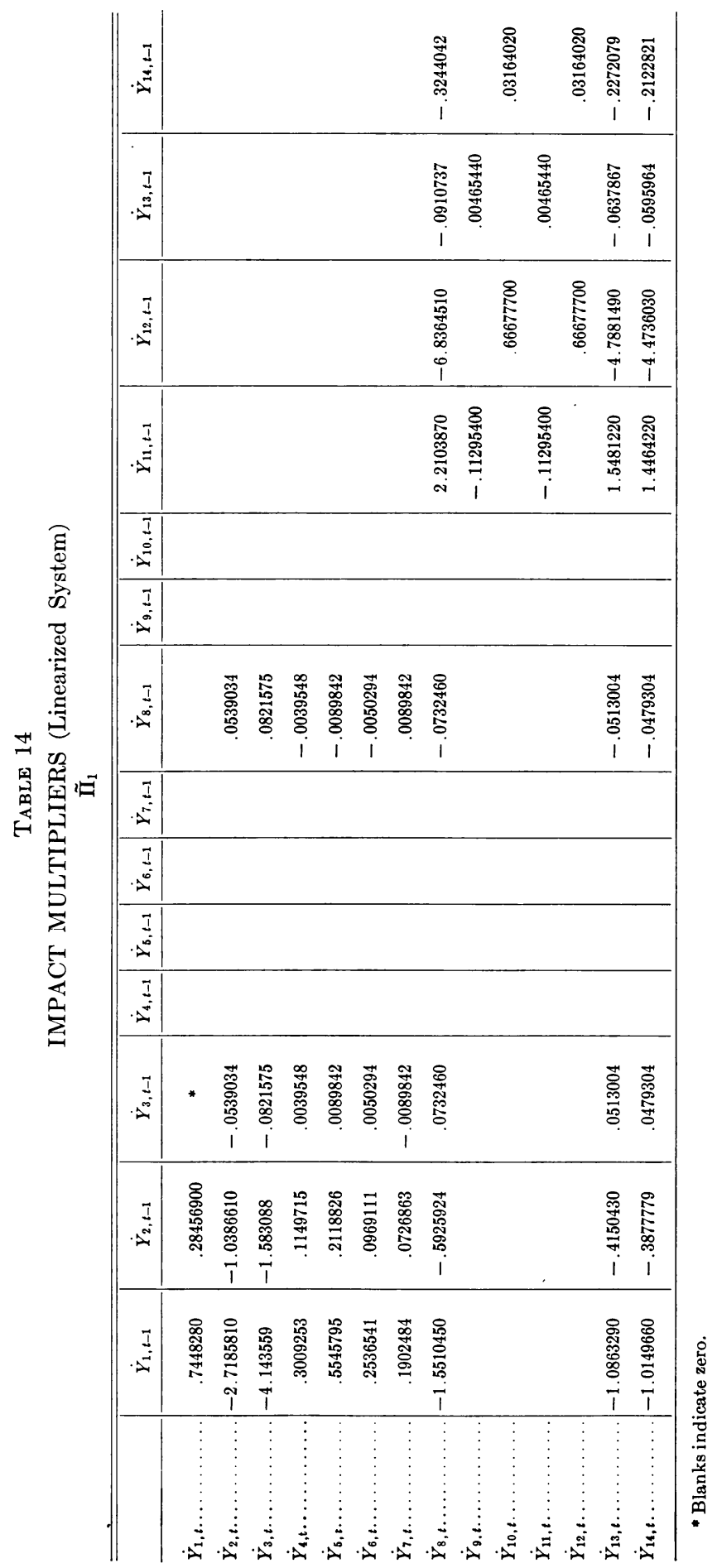




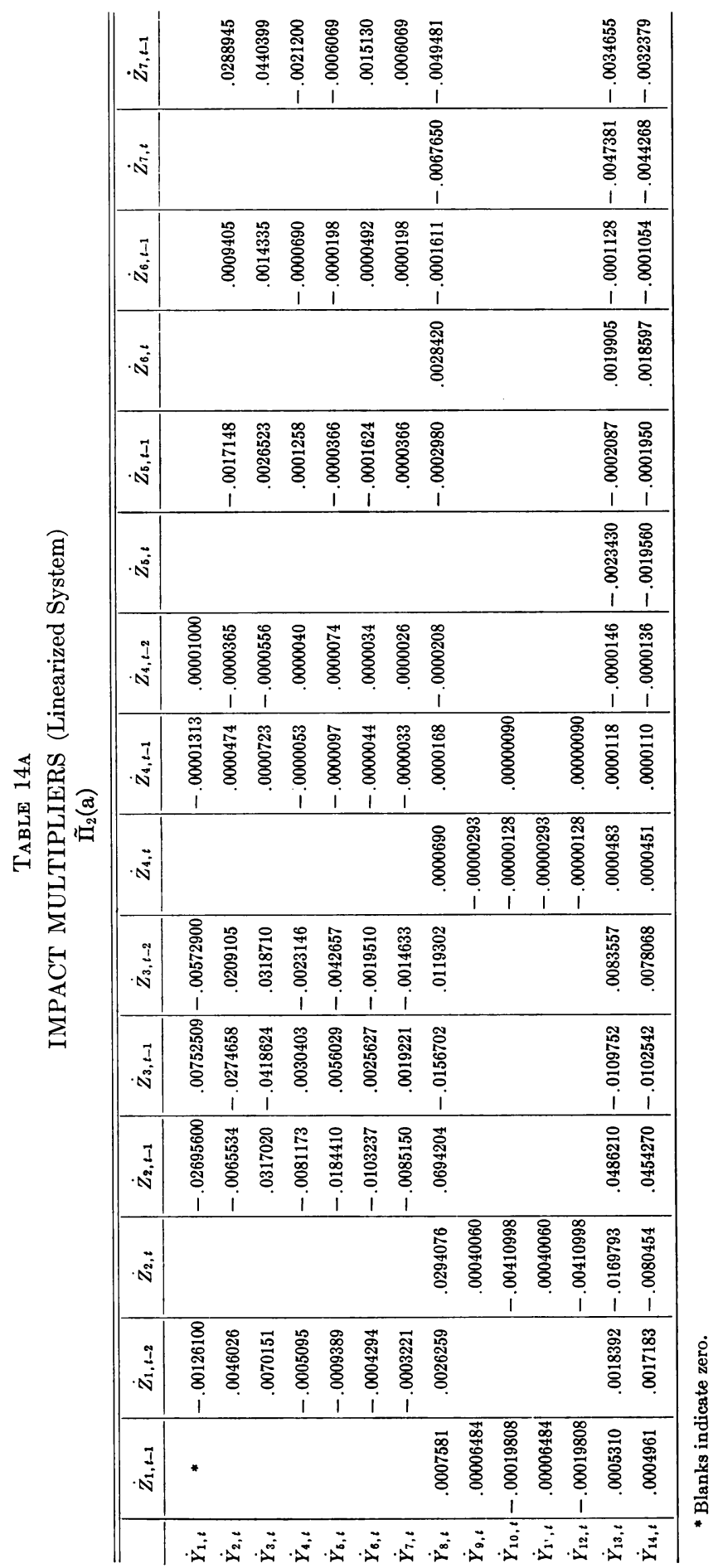




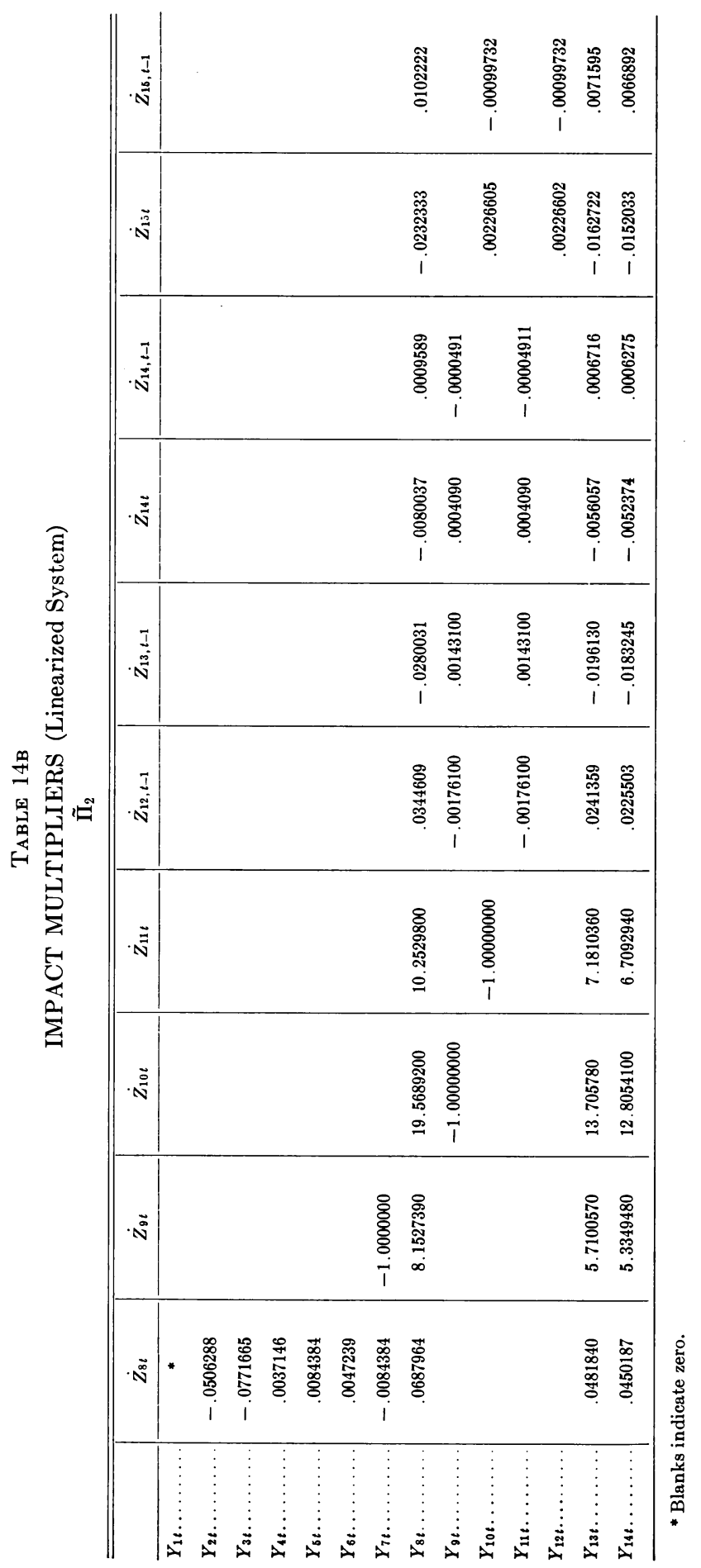


California for the period 1950-1958. In view of the limited number of observations included in the latter period, it seemed preferable not to re-estimate all parameters of the response relation. Instead, only the trend coefficient was estimated on the assumption that all other parameters were equal to their estimated values based on the complete period. The newly estimated equation is:

$$
\begin{aligned}
X_{t}=74.721712+4.065137 P_{t-1}^{p} & -1.537773 P_{t-1}^{c}+1.2500035 P_{t}^{a} \\
& -.11489547 X_{t-1}+.1470088 t
\end{aligned}
$$

For definition of variables, see page 591.

Referring now to table 14, it is seen that a bushel increase in production per capita of late crop in the preceding year, $Y_{1}(t-1)$-which is a change of about 50 per cent-has associated with it an increase of .745 bushel in late crop per-capita production in the current year. This is the effect of a change in lagged production, given that all other variables were constant. The increase in lagged production of late crop will lead also to a decline in current real prices- $\$ 2.72$ per bushel in farm prices, $Y_{2}(t)$, and $\$ 4.14$ per bushel in the retail price, $Y_{3}(t)$. The decline in price is brought about via the increase in current production. The actual change in a current endogenous variable is a sum of all changes in it, due to changes in the several lagged endogenous and exogenous variables. The total change thus computed, plus a random element, accounts for the actually observed change.

Consider now the various impact multipliers associated with production of the California early crop, $Y_{11}(t)$. From tables 14 and $14 \mathrm{~A}$, B, it is clear that the only effective lagged endogenous variables are production of California's early crop, $Y_{11}(t-1)$, and farm price, $Y_{13}(t-1)$. Thus, a unit increase in the preceding year's per-capita production of California's early potatoes leads to a decrease of .113 units of current per-capita production. ${ }^{71} \mathrm{~A}$ unit increase in the real price received by California potato growers last year generates an increase of .005 in current per-capita production.

With respect to exogenous variables, we find that the passage of one year leads to an increase of .0004 bushel in production per capita. An increase of 1,000 persons in total population reduces current per-capita production of California early potatoes by .00000293 bushel, since total production is not affected by this change, whereas the denominator of per-capita production is increased.

An increase of 1 unit in the real index of prices received by farmers for all farm products in the preceding year will bring about an increase of .00006484 bushel in per-capita production of California early potatoes. This reflects the effect of a change in the index of prices received on the relative profitability of potatoes, cotton, alfalfa, and other crops.

${ }^{71}$ The change in preceding year per-capita production of California early potatoes may have no effect on current production. See page 600 . 
As to competing crops, an increase of 1 unit in real prices received by California farmers for cotton and for alfalfa leads to a decline of .0018 bushel and a rise of .0014 bushel in per-capita production, respectively.

A change in any exogenous variable and most of the endogenous variables will affect real prices received by farmers for early potatoes in California and other early states. Thus, for instance, a unit increase in lagged production of the preceding year's late crop will operate to increase current production of this crop and, consequently, the quantity carried over to the spring. It will therefore have a depressing effect on current retail and farm prices of early potatoes. The impact multiplier provides a measure of this effect. In this instance, the decline in California farm price will amount to $\$ 1.09$.

In a similar fashion, a unit increase in lagged per-capita production of early potatoes in other states will lead to a decline of $\$ 4.79$ per bushel in the real price received by California growers. Needless to say, such large changes in production alone are not realistic, but the multipliers still provide valid measures of the relative marginal changes. Other coefficients in tables 14 and $14 \mathrm{~A}, \mathrm{~B}$, may be interpreted in a similar fashion.

It is worth noting that the set of equations (56) is, in fact, a set of linear difference equations in $\dot{Y}(t)$ where all exogenous variables in the system enter linearly. ${ }^{72}$ If $Y(t)$ is defined only for integral values of $t$, it is possible to set

$$
\begin{aligned}
& \dot{Y}(t)=\Delta Y(t)=Y(t+1)-Y(t) \\
& \dot{Z}(t)=\Delta \widetilde{Z}(t)=\widetilde{Z}(t+1)-\widetilde{Z}(t)
\end{aligned}
$$

and equation (56) still holds for sufficiently small $\Delta \tilde{Z}(t)$. If it is assumed that the system is approximately linear and if only those movements are considered where $\tilde{Z}(t)$ is either constant or varies in a compensatory way, thai is, coefficients in $\tilde{\Pi}_{1}$ and $\tilde{\Pi}_{2}$ remain constant, the resulting linearized system is useful for many purposes.

\section{Stability of the Market for California Early Potatoes}

The Concept of Stability. In analyzing the stability properties of the market for California early potatoes, the concept of stability will be treated along the lines developed by P. A. Samuelson. ${ }^{73}$ Thus, a system is said to possess stability of the first kind if every motion of the system approaches in the limit the position of equilibrium. ${ }^{74}$ In contrast to stability of the first kind, stability

${ }^{72}$ If equation (54) is expanded in a Taylor expansion about the mean values of $Y(t)$, $Y(t-1)$, and $\tilde{Z}(t)$ and only linear terms of the expansion are considered, then, except for a vector of constants, a system is obtained that is the same as equation (56) but with $\dot{Y}(t), \dot{Y}(t-1)$, and $\tilde{Z}(t)$ substituted for $Y(t), Y(t-1)$, and $\tilde{Z}(t)$, respectively.

${ }_{73}$ Samuelson, Foundations of Economic Analysis, Harvard Univer sity Press, 1947.

${ }^{74}$ The position of equilibrium need not be stationary. A system will still be stable if all motions converge to each other so that the limiting motion can be regarded as a "moving equilibrium." A motion $Y(t)$ is said to converge to another motion $Y^{*}(t)$ if for any given positive $\epsilon$, however small, there exist some $t^{0}$ such that:

$$
\left|Y(t)-Y^{*}(t)\right|<\epsilon \quad \text { for } \quad t>t^{0}
$$


of the second kind exists if every motion of the system is bounded about the equilibrium position but does not converge to it. A system possesses stability of the first kind in the small if in a sufficiently small neighborhood of a given motion all motions are stable. The system will be perfectly stable if in the entire region over which the system is defined all motions are stable. It can be shown that in linear systems, stability in the small implies perfect stability. Hence, this distinction is of no interest in our case so long as the linearity assumption is maintained. As indicated on page 607, the motion of the system is given by equation (47):

$$
Y(t)=Y^{*}(t)+y(t)
$$

where $Y^{*}(t)$ is a particular solution to equation (45) and $y(t)$ is a general solution to the homogeneous set, equation (46). The particular solution $Y^{*}(t)$ is uniquely determined by $Z(t)$, whereas $y(t)$ represents a family of motions. The members of this family depend on the initial conditions, $Y(o)$. From the above argument, it follows that $Y(t)$ possesses perfect stability of the first kind if all $y(t)$ converge in the limit to the same constant value $y^{o}$; that is:

$$
\operatorname{Lim}_{t \rightarrow \infty} y(t)=y^{o}
$$

In particular, if $y^{o}=0$, all motions $Y(t)$ will converge in the limit to $Y^{*}(t)$; that is:

$$
\operatorname{Lim}_{t \rightarrow \infty} Y(t)=Y_{(t)}^{*}
$$

To derive the conditions under which equation (58) holds, it is necessary to examine the properties of the general solution to equation (46). It was mentioned on pages 606 and 608 that the general solution to equation (46) takes the form of equation (53):

$$
y_{g}(t)=\sum_{j=1}^{m} A_{g j} r_{j}^{t}\left(\theta_{j} t-\epsilon_{j}\right)+\sum_{i=2 m+1}^{k} A_{g} \lambda_{i}^{t} \quad g=1,2, \cdots, G .
$$

It is therefore clear that if $\left|r_{j}\right|<1$ for $j=1, \cdots, m$ and $\left|\lambda_{i}\right|<1$ for $i=$ $2 m+1, \cdots, k$; that is, if all $\lambda_{i}(i=1,2, \cdots, k)$ are elements of the open unit circle, then equations (58) and (59) hold. It follows that if the maximum modulus of $\lambda_{i}(i=1, \cdots, k)$ is smaller than unity, the system, equation (45), is perfectly stable. We notice also that if the maximum modulus is exactly equal to unity and all roots are distinct, the system possesses stability of the second kind..$^{75}$

The actual path of convergence will depend on the latent roots $\lambda_{i}$ and on the initial conditions $Y(o)$. The latter will determine $A_{g j}, A_{g i}$, and $\epsilon_{j}$. In general, if $\lambda_{i}$ is real and positive, it will contribute a monotone convergent

\footnotetext{
${ }^{75}$ In the case of multiple roots, the system will still be stable if the maximum modulus is less than unity but will explode if the maximum modulus is exactly equal to unity. This is because the solutions will involve terms of the form $\lambda_{i}{ }^{t}, t \lambda_{i}{ }^{t}, t^{2} \lambda_{i}{ }^{t}, \ldots t^{m i-1} \lambda_{i}{ }^{t}$, where $m_{i}$ is the multiplicity of $\lambda_{i}$. All such terms vanish in the limit if $\lambda_{i}$ is an element of the open unit circle but grow indefinitely if it is on the circumference.
} 
term. If it is real and negative, it will contribute an oscillatory and convergent term. If it is complex, it will contribute a damped cyclical term. The initial "weight" of each such term depends on the initial conditions but will soon become relatively small if the modulus of the corresponding latent root is small.

Empirical Results. In analyzing the stability properties of the estimated model, it was first assumed that the exogenous variables that enter the structural coefficients are constant. This was an unavoidable assumption, since the solution of equation (45) becomes very difficult if the coefficients are functions of time. In fact, the method of solution discussed above would no longer hold. Recognizing that these exogenous variables have changed substantially over the period of analysis, the system was evaluated for the years 1930 , 1942 , and 1958, respectively. For the purpose of comparison, the "linearized" system was included in the analysis.

The latent roots of $\Pi_{1}$ for each year and for the linearized system were then computed by an iterative procedure. ${ }^{76}$ Since only 4 of the 14 relations in the present model include lagged endogenous variables, $\Pi_{1}$ is not of full rank and is, in fact, of rank four, so that $\Pi_{1}$ has four nonzero latent roots. The latent roots of $\Pi_{1}$ for different years were found to be:

$$
\begin{aligned}
& 1930 \\
\lambda_{1}= & -.2034267+.0475017 i \\
\lambda_{2}= & -.2034267-.0475017 i \\
\lambda_{3}= & .5092538 \\
\lambda_{4}= & .1898397 \\
& 1942 \\
\lambda_{1}= & -.1822920 \\
\lambda_{2}= & -.2679994 \\
\lambda_{3}= & .5428181 \\
\lambda_{4}= & .1692138 \\
& 1958 \\
\lambda_{1}= & -.0059150 \\
\lambda_{2}= & -.6594620 \\
\lambda_{3}= & .4679247 \\
\lambda_{4}= & -.3050507
\end{aligned}
$$

\section{Linearized System (Evaluated at the Mean Values for 1948-1958)}

$$
\begin{aligned}
& \lambda_{1}=-.2722733 \\
& \lambda_{2}=-.4352924 \\
& \lambda_{3}=.5079373 \\
& \lambda_{4}=.02847503
\end{aligned}
$$

\footnotetext{
${ }^{76}$ Computations were carried out on the electronic digital computer LGP-30, using the
} "Eigen values-eigenvectors" program by A. Total, American Cyanamid Company. 
The general solutions to the homogeneous set, equation (46), are therefore: 1930

$$
\begin{aligned}
Y g(t)=A g_{1}(.208896)^{t} \cos (.235620 t-\epsilon g) & +A g_{2}(.5092538)^{t} \\
& +A g_{3}(.1898397)^{t} \\
1942 & +A g_{4}(.1692138)^{t} \\
Y g(t)=A g_{1}(-.1822920)^{t}+A g_{2}(-.2679994)^{t} & +A g_{3}(.5428181)^{t} \\
1958 & +A g_{3}(.4679247)^{t} \\
Y g(t)=A g_{1}(-.0059160)^{t}+A g_{2}(-.6594620)^{t} & +A g_{4}(-.3050507)^{t}
\end{aligned}
$$

\section{Linearized System}

$$
\begin{aligned}
Y g(t)=A g_{1}(-.2722733)^{t}+A g_{2}(-.4352924)^{t} & +A g_{3}(.5079373)^{t} \\
& +(.02847503)^{t}
\end{aligned}
$$

It is evident from the general solutions, equations (60) through (63), that in years 1930, 1942, and 1958 the potato industry possessed stability of the first kind. Another interesting feature characterizing the period 1930-1940 and probably until the early 1950's (as is suggested by the linearized system) is the dominance of the monotone terms; that is, the dominant real root is positive in these years. The exact motion of the system depends, of course, on the initial conditions, but, on the whole, convergence will tend to be monotonous. This is in obvious contrast to opinions that sometimes have appeared attributing to the potato industry a typical cobweb behavior. ${ }^{77}$

The monotonous convergence of the system is not unexpected. It is a direct outcome of the way potato growers respond to price. As was indicated on page 590, growers' response may be approached in two ways; namely, via the adjustment process or via the price expectation model. M. Nerlove has shown that the expectation model assumed in his analysis of supply ${ }^{78}$ leads to an extension of the region in parameters space that is compatible with stability. Nerlove's analysis deals with a single commodity market where the supply and demand relations are linear functions in quantity and price. Fol-

77 Thus, for instance, M. Ezekiel cites the actual performance of the potato market in the United States as an illustration of a typical cobweb behavior. Cf. M. Ezekiel, "The Cobweb Theorem," Quarterly Journal of Economics, 52 (2): 255-80, 1938. Gray, Sorenson, and Cochrane, in their analysis of the potato industry and the government programs, develop a rather detailed analysis of the policy implications of this cobweb behavior. Cf. Gray, Sorenson, and Cochrane, op. cit., pp. 172-84.

${ }^{78}$ Nerlove, op. cit., chap. 2. 
lowing his method, it will now be shown that under the type of expectation function considered, there is also a substantial extension of the region in the parameters space that corresponds to monotone convergence.

Consider the system:

Demand relation: $q_{t}^{D}=c+d P_{t}$

Supply relation: $q_{t}{ }^{s}=a+b P_{t}{ }^{*}$

where

$$
\begin{aligned}
& q_{t}^{D}=\text { quantity demanded at } t \\
& q_{t^{s}}=\text { quantity supplied at } t \\
& P_{t}=\text { actual price at } t \\
& P_{t^{*}}=\text { price expected to prevail at } t .
\end{aligned}
$$

Assume, further, the following expectation model:

$$
P_{t}^{*}=P_{t-1}^{*}+\beta\left[P_{t-1}-P_{t-1}^{*}\right]
$$

where $\beta$ equals the coefficient of expectation.

Recalling that ex post $q_{t}{ }^{D}=q_{t}^{s}$ and combining equations (64) and (65), we get the following difference equation in the actual prices.

$$
P_{t}=\frac{\beta(a-c)}{d}+\left[\beta \frac{b}{d}+(1-\beta)\right] P_{t-1}
$$

From earlier discussion, it is clear that the solution to the homogeneous part of equation (66) is:

$$
P_{t}=\left[\beta \frac{b}{d}+(1-\beta)\right]^{t} P_{o}
$$

so that $P_{t}$ is stable if and only if:

$$
-1<\beta \frac{b}{d}+(1-\beta)<1
$$

and will converge monotonously if and only if:

$$
o<\beta \frac{b}{d}+(1-\beta)<1
$$

that is, if and only if:

$$
1-\frac{1}{\beta}<\frac{b}{d}<1
$$


If it is assumed that farmers expect this year's price to prevail in the following year, that is, $\beta=1$, the system will converge monotonously if and only if:

$$
o<\frac{b}{d}<1
$$

If, however, we allow $o<\beta \leqq 1$, and define $R(\beta)$ to be the range, as a function of $\beta$, over which $b / d$ corresponds to monotone convergence, then:

$$
R(1)=\min _{o<\beta \leqq 1} R(\beta)
$$

and, of course, no negative values of $b / d$ are contained in $R(1)$.

The above analysis is developed in terms of a single market. The case of a multiple market is much more complicated and will therefore not be analyzed. It is not impossible, however, that such an analysis will yield similar conclusions.

A further investigation of equations (60) through (63) indicates that the importance of the oscillatory component (negative latent roots of $\Pi_{1}$ ) has gradually increased during the period of analysis until it became the dominant component in 1958. This suggests that the potato market has become a typical cobweb system. The shift to this type of behavior apparently took place in the mid-1950's, although the exact year cannot be determined without more complete results. Intuitively, the hypothesis that the increasing role of the oscillatory component is due to increasing yields seems plausible. Since the production response is in terms of acreage, rising yields lead to increasing price elasticities of production response. It can be easily demonstrated graphically that in a single market such a change leads to increasing oscillations. In 1930, a cyclical component was involved in the time path of the system. This term was heavily damped and had a period of 26.7 years. The short-run fluctuation in quantities and prices cannot, therefore, be attributed to the cyclical component.

The Role of Random Shocks. The foregoing analysis of the stability properties of the potato market was completely deterministic and led to the conclusion that the system is stable. Thus, the underlying systematic mechanism alone fails to explain the strong short-run fluctuations of prices and quantities typical of the potato industry. It is of some interest, therefore, to consider the role of exogenous factors in generating these fluctuations. In this respect, a distinction should be made between two types of exogenous changes: (1) changes in the exogenous variables and (2) random shocks, denoted originally by $U(t)$. The first group of changes may involve systematic changes (trends) of the exogenous variables but will typically involve erratic changes also. The shocks included in the latter group are due to variations in relevant variables that were not included explicitly in the analysis or to random shifts in the decision functions of the individual economic units. They are thus generated partly by internal factors. 
Consider first the role of the random shocks $U(t)$. Once random shocks are introduced into the system, all endogenous variables become jointly distributed random variables, and the deterministic economic process becomes a stochastic process. Two questions arise as a result of the introduction of random disturbances: (1) what is the relationship between the variancecovariance matrix $\boldsymbol{\Sigma} y(t)$ of the endogenous variables $Y(t)$ and the variancecovariance matrix $\mathbf{\Sigma} u$ of the random disturbances, and (2) how is the time path of the system affected by the random shocks?

Having introduced the random disturbances, the reduced form, equation (45), becomes:

$$
Y(t)=\Pi_{1} Y(t-1)+\Pi_{2} Z(t)+V(t)
$$

where

$$
\begin{aligned}
V(t) & =B^{-1} U(t) \\
E\left\{V(t) V^{\prime}(t-\tau)\right\} & =\left\{\begin{array}{c}
o \text { for } \tau \neq 0 \\
\boldsymbol{\Sigma}_{v} \text { for } \tau=0
\end{array}\right\} \\
E\{V(t)\} & =0
\end{aligned}
$$

Assume the exogenous variables to be constant; that is,

$$
Z(t) \equiv Z^{*}
$$

Then it can be verified by substitution that:

$$
Y(t)=\left(I-\Pi_{1}\right)^{-1} \Pi_{2} Z^{*}+\Pi_{1}^{t} y(o)+\sum_{i=0}^{t-1} \Pi_{1}^{i} V(t-i)
$$

where

$$
y(o)=Y(o)-\left(I-\Pi_{1}\right)^{-1} \Pi_{2} Z^{*}
$$

is a solution to equation (73).

Hence, the variance-covariance matrix of the endogenous variables is:

$$
\mathbf{\Sigma}_{Y(t) \mid Y(o)}=\sum_{i=0}^{t-1} \Pi_{1}^{i} \boldsymbol{\Sigma}_{v} \Pi_{1}^{i^{\prime}}
$$

Assume now that $\Pi_{1}$ is a nondefective matrix. ${ }^{79}$ Then by the spectral decomposition theorem: ${ }^{80}$

$$
\Pi_{1}=\sum_{j=1}^{G} \lambda_{j} Q_{j}
$$

${ }^{79}$ In the present study, $\Pi_{1}$ is nondefective, since it was similar to a diagonal matrix over the entire period of analysis.

${ }^{80}$ Cf. D. C. Murdock, Linear Algebra for Undergraduates (New York: John Wiley and Sons, 1957), pp. 180-81. 
where

$$
\begin{aligned}
\lambda_{j} & =j \text {-th latent root of } \Pi_{1} \\
Q_{j} & =G \times G \text { matrix such that } Q_{j}{ }^{2}=Q_{j} ; \\
Q_{j} Q_{j^{\prime}} & =0 \quad \text { for } \quad j \neq j^{\prime} \quad \text { and } \quad \sum_{j=1}^{G} Q_{j}=I
\end{aligned}
$$

so that

$$
\Pi_{1}^{i}=\sum_{j} \lambda_{j}^{i} Q_{j}
$$

Substituting equation (77) into equation (75), we get:

$$
\begin{aligned}
\boldsymbol{\Sigma}_{Y(t) \mid Y(o)} & =\sum_{i=0}^{t-1}\left(\sum_{j=1}^{G} \lambda_{j}^{i} Q_{j}\right) \boldsymbol{\Sigma}_{v}\left(\sum_{j^{\prime}=1}^{G} \lambda_{j^{\prime}}^{i} Q_{j^{\prime}}^{1}\right) \\
& =\sum_{j=1}^{G} \sum_{j^{\prime}=1}^{G} \sum_{i=0}^{t-1}\left(\lambda_{i} \lambda_{j^{\prime}}\right)^{i} Q_{j} \boldsymbol{\Sigma}_{v} Q_{j^{\prime}}^{1}
\end{aligned}
$$

As $t$ tends to infinity, $\Sigma_{Y(t) \mid Y(o)}$ will converge to a finite matrix if and only if the largest modulus of $\lambda_{j}$ is less than unity. In this case, we get:

$$
\operatorname{Lim}_{t \rightarrow \infty} \boldsymbol{\Sigma}_{Y(t) \mid Y(o)}=\sum_{j=1}^{G} \sum_{j^{\prime}=1}^{G} \frac{1}{1-\overline{\lambda_{j} \lambda_{j^{\prime}}}} Q_{j} \boldsymbol{\Sigma}_{v} Q_{j^{\prime}}^{1}
$$

Hence, the limiting variance-covariance matrix exists if and only if the system possesses stability of the first kind. ${ }^{81}$

The effect of random shocks on the evolution of economic systems was analyzed in some detail by R. Frisch in $1933 .{ }^{82}$ Frisch based his analysis on earlier studies by E. Slutzky ${ }^{83}$ and G. U. Yule. ${ }^{84}$ He pointed out that even though a system may be stable, erratic shocks will generate periodic motions similar to those performed by the deterministic system when starting from nonequilibrium initial conditions. I. Adelman and F. L. Adelman ${ }^{85}$ have demonstrated this by simulating behavior of the United States economy using the Klein-Goldberger model. ${ }^{86}$

${ }^{81}$ Essentially, the above argument is contained in H. Wold, A Study in the Analysis of Stationary Time Series (2d ed.; Stockholm: Almqvist and Wiksell, 1954), theorem 9, p. 99. Although theorem 9 applies to an $n$-order linear difference stochastic equation, it might have been used to prove the above argument by a proper translation of the system.

${ }^{82}$ R. Frisch, "Propagation Problems and Impulse Problems in Dynamic Economics," Economic Essays in Honour of G. Cassel (London: George Allen \& Unwin, Ltd., 1933), pp. 171-205.

${ }^{83}$ E. Slutzky, "The Summation of Random Causes as the Source of Cyclic Processes," Econometrica, 5 (2): 105-46, 1937.

${ }^{84}$ G. U. Yule, On a Method of Investigating Periodicity in Disturbed Series ("Philosophical Transaction Series A," Vol. 226; London: Royal Society, 1927).

${ }^{85}$ I. Adelman and F. L. Adelman, "The Dynamic Properties of the Klein-Goldberger Model," Econometrica, 27 (4): 596-625, 1959.

${ }^{86}$ Klein and Goldberger, op. cit. 


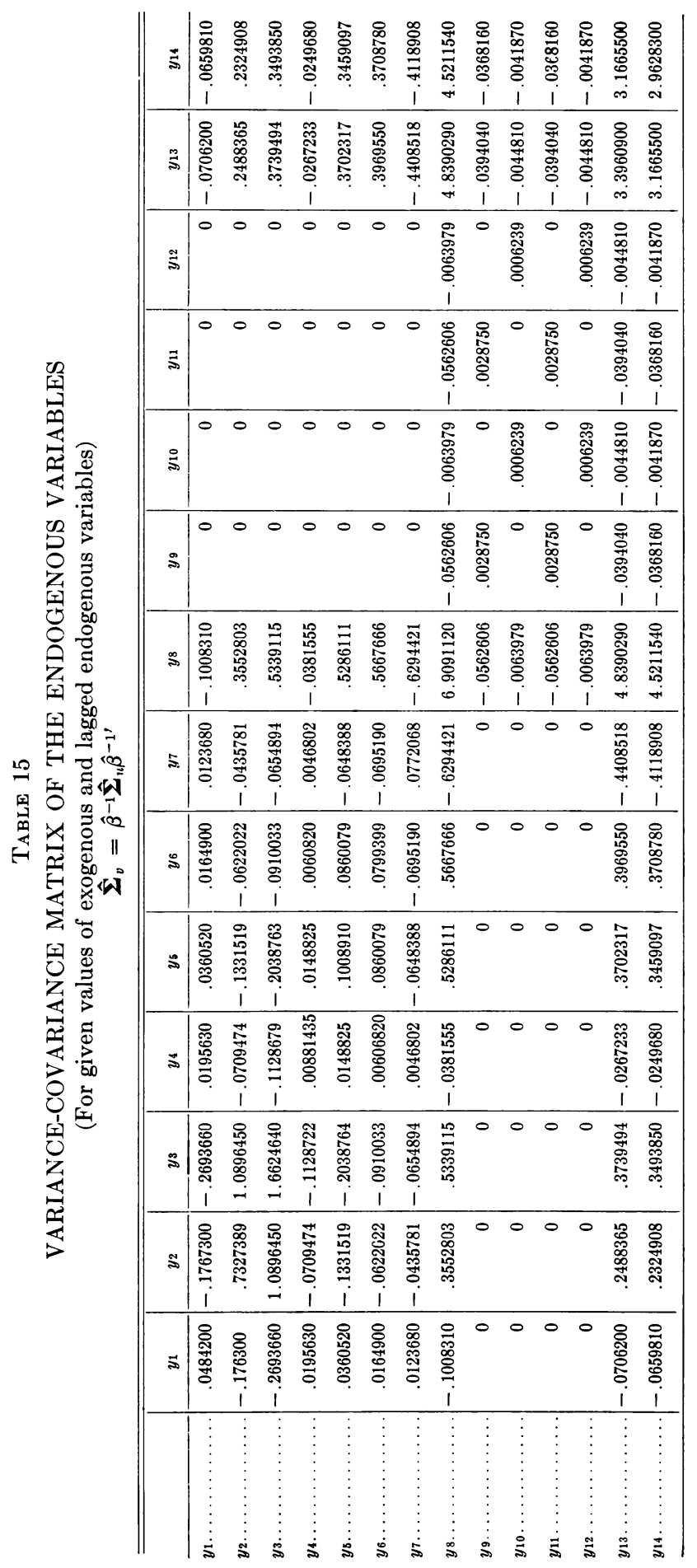


For the present model, consider the deviations $y(t)$ of the endogenous variables $y(t)$ from their equilibrium position

$$
y(t)=\Pi_{1}^{t} y(o)+\sum_{i=0}^{t-1} \Pi^{i} V(t-i)
$$

If $y(t)$ is stable, then after a sufficiently long period, $y(t)$ becomes independent of the initial conditions $y(o)$. Accordingly, we may write:

$$
y^{*}(t)=\sum_{i=0}^{t-1} \Pi_{1}^{i} V(t-i)
$$

from which it follows that:

$$
y^{*}(t)=\Pi_{1}^{k} y^{*}(t-k)+\sum_{i=0}^{k-1} \Pi_{1}^{i} V(t-i)
$$

Hence, the conditional expectation and variance-covariance matrix of $y(t)$, given $y^{*}(t-k)$, are, respectively:

$$
\begin{aligned}
& \text { (a) } E\left\{y^{*}(t) \mid y^{*}(t-k)\right\}=\Pi_{1}^{k} y^{*}(t-k) \\
& \text { (b) } \boldsymbol{\Sigma} y^{*}(t) \mid y^{*}(t-k)=\sum_{i=0}^{k-1} \Pi_{1}^{i} \boldsymbol{\Sigma}_{v} \Pi_{1}^{i^{\prime}}
\end{aligned}
$$

This implies that the system $y^{*}(t)$ will tend to follow an evolution similar to that followed by the nonstochastic part of the system. Thus, for the 1930 structure of the system, $y^{*}(t)$ will tend to show a periodic behavior with a period of about 27 years; and for the 1958 structure, an oscillatory behavior. It is also obvious from equation (82) that it will be easier to observe and capture this "hidden periodicity" in actual time series (by a periodogram analysis, say) the smaller the diagonal elements of $\mathbf{\Sigma} y^{*}(t) \mid y^{*}(t-k)$. The greater the variance of $y^{*}(t)$, the more erratic will be the behavior of the endogenous variables about their equilibrium values and the less obvious will be the time path typical of the nonstochastic elements of the system. Since $\mathbf{\Sigma} y^{*}(t) \mid y^{*}(t-k)$ increases with $k$, the systematic evolution will be clearer within shorter time intervals. In table 15 , the estimated variance-covariance matrix $\hat{\boldsymbol{\Sigma}}_{u}$ is presented. Table 15 was derived from $\hat{\boldsymbol{\Sigma}}_{u}$ (table 12), using the relation:

$$
\hat{\boldsymbol{\Sigma}}_{v}=\hat{\mathrm{B}}^{-1} \hat{\boldsymbol{\Sigma}}_{u} \hat{\mathrm{B}}^{-1}
$$

In order to explore the effect of increasing $k$ on the variance of the endogenous variables, the diagonal elements of the first two terms in the sum in equation (75) were computed (using $\tilde{\Pi}_{1}$ of the linearized system). This sum provides a measure of the variance-covariance matrix of $y^{*}(t)$, given $y^{*}(t-2)$.

$$
\boldsymbol{\Sigma}_{y^{*}(t) \mid y(t-2)}=\hat{\boldsymbol{\Sigma}}_{v}+\hat{\Pi}_{1} \boldsymbol{\Sigma}_{v} \hat{\Pi}_{1}^{\prime}
$$




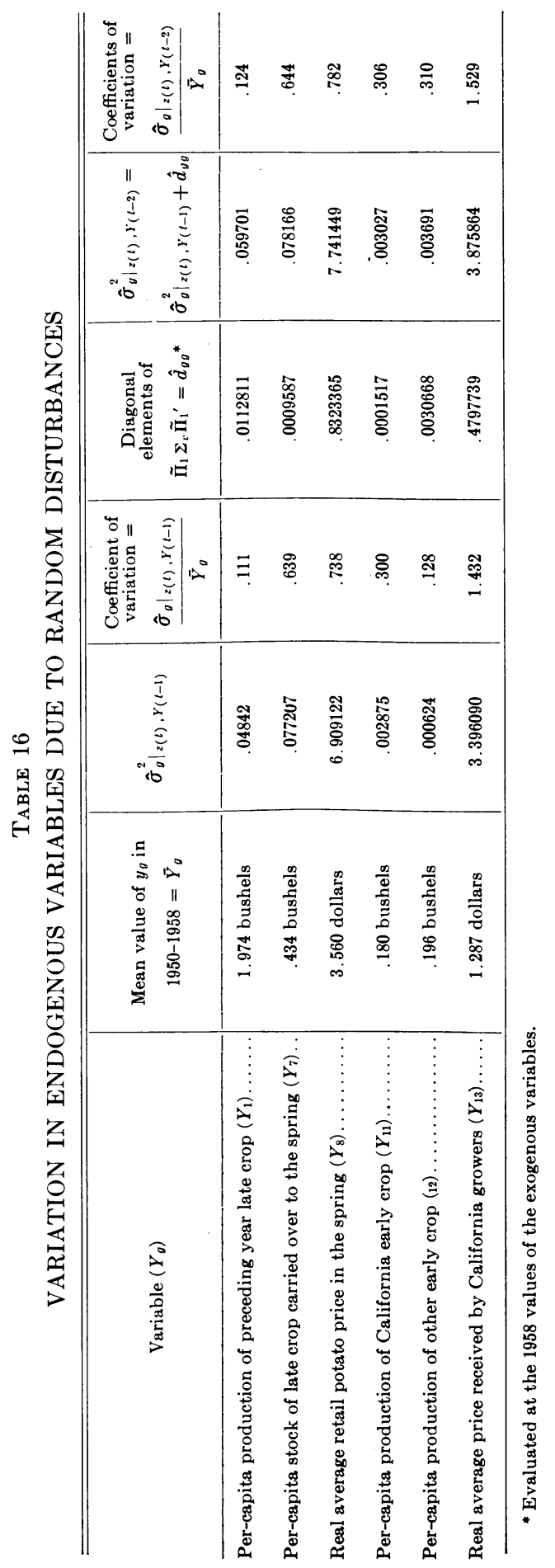


$\boldsymbol{\Sigma}_{y^{*}(t) \mid y(t-2)}$ may also be regarded as a first approximation to the limiting variance-covariance matrix, equation (79), since all other terms of the sum in equation (75) are of order $(.5)^{q}, q>4$. This is due to the fact that in the linearized system the largest modulus of the latent roots of $\tilde{\Pi}_{1}$, is approximately .5. The computed variances as well as the coefficients of variation of certain endogenous variables are presented in table 16 . What conclusions may be drawn from tables 15 and 16? First, note that relative variation in prices due to random shocks is substantial, particularly the variation in prices received by California growers. Evidently the considerable variation in prices received reflects the large variation in retail prices. The variance is greater for retail prices than for farm prices. In other words, the system operates in such a way that variations in retail price are reduced in magnitude when transmitted to the farm level. In relative terms, however, the variation in farm prices is much larger. Variation in quantities of potatoes produced is relatively moderate, provided all exogenous variables, including yields, are held constant. Another important observation pertains to the effect of time on the variability of the endogenous variables. It is evident from table 16 that the accumulative effect of past shocks carried through time by the operation of the system adds relatively little to the variances. Only in the case of other states' early crop production was there a considerable increase in variability, evidently because of its responsiveness to a highly variable price. From earlier arguments, we may expect only minor increases in the variance in subsequent years. Such behavior of the system is consistent with its stabilizing properties.

The Importance of Random Variation in Exogenous Variables. The role of random variation in the exogenous variables is more difficult to evaluate in the framework of the present system, mainly because some of the variables enter nonlinearly into the functional relations. The following attempt to evaluate the importance of these shocks will therefore rest on certain simplifying assumptions. First, it is assumed that the exogenous variables are independently distributed random variables with constant expected values. ${ }^{87}$ Second, it is assumed that the coefficients of the linearized system are constant. ${ }^{88}$ Finally, the random disturbances $U(t)$ are assumed identically equal to zero. Integrating the linearized system, equation (56), we get:

$$
Y(t)=\tilde{\Pi}_{1} Y(t-1)+\tilde{\Pi}_{2} \widetilde{Z}(t)+C
$$

where $C$ represents a vector of coefficients of integration.

By the first assumption above, write:

$$
\tilde{Z}(t)=\eta+W(t)
$$

\footnotetext{
${ }^{87}$ In general, changes in exogenous variables can be thought of as being generated by a different independent system. The first assumption above is with reference to this system.

${ }^{88}$ This assumption is not so bad if the variance of the particular exogenous variable is sufficiently small and if the system is approximately linear.
} 
where

and

$$
E\left\{W(t) W^{\prime}(t-\tau)\right\}=\left\{\begin{array}{l}
0 \text { for } \tau \neq 0 \\
\boldsymbol{\Sigma}_{w} \text { for } \tau=0
\end{array}\right.
$$

$$
E\{W(t)\}=0
$$

Substituting equation (87) into equation (86), there results a system that has the same form as equation (73). Hence, the vector $\tilde{V}(t)=\tilde{\Pi}_{2} W(t)$ serves now as a vector of random disturbances. Its variance-covariance matrix is:

$$
\boldsymbol{\Sigma}_{\tilde{v}}=\tilde{\Pi}_{2} \boldsymbol{\Sigma}_{w} \tilde{\Pi}_{2}^{\prime}
$$

The effect of the random changes $\tilde{V}(t)$ on the behavior of the system is formally the same as in the earlier case, the effects differing in the two cases due only to differences between the respective variance-covariance matrices. By the first assumption above, $\boldsymbol{\Sigma}_{w}$ is a diagonal matrix. In table 17, the diagonal terms of $\boldsymbol{\Sigma}_{w}$ and the associated variances in two endogenous variablesCalifornia production and farm price-are presented. The elements $\hat{\sigma}_{w_{k}}^{2}$ of $\hat{\boldsymbol{\Sigma}}_{w}$ are residual variances from simple regressions of each of the exogenous variables on time, based on the period 1948-1958. (See Appendix B.) Estimates of the variances of California per-capita production and farm price were derived from the formula:

$$
\hat{\sigma}_{\tilde{v}_{o}}^{2}=\sum_{k=1}^{K} \pi_{g_{k}}^{2} \hat{\sigma}_{w_{k}}^{2} \quad \text { for } \quad g=11,13
$$

Comparing corresponding measures in tables 16 and 17, it is apparent that variation in California per-capita production, and in prices received by California growers, due to random variation in exogenous variables ${ }^{89}$ is small compared with variation due to random disturbances $U(t)$. This is particularly evident in the case of prices received by California growers.

The main contribution to variation in production comes from variation in yields. Consequently, variation in prices is to a large extent due to variation in yields. Changes in yields of the preceding year's late crop generate changes in the quantity of late crop carried over to the spring. Changes in yields of California and other states' early crops affect directly the retail price and thus prices received by farmers.

The propagation of erratic changes in the exogenous variables through time follows exactly the same pattern as in the case of random disturbances.

Concluding Remarks. The empirical analysis of stability properties of the potato market presented in this section reveals that the nonstochastic component of the system is stable. Further analysis suggests that marked short-

\footnotetext{
${ }^{89}$ Only erratic variation in exogenous variables is considered at this stage, whereas systematic variation-assumed to be represented by a linear trend during the period 1948-1958-is not taken into account.
} 
TABLE 17

VARIATION IN CALIFORNIA PER-CAPITA PRODUCTION AND PRICES RECEIVED BY GROWERS DUE TO RANDOM VARIATION IN EXOGENOUS VARIABLES

\begin{tabular}{|c|c|c|c|c|c|}
\hline \multirow{2}{*}{$\begin{array}{l}\text { Exogenous variable } \\
Z_{k}(t)\end{array}$} & \multirow{2}{*}{$\begin{array}{c}\begin{array}{c}\text { Variances of } \\
\text { exogenous } \\
\text { variables }\end{array} \\
\hat{\sigma}_{u_{k}}^{2}\end{array}$} & \multicolumn{2}{|c|}{$\begin{array}{c}\text { California per-capita production } \\
Y_{11}(t)\end{array}$} & \multicolumn{2}{|c|}{$\begin{array}{l}\text { Real prices received by } \\
\text { California growers } \\
Y_{13}(t)\end{array}$} \\
\hline & & $\tilde{\pi}_{11, k}^{2}$ & $\tilde{\pi}_{11, k}^{2} \hat{\sigma}_{w_{k}}^{2}$ & $\tilde{\pi}_{18, k}^{2}$ & $\tilde{\pi}_{13, k}^{2} \hat{\sigma}_{w_{k}}^{2}$ \\
\hline 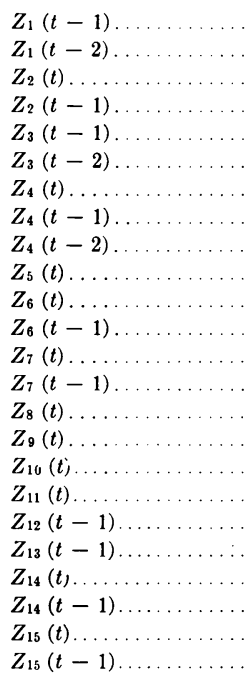 & $\begin{array}{r}119.827624 \\
119.827624 \\
283,039.652474 \\
283,039.652474 \\
283,039.652474 \\
11.243433 \\
865.671136 \\
865.671136 \\
5.056201 \\
5.056201 \\
.033600 \\
.000143 \\
.000027 \\
.006030 \\
12.195106 \\
9.678075 \\
1,136.701906 \\
1,136.701906 \\
44.519379 \\
44.519379\end{array}$ & $\begin{array}{l}.00000310 \\
.00000205 \\
.00000017\end{array}$ & $\begin{array}{l}.000037805 \\
.000020324 \\
.000193239\end{array}$ & $\begin{array}{c}.00012046 \\
.00006981 \\
.000000002 \\
\\
.00000549 \\
.00000396 \\
.00000001 \\
.00002245 \\
.00001201 \\
.00232170 \\
32.60476465 \\
187.84840541 \\
51.56727803 \\
.00058254 \\
.00038467 \\
.00003142 \\
.00000045 \\
.00026478 \\
.00005126\end{array}$ & $\begin{array}{l}.000062 \\
.003428 \\
.000009 \\
.000113 \\
.000061 \\
.000078 \\
.004662 \\
.005071 \\
.001547 \\
.007104 \\
.003723 \\
.035715 \\
.000512 \\
.011788 \\
.002283\end{array}$ \\
\hline $\begin{array}{l}\text { Total variance ...... } \\
\text { Coefficient of varia- } \\
\text { tion } \ldots . . . . . . . .\end{array}$ & & & $\begin{array}{l}.000255306 \\
.089\end{array}$ & & $\begin{array}{l}.099882 \\
.246\end{array}$ \\
\hline
\end{tabular}

* Blank spaces indicate zeros or negligible values.

run fluctuations may be due primarily to random disturbances $U(t)$ and secondarily to random variation in the exogenous variables. One may argue, of course, that variation in random disturbances is indicative of failure to include relevant variables in the analysis or of adopting an inadequate formulation. The relevance of such arguments is acknowledged. There are always, of course, many relevant variables from which the researcher seeks to choose the few most important for his analysis, assuming that the combined effect of all excluded variables can be regarded as a random effect satisfying certain a priori specifications. It is believed that the most important relevant variables were included in the present analysis, but the accumulated effect of excluded variables results in relatively large variance. Inadequate formulation is, of course, always a possibility, since economic theory provides an inadequate basis for specifying precisely the forms of functional relationships. Several alternative formulations were considered in the present study, and 
plausibility of estimated structure as well as manageability in subsequent analysis were major criteria in selection of the final model. Modification in underlying formulation may well alter the results, but it seems. unlikely that a considerable reduction in the effects of random disturbances could be expected. Accepting the present model as a valid representation of the real system, it is clear that any policy designed to stabilize the nonstochastic part of the system will achieve but little in reducing fluctuations of prices and quantities. Policy measures aimed at reducing the variability of random disturbances are conceivable but are much more difficult to implement.

\section{The Stationary State and Long-Run Multipliers}

The Stationary State. In the previous section the stability of the market for California early potatoes was established. This implies that following any disturbance, the system will return to equilibrium. Equilibrium conditions

TABLE 18

STATIONARY VALUES OF SELECTED ENIOGENOUS VARIABLE, SELECTED YEARS 1930-1958*

\begin{tabular}{|c|c|c|c|c|c|c|}
\hline Year & $Y_{1}$ & $Y_{7}$ & $Y_{8}$ & $Y_{11}$ & $Y_{12}$ & $Y_{13}$ \\
\hline 1930. & 2.452 & .441 & 3.069 & .016 & .439 & 1.673 \\
\hline 1934 & 2.359 & .412 & 3.311 & .028 & .345 & 1.667 \\
\hline 1938 & 2.292 & .443 & 3.068 & .068 & .314 & 1.366 \\
\hline $1942 \dagger$ & 2.120 & .420 & 4.240 & .094 & .283 & 2.118 \\
\hline $1946 \ldots \ldots$ & 2.048 & .420 & 4.175 & .130 & .246 & 1.976 \\
\hline $1950 \ldots$ & 2.012 & .453 & 2.856 & .135 & .179 & .848 \\
\hline $1954 \ldots \ldots \ldots \ldots \ldots \ldots \ldots \ldots \ldots$ & 1.931 & .417 & 3.588 & .172 & .180 & 1.255 \\
\hline $1958 \ldots \ldots \ldots \ldots \ldots \ldots \ldots \ldots \ldots$ & 1.830 & .381 & 3.819 & .198 & .166 & 1.264 \\
\hline
\end{tabular}

* Stationary values of endogenous variables were evaluated using actual values of exogenous variables in the corresponding years except for yield variables, in which case, a three-year average was used instead of the single-year value.

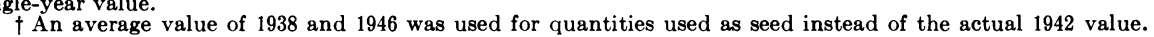

imposed in previous development correspond to those of the stationary state. Stationary values of the endogenous variables corresponding to given and fixed exogenous variables are now derived from pages $606 \mathrm{ff}$.

$$
Y(t)=\Pi_{1} Y(t-1)+\Pi_{2} Z(t)
$$

The stationary state is defined by the constancy of the endogenous variables over time. To derive the stationary values of the endogenous variable, for given exogenous variables $Z^{*}$, impose the constancy conditions $Y(t) \equiv Y^{*}$ and solve equation (90). Provided $\left(I-\Pi_{1}\right)$ is nonsingular, the following solution for $Y^{*}$ is obtained:

$$
Y^{*}=\left(I-\mathrm{II}_{1}\right)^{-1} \Pi_{2} Z^{*}
$$

In table 18, computed stationary values of selected endogenous variables are presented fon every fourth year in the period 1930-1958. These stationary values are computed for fixed values of the exogenous variables actually pre- 


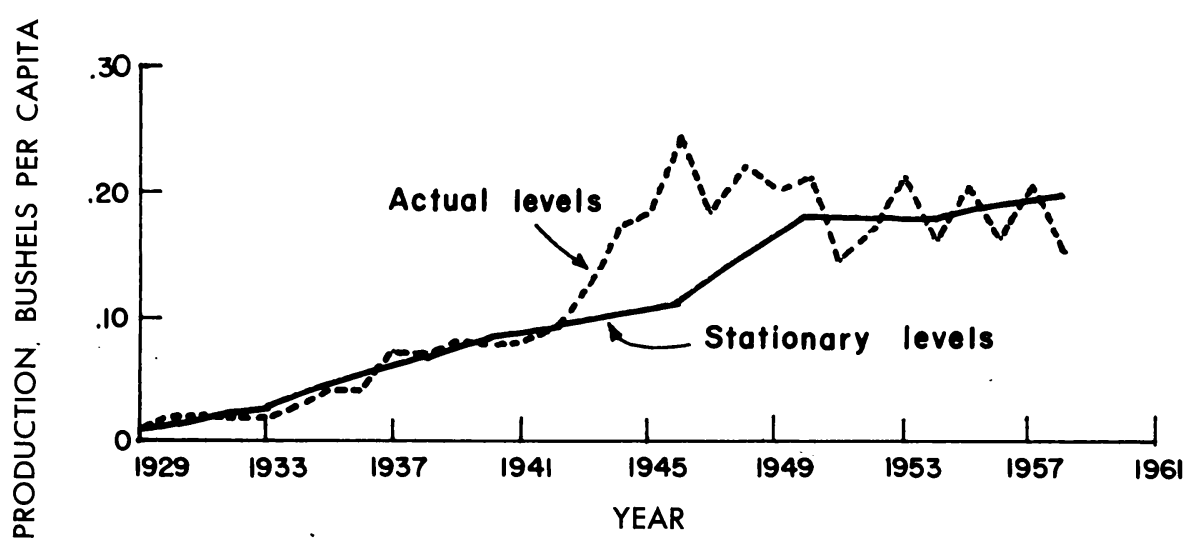

Fig. 16. Actual and stationary levels of selected endogenous variables. Per-capita production-California late spring, 1929-1958.

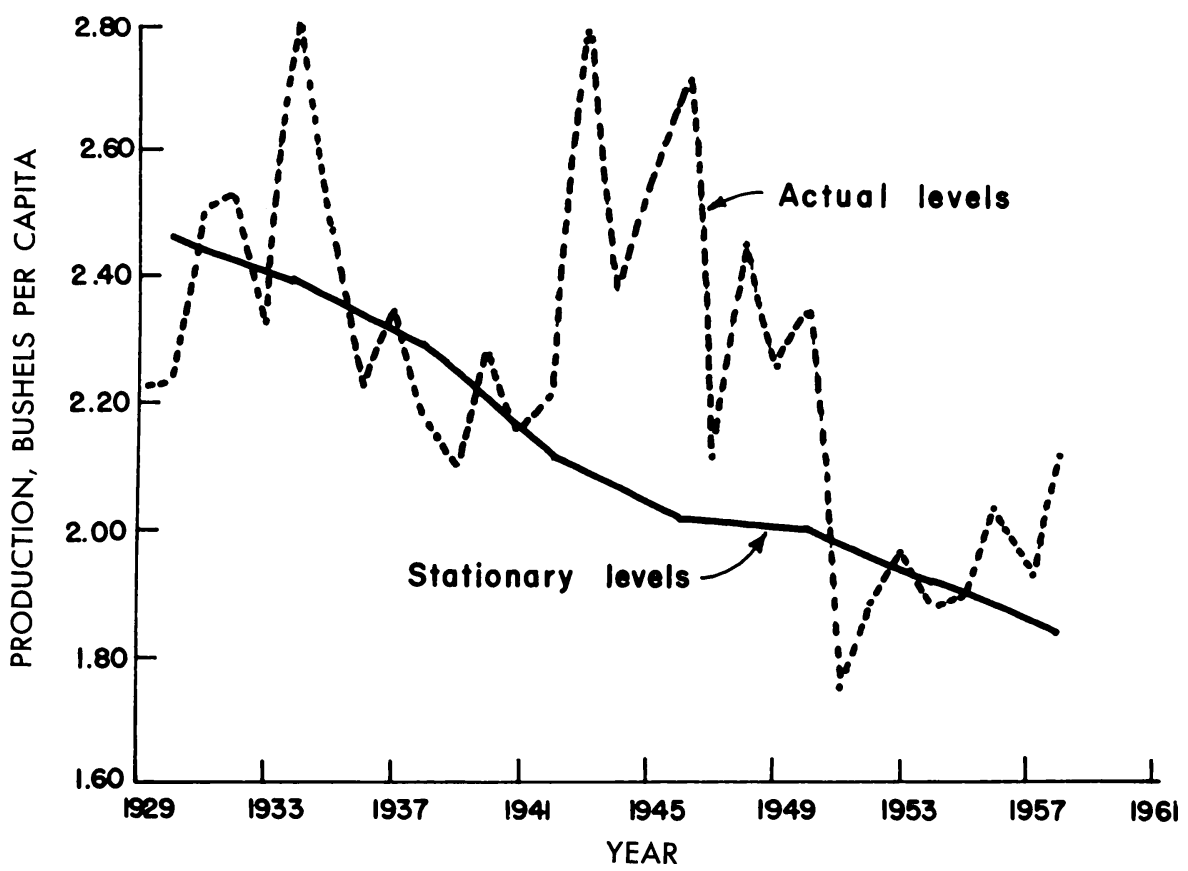

Fig. 17. Actual and stationary levels of selected endogenous variables. Per-capita production-late potatoes, 1929-1958. 


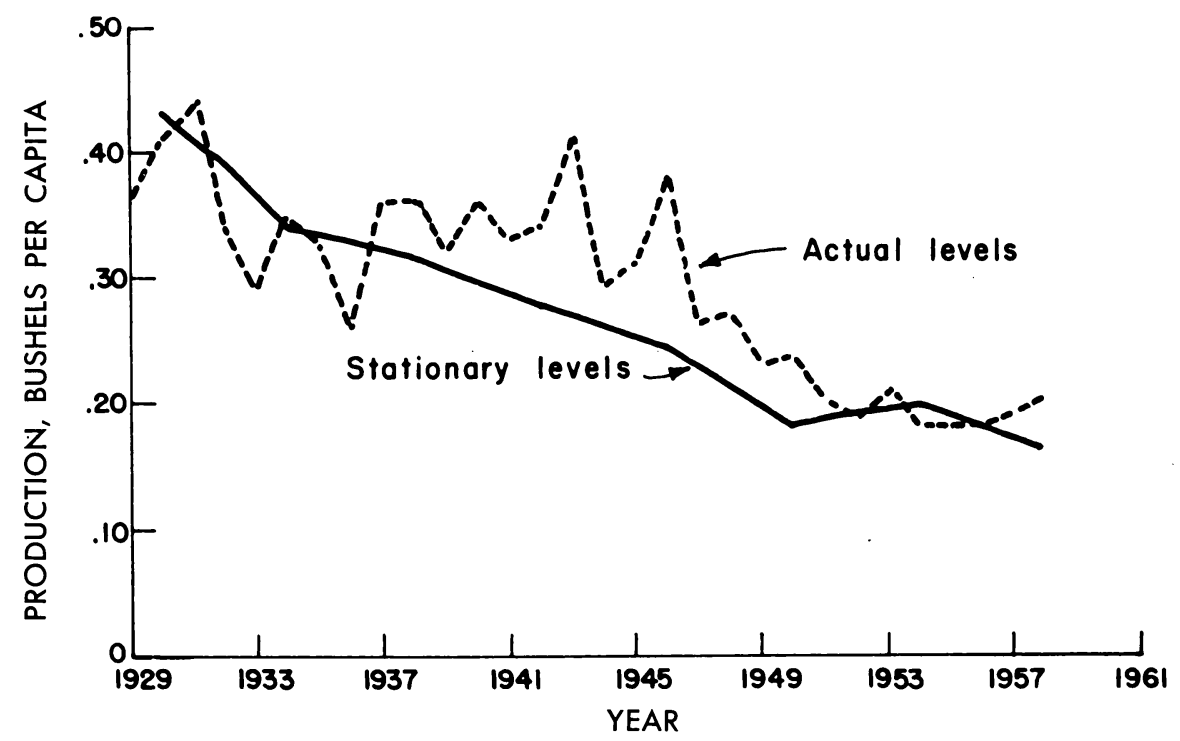

Fig. 18. Actual and stationary levels of selected endogenous variables. Per-capita production--early crop other than California, 1929-1958.

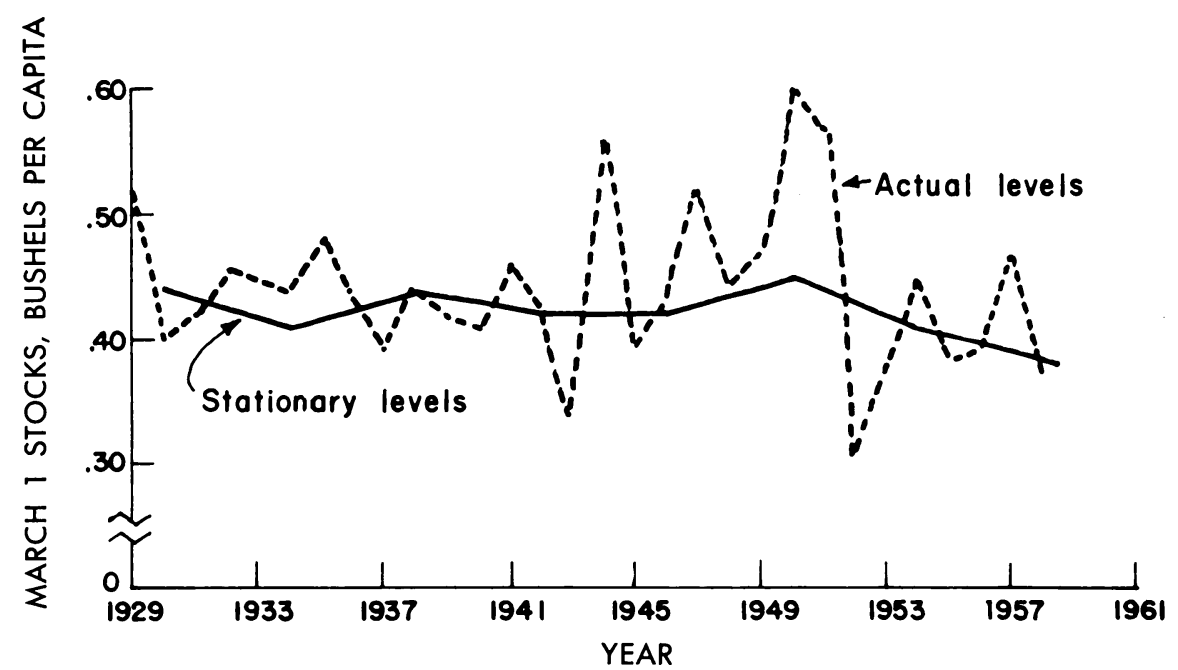

Fig. 19. Actual and stationary levels of selected endogenous variables. Late potatoes carried over to the spring (March 1 stocks), 1929-1958. 
-...- Actual levels

Stationary levels

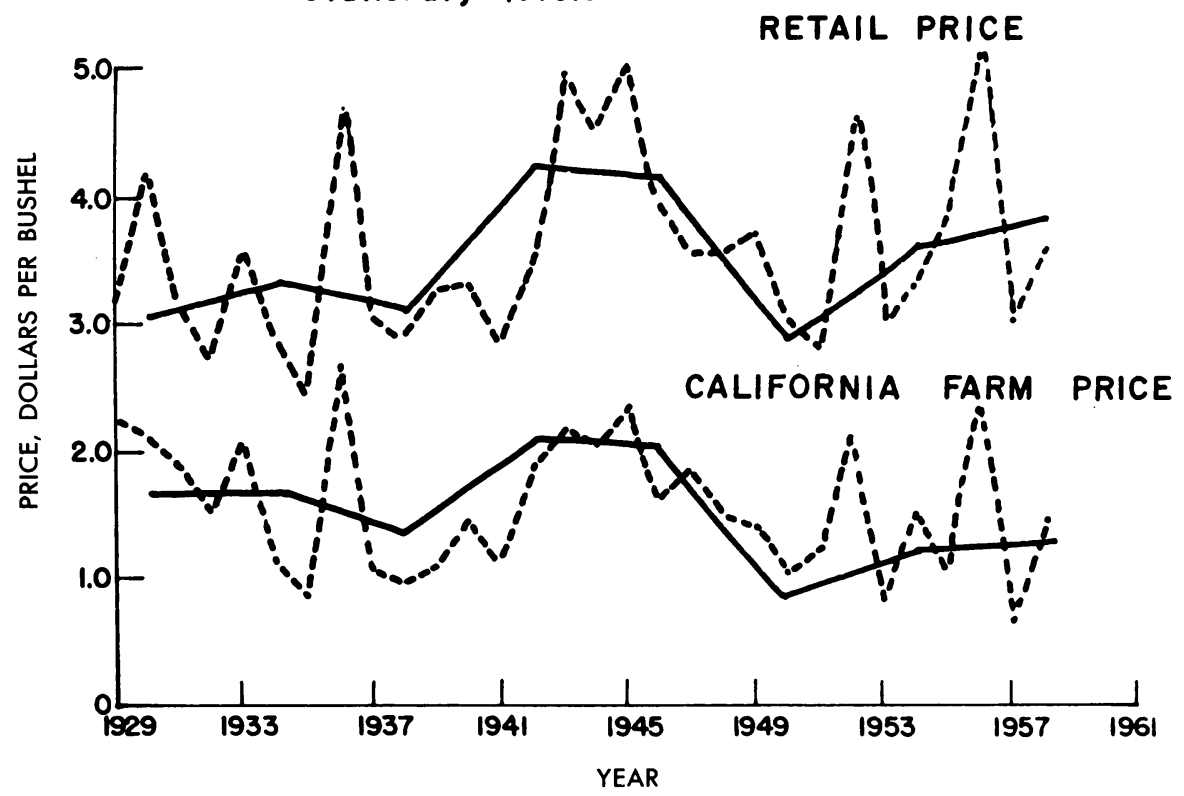

Fig. 20. Actual and stationary levels of selected endogenous variables. Real potato prices, 1929-1958.

vailing in corresponding years. They thus correspond to the values that each endogenous variable would have assumed in the limit had all historical changes been suspended.

In figures 16 through 20 , these values are plotted and compared to the actual values assumed by corresponding endogenous variables. It is obvious from these figures that in all years except 1942-1950, the time path of the stationary values represents the general trend of the actual values. Actual values fluctuate about the stationary values in conformity with earlier findings on the stability properties of the system. It is worth noting that during the price support period (1943-1950) the actual levels assumed by the various production variables are much higher than the corresponding stationary levels. Actual prices, however, do not differ materially from corresponding stationary prices. This seems to support the view adopted by Gray, Sorenson, and Cochrane ${ }^{90}$ that the incentive to expand production during the price support period was provided not by higher prices but by the reduction in risk afforded by announced prices. According to D. N. Wright, ${ }^{91}$ average total costs of production in Kern County, California, for a renter operator in 1957 was about

${ }^{90}$ Gray, Sorenson, and Cochrane, op. cit.

${ }^{91}$ D. N. Wright, Irish Potatoes, Costs and General Hints on Production (Bakersfield: Calif. Agr. Ext. Serv., March, 1957). 


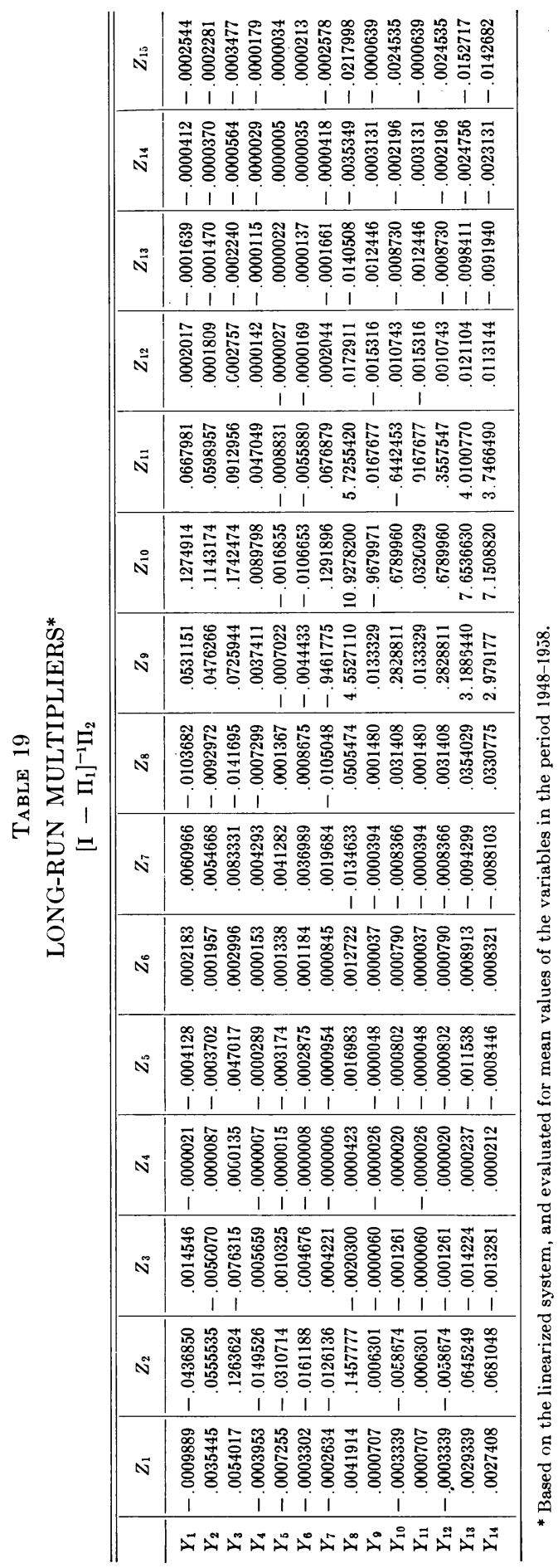


$\$ 1.24$ per bushel of marketable potatoes. According to table 18, the stationary deflated farm price for this year was about $\$ 1.26$, which is equivalent to around $\$ 1.49$ per bushel at 1958 prices. The difference of 25 cents between the stationary price and total per-unit costs reflects return to entrepreneurship and a risk premium. In a highly competitive market, such as the potato market, 25 cents per bushel represents a relatively large margin. Presumably, the main component of the margin is risk premium. Elimination of the risk element is thus equivalent to a considerable increase in price.

Long-Run Multrpliers. A long-run multiplier (stationary multiplier) is defined as the change in the level of an endogenous variable between two stationary states, these two stationary states differing from each other by a unit change in one exogenous variable. Assume that a stationary state prevailed before the change. The long-run multiplier then measures the effect on an endogenous variable corresponding to a maintained unit change in an exogenous variable; the change in the exogenous variable is maintained for a sufficiently long time to allow completion of the ensuing adjustment process.

The set of long-run multipliers is derived from the solution, equation (91), of the stationary state by obtaining measures of the partial derivatives of each component of $Y^{*}$ with respect to the components of $Z^{*}$. Accordingly:

$$
\frac{\partial Y^{*}}{\partial Z^{*}}=\left[I-\Pi_{1}\right]^{-1} \Pi_{2}
$$

is the matrix of long-run multipliers. Since certain exogenous variables enter the system nonlinearly, the direct derivation of the long-run multipliers corresponding to these exogenous variables is rather difficult. Multipliers presented are not derived directly. Instead, the linearized system presented on pages $610 \mathrm{ff}$. is employed on the assumption that this system represents a good approximation to the nonlinear system - at least within the range of changes considered. The resulting set of long-run multipliers is presented in table 19.

Before a detailed examination of table 19 is undertaken, recall that the values assumed by endogenous variables depend on both current and lagged values of exogenous variables. A maintained change in the level of an exogenous variable will therefore affect the endogenous variables via the change in current value and lagged value of the exogenous variable. Long-run multipliers are defined with reference to total changes in the endogenous variables. In a linear system, the total effect is simply the sum of the two effects.

From table 19 it is clear that a change in any exogenous variable will in the long run generate changes in the levels of all endogenous variables. On the other hand, in the short run, changes generated by a given exogenous variable are in the present study restricted to some subsets of endogenous variables. Thus, in the long run, a rise in yields of late crop potatoes $\left(Z_{3}\right)$ generates an increase in per-capita production, supply, and carry-over of late potatoes and a decline in winter and spring potato prices as well as in produc- 
tion and supply of all early potatoes. In the short run, ${ }^{92}$ however, production and supplies of early potatoes are not affected at all. It is also interesting to note that all long-run, late-crop-yield multipliers are smaller in absolute values than the corresponding impact multipliers. This is because the increase in production due to an increase in yields is eventually offset by a diminished acreage resulting from lower farm prices.

Similarly, a rise in yield of California early potatoes $\left(Z_{14}\right)$ leads to an increase in California production and supply but a decrease in all other production and price variables. Since the reduction in quantity of late potatoes carried over to the spring is greater than the decline in late crop production, actual supply to the winter market is increased. Here again, the winter market is not affected at all in the short run but only in the long run. Again, wherever changes appear, both in the long run and in the short run, they are greater in absolute value in the short run.

An increase in real per-capita disposable income $\left(Z_{6}\right)$ generates an increase in all prices and quantities in the long run but does not affect the production variables in the short run. Again, short-run changes in prices are greater in absolute value than long-run changes. This is due to the offsetting effect of increases in production variables.

An increase in population $\left(Z_{4}\right)$ leads to an increase in variables in the long run and in the short run. All per-capita production variables decrease in the short run, since an unchanged total output is divided among a larger population. In the long run, production responds to the higher farm prices in such a way that the change in other early potatoes per-capita production $\left(Y_{12}\right)$ becomes, in fact, positive, while the change in California and late crop percapita production remains negative but smaller in absolute value than the short-run change.

The multipliers associated with other exogenous variables can be interpreted in the same way. The total change in the stationary level of an endogenous variable following maintained changes in several exogenous variables can be estimated as the sum of the products of changes in the exogenous variables times their corresponding multipliers. Table 19 can therefore be used to project changes in the stationary levels.

\section{The Evolution of the System Under Changing Exogenous Conditions}

In preceding sections, the system properties were studied under the simplifying assumption that the exogenous variables take fixed values. By virtue of this unrealistic assumption, the system, which is otherwise historical, becomes in fact a causal one. In this section, we intend to relax this assumption and explore the case in which all exogenous variables are allowed to vary. For simplicity, only linear changes will be considered; that is, the evolution of the

\footnotetext{
${ }_{92}$ The corresponding short-run changes are given by the "impact multipliers." See tables 13 and 14.
} 
exogenous variables is assumed to be represented by the following set of linear equations in time.

$$
Z(t)=B_{0}+B_{1} t
$$

where $B_{0}$ and $B_{1}$ are vectors of constant coefficients.

Substituting equation (93) into equation (45), we get:

$$
Y(t)=\Pi_{1} Y(t-1)+\Pi_{2}\left(B_{0}+B_{1} t\right)
$$

As indicated on page 606, the solution to equation (94) is a sum of a particular solution $Y^{*}(t)$ and a general solution $y(t)$ to the homogeneous set, equation (46). It is easy to verify that:

$$
Y^{*}(t)=\left[I-\Pi_{1}\right]^{-1} \Pi_{2}\left(B_{0}+B_{1} t\right)-\left[I-\Pi_{1}\right]^{-2} \Pi_{1} \Pi_{2} B_{1}
$$

is a particular solution to equation (94) and hence:

$$
Y(t)=\Pi_{1}^{t} y(o)+\left[I-\Pi_{1}\right]^{-1} \Pi_{2}\left(B_{0}+B_{1} t\right)-\left[I-\Pi_{1}\right]^{-2} \Pi_{1} \Pi_{2} B_{1}
$$

is a general solution to equation (94), the specific path of $Y(t)$ depending on the initial conditions $Y_{0}$ and vectors $B_{0}$ and $B_{1}$. Since the absolute values of all latent roots of $\Pi_{1}$ were found to be less than unity, the term in equation (96) involving $\Pi_{1}{ }^{t}$ will tend to vanish as $t$ increases; that is:

$$
\operatorname{Lim}_{t \rightarrow \infty} Y(t)=\left[I-\Pi_{1}\right]^{-1} \Pi_{2}\left(B_{0}+B_{1} t\right)-\left[I-\Pi_{1}\right]^{-2} \Pi_{1} \Pi_{2} B_{1}
$$

In other words, as $t$ increases, all motions $Y(t)$ converge to the motion described by equation (97) and therefore converge to each other. That is, in essence, the concept of stability applied to economic systems that are dynamical and historical. ${ }^{93}$ The path described by equation (97) will be referred to as a limiting path. Notice that the limiting path is in itself a linear function of time.

Consider first the term $\left[I-\Pi_{1}\right]^{-1} \Pi_{2}\left(B_{0}+B_{1} t\right)$. The path described by this term alone is referred to by P. A. Samuelson ${ }^{94}$ as the "receding equilibrium."

$\ldots$ it is the position of stationary equilibrium which might be attained if, subsequent to $\bar{t}$, all historical changes were suspended. That is to say, in all our functional equations a bar is placed over $t$ wherever it occurs explicitly for times subsequent to $\vec{t}^{95}$

The second term $-\left[I-\Pi_{1}\right]^{-2} \Pi_{1} \Pi_{2} B_{1}$ is a vector of constants independent of $t$ but depending on the rates of change in the exogenous variables $\left(B_{1}\right)$. If the exogenous variables happen to be constant over time, this term vanishes and the limiting path becomes identical with the stationary state. If the system is static and historical, this term again vanishes, since then $\Pi_{1}=0$.

${ }^{93}$ Cf. Samuelson, Foundations of Economic Analysis, chap. XI.

${ }^{94}$ Ibid.

${ }^{95}$ Ibid., p. 326. 


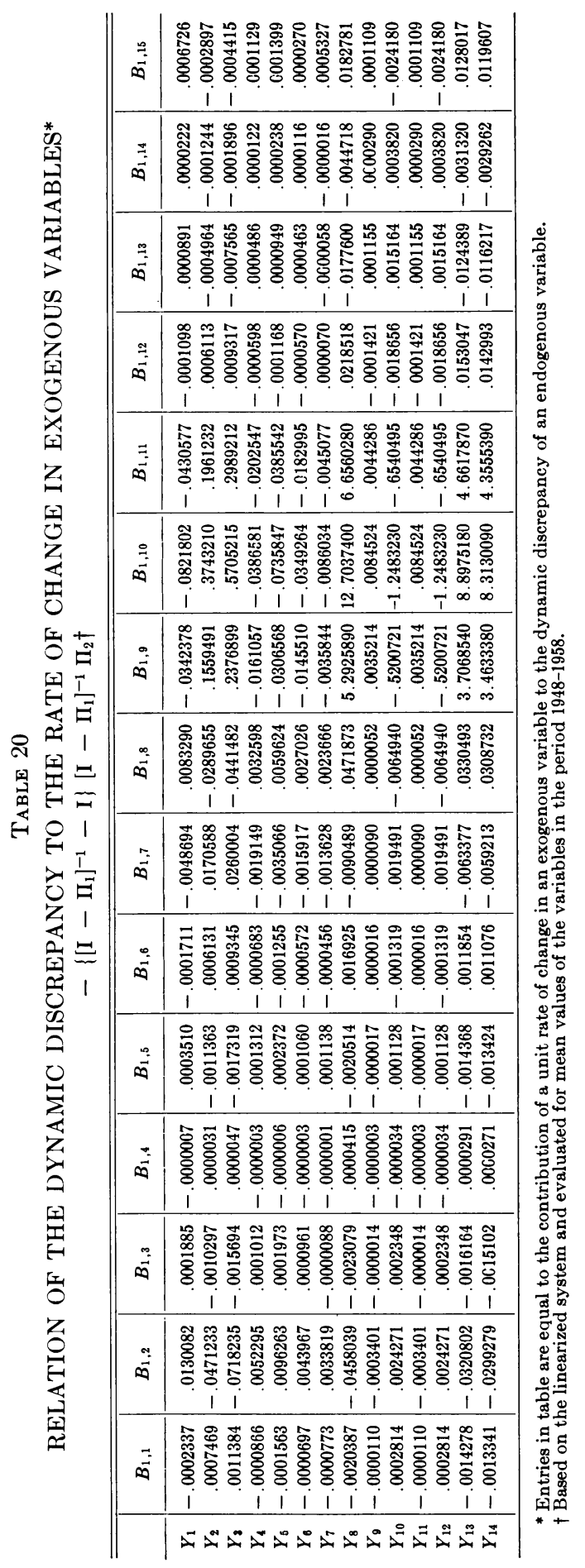


Accordingly, this term is referred to subsequently as the "dynamic discrepancy." The "dynamic discrepancy" provides a measure of the difference between the actual levels of the endogenous variables (in the limit) and their corresponding stationary levels. Furthermore, the matrix $-\left[I-\Pi_{1}\right]^{-2} \Pi_{1} \Pi_{2}$ provides measures of the relations between the dynamic discrepancy of the set of endogenous variables and the rates of change in the exogenous variables.

In applying the foregoing derivations to the present analysis, only the limiting path is considered. The term involving $\Pi_{1}{ }^{t}$ is disregarded, since it tends to become negligible within a relatively short period. The limiting path is of greater interest, since it defines the path about which the system fluctuates. As the receding equilibrium (path of stationary states) was treated in the preceding section, the main attention in this section is centered on the dynamic discrepancy. Table 20 contains the matrix $-\left[I-\Pi_{1}\right]^{-2} \Pi_{1} \Pi_{2} \cdot{ }^{96}$ Since certain exogenous variables enter the various equations nonlinearly, the linearized system was used in deriving table 20. All qualifications mentioned in the section on pages 630 to 636 with respect to the use of the linearized system are relevant to the present analysis also. It may also be recalled that both current and lagged values of several exogenous variables enter the system of equations. The total effect of any exogenous variable on the dynamic discrepancy is the sum of its effects through the current and the lagged values. ${ }^{97}$ The entries in table 20 are measures of the contribution of a unit rate of change in the exogenous variables to the dynamic discrepancy of the endogenous variables. Thus, for instance, if the real index of prices received by farmers for all farm products $\left(Z_{1}\right)$ increases at the rate of one index unit per annum, it causes per-capita production of late potatoes and of California early potatoes to be lower than the corresponding stationary values, whereas percapita production of other early potatoes will be above its stationary level. Accordingly, all potato prices in the winter will be above their corresponding stationary levels, while all spring potato prices will be below their stationary values. Similarly, a constant annual rate of increase of 1 bushel per acre in the yield of late crops $\left(Z_{3}\right)$ will keep late crop production, and production of other early potatoes, above their corresponding stationary levels. California production, on the other hand, will be somewhat below its stationary levels. Accordingly, all potato prices will be depressed below their stationary levels.

A constant population growth of 1,000 persons per year will cause all production variables to lag behind their stationary values, whereas all potato prices will lead the corresponding stationary prices. A similar behavior is observed in the case of a constant increase in real per-capita disposable income. Entries in table 20 that are related to changes in other exogenous variables can be interpreted in much the same way. To quantify the dynamic discrep-

${ }^{96}$ The discrepancy was computed from the relation:

$$
\left[I-\tilde{\Pi}_{1}\right]^{-2} \tilde{\Pi}_{1} \tilde{\Pi}_{2}=\left\{\left[I-\tilde{\Pi}_{1}\right]^{-1}-I\right\}\left[I-\tilde{\Pi}_{1}\right]^{-1} \tilde{\Pi}_{2} .
$$

${ }^{97}$ Since both lagged and current values of exogenous variables vary at the same rate, the corresponding columns in the matrix $\tilde{\Pi}_{2}$ may be combined into a single column by simple summation. 
ancy for the period 1948-1958, a linear regression of each exogenous variable on time was computed by least squares. ${ }^{98}$ An estimate of the dynamic discrepancy was then obtained by premultiplying the vector of slope coefficients $\hat{\mathrm{B}}_{1}$ of the exogenous variables by the matrix $\left[I-\tilde{\Pi}_{1}\right]^{-2} \tilde{\Pi}_{1} \tilde{\Pi}_{2}$. Table 21 contains the estimated dynamic discrepancy of selected endogenous variables for the period 1948-1958.

It is evident from table 21 that during the period 1948-1958 the dynamic discrepancy was relatively unimportant. Only in the case of per-capita production of other early potatoes and in the case of early potato prices did it amount to any significant magnitude. Even in these cases, it did not exceed

TABLE 21

THE DYNAMIC DISCREPANCY OF SELECTED ENDOGENOUS VARIABLES, $1948-1958$

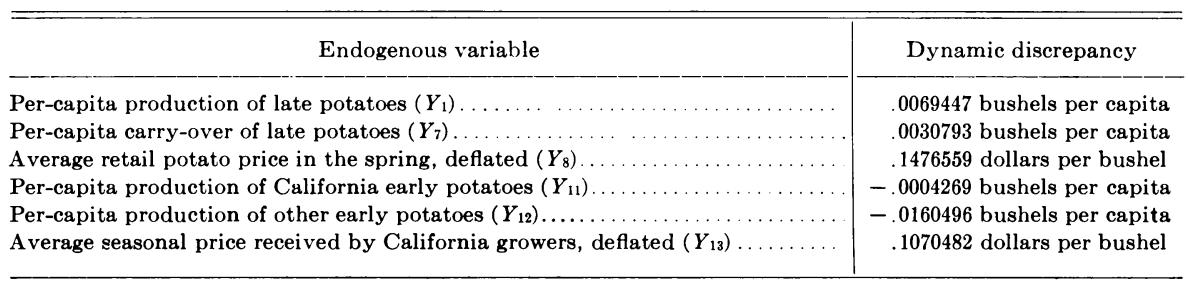

10 per cent of the stationary values. These findings are consistent with the conclusions developed in the section on pages 630 to 636 . No specific analysis of the dynamic discrepancy for the price support period has been carried out. The data in table 21 suggest, however, that only a small portion of the deviation from the stationary state observed during this period may be attributed to the rapidly increasing yields as some authors have suggested. ${ }^{99}$ It appears, therefore, that actual rates of changes in the exogenous variables and the structural characteristics of the potato market are such that dynamic discrepancies are of rather limited importance.

\footnotetext{
98 See Appendix B.

${ }^{99}$ See, for instance, Benedict and Stine, op. cit.
} 


\section{SOME APPLICATIONS OF THE ECONOMETRIC MODEL IN THE EVALUATION OF ECONOMIC POLICIES AND PREDICTION}

\section{Evaluation of Economic Policies}

The main objective of the present section is to apply the econometric model of the potato market in the formation of some economic policies which may be of interest to California potato growers.

The various policies to be considered will all deal with the problem of a true joint profit maximization ${ }^{100}$ by a collusion of all early potato producers in California. Furthermore, the only instruments assumed to be employed to this effect are variations in per-capita production of California early crop. This, of course, does not exhaust the list of available instruments that might be employed once a collusion of growers is admitted. Variation in the quality of California early potatoes, sales promotion efforts, and other measures could also be instrumental in maximizing profits. In order that the best policy be selected, it is necessary that both short-run and long-run consequences of the various policy measures be evaluated. The policy maker can then order the various policies according to his preference and adopt the one ranking highest. Most of this section will therefore deal with the evaluation of the consequences of the policies considered.

The following general treatment of the policy problem in its relation to econometric models draws upon the works of J. Marschak, ${ }^{101} \mathrm{~J}$. Tinbergen, ${ }^{102}$ and $\mathrm{H}$. Theil. ${ }^{103}$ In the present section, however, the general analysis will be restricted to the type of econometric model developed in the preceding chapters.

Consider a planning period extending from $t+1$ through $t+n$ and denote by $W$ the objective function of California potato growers. We may then write:

$$
W=W\left(\begin{array}{cc}
t+n & t+n \\
Y(\tau), & Z(\tau) \\
t+1 & t+1
\end{array}\right)
$$

That is, $W$ is defined over all values taken by $Y$ and $Z$ during the entire period.

Recall that, given the reduced form (45), ${ }^{104}$ the set $\{Y(\tau) \tau=t+1, \cdots$,

100 The term "true profit maximization" implies that the maximum profit attainable is unrestricted by the fact that production decisions are made by a collusion of individual producers rather than by a single producer.

${ }^{101}$ Marschak, op. cit., pp. 1-50. Also, Marschak, "Economic Measurements for Policy and Prediction," Studies in Econometric Methods, ed. William C. Hood and T. C. Koopmans, Cowles Comm. for Res. in Econ. Mono. 14 (New York: John Wiley and Sons, 1953), pp. 1-26.

${ }^{102}$ J. Tinbergen, On the Theory of Economic Policy ("Contributions to Economic Analysis," No. 1; Amsterdam: North-Holland Publ. Co., 1952), 78 p.

103 Theil, op. cit., chaps. VII-VIII.

${ }^{104}$ See page 606 . 
$t+n\}$ is uniquely determined by the set $\left\{Y(t)_{1} Z(\tau)_{1} V(\tau) \mid \tau=t+1, \cdots\right.$, $t+n\}$; that is:

$$
Y(\tau)=\eta_{\Pi}\left[\underset{t+1}{Z(v),} V_{t+1}(v), Y(t)\right]
$$

where $V(v)$ is the vector of random disturbances in the reduced form. Hence, equation (98) may now be rewritten as:

$$
W=W\left[\begin{array}{cc}
t+n \\
Z(\tau) \\
t+1
\end{array}, \underset{t+1}{t+n}(\tau), Y(t), \Pi(s)\right]
$$

where $\Pi(s)$ is the set of parameters in the reduced form relations depending on the underlying structure $S$.

Since $V(\tau)$ is a random variable, $W$ is also random.

Suppose now that the set $Z$ of exogenous variables can be partitioned into two mutually complementary subsets: (1) $Z_{c}$, the set of controllable variables (instruments), and (2) $Z_{u}$, the set of uncontrollable exogenous variables, that is, $Z \equiv\left(Z_{u}, Z_{c}\right)$.

Suppose also that during the planning period we have the economic structure $\bar{S}$ which is related to the structure $S^{0}$ prevailing during the sampling period through the transformation $J$; that is:

$$
\bar{S}=J S^{0}
$$

Some of the structural changes are controllable and some are uncontrollable; that is:

$$
J=J_{u} J_{c}
$$

where $J_{u}$ and $J_{c}$ are uncontrollable and controllable transformations, respectively. Clearly, the set of parameters $\bar{\Pi}$ of the new reduced form will depend on $\bar{S}$; that is:

$$
\begin{aligned}
\bar{\Pi} & =\bar{\Pi}(\bar{S}) \\
& =\bar{\Pi}\left(J_{u} J_{c} S^{0}\right)
\end{aligned}
$$

The problem of policy formulation consists of choosing such values of $Z_{c}$ and carrying out such changes in the structure $J_{c}$ that will maximize $W$.

The "best policy" $\hat{Z}_{c}$ and $\hat{J}_{c}$ is therefore defined by:

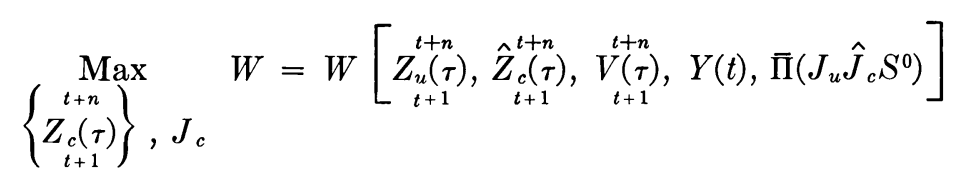

Notice that the $\{V(\tau) \mid \tau=t+1, \cdots, t+n\}$ are not known in time $t$. 
If, however, the probability density function

$$
P\left(\begin{array}{l}
t+n \\
V(\tau) \\
t+1
\end{array} ; \theta\right)
$$

( $\theta=$ vector of parameters) is known, then $W$ can be defined as a functional in the density functions. It will be assumed that the policy maker aims at maximizing $W^{*}=E W .{ }^{105}$ Since in the present analysis there were no grounds for preferring any particular values of $n$, two extreme values of $n$ were considered. These were: (1) $n=1$ (a "short-sighted" policy) and (2) $n=\infty$ (a "long-run" policy). A further simplification was achieved by identifying the objective function $W$ with total net revenue of California growers. Finally, the problem of sampling errors in the estimates was completely ignored, assuming that the estimated structure is identical with the unknown "true" structure.

The "Short-Sighted" Policy. It is obvious that, once California potato producers collude, relation 11 of our model, that is, the California production response relation, is no longer relevant. In fact, per-capita production of California early potatoes $\left(Y_{11}\right)$ becomes a controllable exogenous variable. The number of relations in the new structure is now 13. It remains a complete structure inasmuch as only 13 endogenous variables are now jointly determined by the system. The new structure $\bar{S}$ is:

$$
\overline{\mathrm{B}} \bar{Y}(t)+\bar{\Gamma}_{1} \bar{Y}(t-1)+\bar{\Gamma}_{2} \bar{Z}(t)+\gamma_{2,11} \bar{Y}_{11}(t)=\bar{U}(t)
$$

where $\bar{Y}(t)$ is a $13 \times 1$ vector of endogenous variables and is obtained from $Y(t)$ by deleting $Y_{11}(t)$. The matrices $\overline{\mathrm{B}}, \bar{\Gamma}_{1}$, and $\bar{\Gamma}_{2}$ are derived from $\mathrm{B}, \Gamma_{1}$, and $\Gamma_{2}$, respectively, by deleting row 11 and column 11 from $B$ and $\Gamma_{1}$ and row 11 along with columns corresponding to prices received by California growers for alfalfa and cotton lint from $\Gamma_{2}$.

$\gamma_{2,11}$ is a $13 \times 1$ vector of coefficients. It is the same as column 11 in B but with element No. 11 deleted. $\bar{Z}(t)$ is obtained from $Z(t)$ by deleting the prices received by California farmers for alfalfa and cotton lint, and $\bar{U}(t)$ is obtained from $U(t)$ by dropping $U_{11}(t)$. Accordingly, the new reduced form is:

$$
\bar{Y}(t)=\bar{\Pi}_{1} \bar{Y}(t-1)+\bar{\Pi}_{2} \bar{Z}(t)+\bar{\pi}_{2,11} \bar{Y}_{11}(t)+\bar{V}(t)
$$

where

$$
\begin{aligned}
\bar{\Pi}_{1} & =-\overline{\mathrm{B}}^{-1} \bar{\Gamma}_{1} \\
\bar{\Pi}_{2} & =-\overline{\mathrm{B}}^{-1} \bar{\Gamma}_{2} \\
\bar{\pi}_{2,11} & =-\overline{\mathrm{B}}^{-1} \gamma_{2,11} \\
\bar{V}(t) & =\overline{\mathrm{B}}^{-1} \bar{U}(t)
\end{aligned}
$$

${ }^{105}$ If, for instance, $W^{*}$ is the expected utility during the planning period, then both total net income and its variability over time will affect $W^{*}$. Thus, a policy leading to a somewhat lower average income but a much more even flow may be associated with a greater value of $W^{*}$. 
The net revenue function can now be defined in terms of equation (105) as:

$$
\begin{aligned}
W= & \bar{Y}_{13}(t+1)\left[\bar{Y}_{11}(t+1)-Z_{10}(t+1)\right] Z_{4}(t+1) \\
& -C\left[\bar{Y}_{11}(t+1) Z_{4}(t+1)\right] \\
= & Z_{4}(t+1)\left[\bar{\pi}_{1,13} \bar{Y}(t)+\bar{\pi}_{2,13} \bar{Z}(t+1)+\bar{\pi}_{2,11,13} \bar{Y}_{11}(t+1)\right. \\
& \left.+\bar{V}_{13}(t+1)\right]\left[\bar{Y}_{11}(t+1)-Z_{10}(t+1)\right]-C\left[\bar{Y}_{11}(t+1) Z_{4}(t+1)\right]
\end{aligned}
$$

where $C\left[\bar{Y}_{11}(t+1) Z_{4}(t+1)\right]$ is the cost of producing $\bar{Y}_{11}(t+1)$.

$\bar{\pi}_{1,13}, \bar{\pi}_{2,13}$ and $\bar{\pi}_{2,11,13}$ are the row vectors whose elements are the coefficients in the thirteenth rows of $\bar{\Pi}_{1}, \bar{\Pi}_{2}$, and $\bar{\pi}_{2,11}$, respectively. Since all $Z_{k}(t)$ are assumed to be statistically independent of the $V g(t)$ and a similar assumption applies to $\bar{Y}_{11}(t)$, it is clear that:

$$
\begin{aligned}
W^{*} & =E(W) \\
& =W\left\{\bar{Y}(t), \bar{Z}(t+1), \bar{Y}_{11}(t+1), Z_{4}(t+1), E\left[\bar{V}_{13}(t+1)\right]\right\} \\
& =W\left\{\bar{Y}(t), \bar{Z}(t+1), \bar{Y}_{11},(t+1), Z_{4}(t+1), 0\right\}
\end{aligned}
$$

Since by a priori specification $E[\bar{V}(t)]=0$, setting now:

$$
\frac{\partial W^{*}}{\partial \bar{Y}_{11}(t+1)}=0
$$

and solving equation $(108)$ for $\hat{Y}_{11}(t+1)$, the value maximizing $W^{*}$, we obtain:

$$
\begin{gathered}
\hat{Y}_{11}(t+1)=\frac{1}{2 \bar{\pi}_{2,11,13}}\left[C^{\prime}-\bar{\pi}_{1,13} Y(t)-\bar{\pi}_{2,13} \bar{Z}(t+1)\right] \\
\text { where } \quad C^{\prime}=\frac{d C}{d\left[\bar{Y}_{11}(t) \overline{Z_{4}}(t)\right]}
\end{gathered}
$$

Numerical values are of no interest at this stage. They will, of course, vary with $\bar{Y}(t)$ even if $\bar{Z}(t+1)$ is fixed. The importance of equation (109) is in its defining a new behavioral equation for $Y_{11}(t)$ in terms of $\bar{Y}(t-1)$ and $\bar{Z}_{k}(t)$. In the present formulation, (109) is, in fact, a linear equation and can be easily introduced into our system replacing the original California production relation. The effects of the "short-sighted" policy on the potato market can then be evaluated by methods already described. ${ }^{106}$

The reduced form system generated by substituting the derived California production relation based on a "short-sighted" profit maximization policy for the original production response relation will now be represented by:

$$
Y(t)=\Pi_{1}{ }^{*} Y(t-1)+\Pi_{2} * Z(t)+V^{*}(t)
$$

${ }^{106}$ See section starting page 604 . 
In the numerical analysis, $\Pi_{1}{ }^{*}, \Pi_{2}{ }^{*}$, and $Z(t)$ were evaluated for the 1958 values of the exogenous variables. ${ }^{107}$

The cost function $C=C\left[\bar{Y}_{11}(t) Z_{4}(t)\right]$ was assumed to be linear in $\bar{Y}_{11}(t) Z_{4}(t)$, so that the marginal cost is equal to the average variable cost. The data used to represent production costs were for renter operators in Kern County in 1957. ${ }^{108}$ The first step in the analysis involves obtaining the latent roots of $\Pi_{1}^{*}$. The following values were obtained:109

$$
\begin{aligned}
& \lambda_{1}=-.7037736 \\
& \lambda_{2}=.5397978 \\
& \lambda_{3}=.0135707
\end{aligned}
$$

Evidently, the change in behavior of California producers has not altered the stability characteristics of the original system. That is, the new system is still convergent, since all latent roots are less than unity in absolute value. Notice, however, that the dominant latent root is negative, implying that the oscillatory movement dominates the system's motion. Furthermore, the maximum modulus of the latent roots is larger than before the adoption of the "shortsighted" production policy, so that the dampening of fluctuations is much slower.

The main question, however, is: What is the new equilibrium to which all motions converge (assuming fixed values for exogenous variables)? In analysis bearing on this question, the stationary values of the new system were computed by means of the relation:

$$
Y^{*}=\left(I-\Pi_{1}^{*}\right)^{-1} \Pi_{2}{ }^{*} Z^{*}
$$

for the 1958 values of $Z(t)$. The computed stationary values of selected endogenous variables are presented in table 22 .

Comparing the figures in table 22 to the 1958 stationary levels of the same variables, ${ }^{110}$ it is found that the "short-sighted" production policy leads to a reduction of .0686 bushel per capita (about 35 per cent of the 1958 value) in California production, a rise of .0535 bushel per capita in the production of other states' early potatoes and of .0086 bushel per capita in the carry-

${ }^{107}$ The "new" California production relation for 1958 is:

$$
\begin{aligned}
Y_{11}(t)= & .1162115-.0388803 Y_{1}(t-1)-.0188034 Y_{2}(t-1)+.0018714 Y_{3}(t-1) \\
& -.0018714 Y_{8}(t-1)-.1722863 Y_{12}(t-1)-.0101616 Y_{14}(t-1) \\
& -.0003525 Z_{2}(t)+.0018319 Z_{2}(t-1)-.0000855 Z_{5}(t) \\
& -.0000076 Z_{5}(t-1)+.0000726 Z_{6}(t)-.0000041 Z_{6}(t-1) \\
& -.0001729 Z_{7}(t)-.0001264 Z_{7}(t-1)+.0017579 Z_{8}(t) \\
& +.2083086 Z_{9}(t)+.5000007 Z_{10}(t)+.2619714 Z_{11}(t)
\end{aligned}
$$

${ }^{108}$ Cost data were obtained from Wright, op. cit.

${ }^{109}$ Notice that $\Pi_{1}{ }^{*}$ is of rank 3 and not of rank 4 as is $\Pi_{1}$. This is because $Y_{11}(t)$ does not depend any more on $Y_{11}(t-1)$ and $Y_{13}(t-1)$ as is the case in the original structure. Instead, the "new" production relation is a linear combination of all other relations in the model.

${ }^{110}$ See table 18. 
over of preceding year's late crop. Associated with these changes was an increase of $\$ .7223$ per bushel in the deflated retail price and an increase of $\$ .5058$ per bushel in the deflated California farm price. The resulting gain in net real revenue to California producers is about $\$ 4.805$ million.

The "Long-Run" Policy. In addition to the assumption s already made, the following additional assumptions are introduced in the present "long-run" analysis: (1) all exogenous variables are constant over time, that is, $Z(t)=Z^{*}$, and (2) California growers have no particular time preference with respect to the intertemporal flow of income. ${ }^{111}$ The objective function can therefore be written as:

$$
W=\operatorname{Lim}_{n \rightarrow \infty} \frac{1}{n} \sum_{\tau=1}^{n}\left[\bar{Y}_{11}(\tau) \bar{a}^{\prime} \bar{Y}(\tau) Z_{4}^{*}-C\left(\bar{Y}_{11}(\tau) Z_{4}^{*}\right)\right]
$$

where $\bar{a}=\left[a_{i}\right]$ is a $13 \times 1$ vector such that

$$
a_{i}=\left\{\begin{array}{l}
1 \text { for } i=12 \\
0 \text { for } i \neq 12
\end{array}\right\} .
$$

TABLE 22

STATIONARY VALUES OF SELECTED ENDOGENOUS VARIABLES

UNDER A "SHORT-SIGHTED" PRODUCTION POLICY

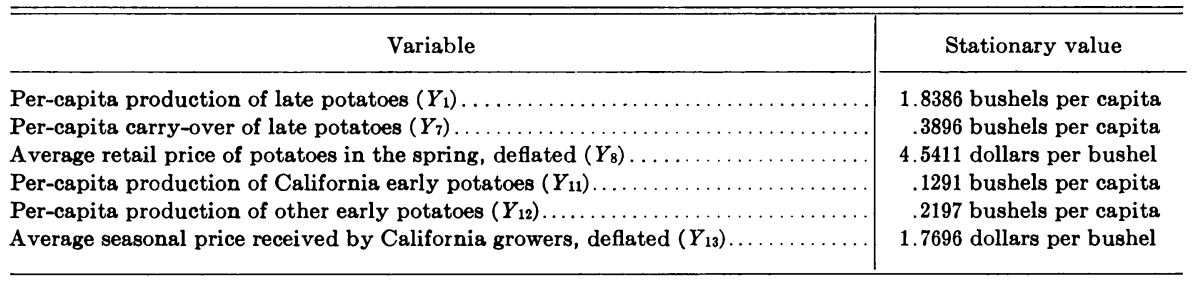

That is, producers aim at maximizing average annual net returns over an infinitely long period.

It can be verified by "substitution that:

$$
\begin{array}{r}
\bar{Y}(\tau)=\bar{\Pi}_{1}^{\tau} \bar{Y}(0)+\sum_{i=0}^{\tau-1} \bar{\Pi}_{1}^{i} \bar{\Pi}_{2} Z^{*}+\sum_{i=0}^{\tau-1} \bar{\Pi}_{1}^{i} \bar{\pi}_{2,11} \bar{Y}_{11}(\tau-i) \\
+\sum_{i=0}^{\tau-1} \bar{\Pi}_{1}^{i} \bar{V}(\tau-i)
\end{array}
$$

constitutes a solution to equation (105). Substituting (113) into (112) and taking expectations, we find that:

$$
\begin{aligned}
W^{*} & =E(W) \\
& =W\left\{\bar{Y}(0), \bar{Z}^{*}, Z_{4}^{*}, Y_{\tau=1}^{\infty}(\tau), E[\underset{\tau=1}{\infty}(\tau)]\right\}
\end{aligned}
$$

${ }^{111}$ Assumptions (1) and (2) are, of course, oversimplifications of reality but are made here for the sake of simplicity. 
Since $Z^{*}$ and the $\left\{\bar{Y}_{11}(\tau)\right\}$ are assumed to be statistically independent of $\{\bar{V}(\tau)\}, W^{*}$ is evaluated at $E\{\bar{V}(\tau)\} \equiv$ policy consists therefore of finding a sequence $\hat{Y}_{11, \infty}=\left\{\hat{Y}_{11}(1), \hat{Y}_{11}(2), \cdots\right\}$ that will maximize $W^{*}$. This sequence depends on the initial conditions $\bar{Y}(0)$ and on the exogenous variables. The general solution for the sequence $\widehat{Y}_{11, \infty}[\bar{Y}(0)]$ as a function of the initial condition has not been derived. The following analysis will therefore proceed on the assumptions that there exist some $\bar{Y}(0)=\bar{Y}^{*}(0)$ such that all elements in the sequence $\hat{Y}_{11, \infty}\left[\bar{Y}^{*}(0)\right]$ are equal, that is, $\widehat{Y}_{11}(\tau) \equiv \widehat{Y}_{11}{ }^{*}$, a "stationary policy." This implies that a stationary state prevails for the system as a whole. It follows that the optimum policy, given $\bar{Y}(0) \equiv \bar{Y}^{*}(0)$, can be derived by maximizing net returns for any single year $\tau$ with respect to $Y_{11}(\tau)$ subject to the constraint that a stationary state prevails. The resulting optimum policy $\hat{Y}_{11} *$ is:

$$
\hat{Y}_{11}^{*}=\frac{C^{\prime}-\bar{a}^{\prime}\left(I-\bar{\Pi}_{1}\right)^{-1} \bar{\Pi}_{2} \bar{Z}^{*}}{2 \bar{a}^{\prime}\left(I-\bar{\Pi}_{1}\right)^{-1} \bar{\pi}_{2,11}}
$$

In the numerical analysis, all matrices and exogenous variables, as well as the cost structure, were computed in exactly the same way as for the analysis of the short-sighted policy. ${ }^{112}$ The value of $\hat{Y}_{11}{ }^{*}$ was then computed according to (115). The long-run optimum level of per-capita production for early California potatoes in 1958 was found to be: $\hat{Y}_{11}{ }^{*}=.1302664$ bushel per capita, which corresponds to a total production of 22,570,000 bushels. Compared with a stationary level of annual income based on an "atomistic" structure of California production, the gain in net real revenue for 1958 is about $\$ 4.826$ million. This represents only a slight improvement over the stationary level of net income corresponding to a short-sighted policy. Relaxing now the highly unrealistic assumption that $\bar{Y}(0) \equiv \bar{Y}^{*}(0)$, a policy which fixes the level of per-capita production at $\hat{Y}_{11} *$ repeatedly is no longer an optimum policy. In the real world, where the system is continuously disturbed, this is clearly an erroneous procedure. What is needed is a "rule" which will provide at least the first term of the sequence $\widehat{Y}_{11, \infty}$ as a function of the initial conditions and the exogenous variables (state variables). We may then conceive of a continuous process of policy formation where the planning horizon is ever moving. Every year a new production policy is adopted in accordance with the "rule" and taking into account the values of the state variables.

Finally, it is necessary to recognize that the system is historical and not causal; that is, exogenous variables are continuously changing so that, in fact, the underlying process is not time independent.

${ }^{112}$ See pages 643 to 646 . 


\section{Forecasts Based on the Econometric Model}

An important application of any econometric model is in forecasting future values of the endogenous variables. Indeed, the reliability of forecasts compared with some naive projections may serve as a criterion for judging the adequacy of the estimated structure. However, it is not the objective of the present study to examine the forecasting performance of the econometric model developed. Such examination as is possible must be of a very limited scope, since observations on the potato market are available for only one year beyond the sample period. To some extent it is possible to draw inferences regarding the forecasting power of a model by examining its performance in explaining the observed values of endogenous variables during the sample period.

The reliability of forecasts will generally depend on the variables whose future values are predicted and on the amount of a priori information available to the forecaster. Hence, no unique measure of forecasting power for the model as a whole can be developed. The explanatory value of the model for all endogenous variables, given full information on exogenous and lagged endogenous variables as well as on certain current endogenous variables, may be measured by the multiple correlation coefficients associated with equations estimated by direct least squares. These were presented in earlier chapters of the study.

The power of the estimated model in predicting long-run changes is possibly best illustrated in figures 16 to 20, although no numerical measures are developed to estimate the explanatory power of the model in this respect.

Short-run predictions, that is, forecasts on endogenous variables from $t$ to $t+1$, can be easily computed by means of a "linearized system," but more accurate results are obtainable from the nonlinearized reduced form, since there is in this case no resort to approximation. In both cases, evaluation of the system at the predicted values of exogenous variables is indispensable.

Long-run forecasts can be arrived at by any one of the following methods.

(1) Numerical Extrapolation. - Start with values taken by endogenous variables at the time forecasts are developed as initial conditions. Generate numerically the deterministic evolution of the system for given evolution of the exogenous variables. This is done by inserting the calculated values of endogenous variables for any year $t$ into the calculation corresponding to year $t+1$ as values of lagged endogenous variables. Numerical extrapolation is particularly useful when the system is nonlinear or when the evolution of exogenous variables is such that particular solutions are not easily obtained. A prerequisite to the use of this method is access to high-speed computing facilities. An estimate of the prediction error due to random disturbances in periods subsequent to $t$ can also be obtained by numerical extrapolation using Monte Carlo techniques.

(2) Explicit Solution of the Reduced Form Equations.-According to this method, a solution to the set of difference equations for the predicted evolu- 
tion of the exogenous variables is first obtained. The forecasts are then arrived at by a suitable evaluation of the solution. This method may be useful when solutions are easily obtained.

(3) "Stationary State Forecasts."-If the deterministic process is convergent, and providing the "dynamic discrepancy" is negligible, then the appropriate stationary values of the endogenous variables may be considered as adequate long-run predictors. That is, the following predictor is used to forecast $Y(t+k)$ at time $t$.

$$
\hat{Y}(t+k)=\left(I-\hat{\Pi}_{1}\right)^{-1} \hat{\Pi}_{2} Z(t+k)
$$

If we now define the forecast error as:

$$
\begin{aligned}
D_{k}= & Y(t+k)-\hat{Y}(t+k) \\
= & \Pi_{1}{ }^{k} y(t)+\left[I-\Pi_{1}\right]^{-1} \Pi_{2} Z(t+k)+d_{t+k}-y^{*}(t+k) \\
& -\left(I-\hat{\Pi}_{1}\right)^{-1} \hat{\Pi}_{2} Z(t+k)
\end{aligned}
$$

where $d_{t+k}$ is the dynamic discrepancy (which may be a function of time). $y^{*}(t+k)$ is defined as on page 622 to be the weighted sum of random shocks during the interval $(t, t+k)$; that is, $y^{*}(t+k)=\sum_{i=0}^{k-1} \Pi_{1}{ }^{i} V(t+k-i)$. Now, as $k$ increases, $\Pi_{1}{ }^{k} \rightarrow 0$. $\Pi_{1}{ }^{k} y(t)$ may therefore be neglected for sufficiently large $k$. Also, if $\hat{\Pi}_{1}$ and $\hat{\Pi}_{2}$ are maximum likelihood estimators of $\Pi_{1}$ and $\Pi_{2}$, respectively, then by a well-known invariance theorem, ${ }^{113}\left(I-\hat{\Pi}_{1}\right)^{-1} \hat{\Pi}_{2}$ is a maximum likelihood estimator of $\left(I-\Pi_{1}\right)^{-1} \Pi_{2}$. Hence, in large samples, $\left(I-\hat{\Pi}_{1}\right)^{-1} \hat{\Pi}_{2} Z(t+k)-\left(I-\Pi_{1}\right)^{-1} \Pi_{2} Z(t+k)$ is small in comparison with $y^{*}(t+k){ }^{114}$ In fact, $\left(I-\hat{\Pi}_{1}\right)^{-1} \hat{\Pi}_{2} Z(t+k)$ is a consistent and asymptotically unbiased estimate of $\left(I-\Pi_{1}\right)^{-1} \Pi_{2} Z(t+k)$. Hence, by a priori specifications:

$$
\begin{aligned}
& \operatorname{Lim}_{\substack{k \rightarrow \infty \\
T \rightarrow \infty}} E\left(D_{k}\right)=\operatorname{Lim}_{\substack{k \rightarrow \infty \\
T \rightarrow \infty}}\left\{\Pi_{1}^{k} y(t)+\left(I-\Pi_{1}\right)^{-1} \Pi_{2} Z(t+k)+d_{t+k}\right. \\
& =d
\end{aligned}
$$

where $T$ denotes sample size. That is, for any positive $\epsilon$, however small, there exist some $\bar{k}$ and $\bar{T}$ such that

$$
\left|E[Y(t+k)]-d-E\left[\hat{Y}_{T}(t+k)\right]\right|<\epsilon \quad \text { for } \quad T \geqq \bar{T}, k \geqq \bar{k}^{\prime}
$$

${ }^{113}$ Cf. A. M. Mood, Introduction to the Theory of Statistics (1st ed.; New York: McGrawHill Book Co., 1950), p. 159.

${ }^{114}$ In the present model, however, only the estimates of the recursive subsystems are, in fact, maximum likelihood estimates. The assertion made above, which is true for the maximum likelihood estimates in general, need not be true for two-stage least-squares estimates. At any rate, the expression $\left(I-\hat{\Pi}_{1}\right)^{-1} \hat{\Pi}_{2}$, where $\hat{\Pi}_{1}$ and $\hat{\Pi}_{2}$ are two-stages least-squares estimates of $\Pi_{1}$ and $\Pi_{2}$, respectively, is a consistent estimate of $\left(I-\Pi_{1}\right)^{-1} \Pi_{2}$. 
If the dynamic discrepancy $d=0$, then $\hat{Y}(t+k)$ is an asymptotically unbiased predictor. Furthermore, as $k$ and $T$ tend to infinity, the limit of $E\left(D D^{\prime}\right)$ exists; ${ }^{115}$ that is:

$$
\lim _{\substack{k \rightarrow \infty \\ T \rightarrow \infty}} E\left(D D^{\prime}\right)=\mathbf{\Sigma}_{y \infty}+d d^{\prime}
$$

where $\sum_{y_{\infty}}$ is the limiting variance-covariance matrix of $y(t)$ as defined on page 623 . Thus, if the probability density function for $V(t)$ is known, it is possible to construct tolerance ellipsoids for the predicted values $Y(t+k)$. If the "dynamic discrepancy" cannot be considered negligible but a particular

TABLE 23

PREDICTED RATES OF CHANGE IN ENDOGENOUS VARIABLES

\begin{tabular}{l|r}
\hline \hline \multicolumn{1}{c|}{ Endogenous variable } & \multicolumn{1}{c}{ Annual rate of change } \\
\hline Per-capita production of late potatoes $\left(Y_{1}\right) \ldots \ldots \ldots \ldots \ldots \ldots \ldots \ldots \ldots \ldots$ & -.020045 bushels per capita per year \\
Per-capita carry-over of late potatoes $\left(Y_{7}\right) \ldots \ldots \ldots \ldots \ldots \ldots \ldots \ldots \ldots$ & -.004914 bushels per capita per year \\
Average retail price of potatoes in the spring, deflated $\left(Y_{8}\right) \ldots \ldots \ldots \ldots$ & .118748 dollars per bushel per year \\
Per-capita production of California early potatoes $\left(Y_{11}\right) \ldots \ldots \ldots \ldots \ldots$ & -.005744 bushels per capita per year \\
Per-capita production of other early potatoes $\left(Y_{12}\right) \ldots \ldots \ldots \ldots \ldots \ldots \ldots$ & .011159 bushels per capita per year \\
Average seasonal price received by California growers, deflated $\left(Y_{13}\right) \ldots$ & .028003 dollars per bushel per year \\
\hline
\end{tabular}

evolution of $Z(t)$ which allows its derivation is assumed (such as a linear solution), then the stationary predictors can be easily adjusted. The small sample prediction problem is much more difficult and will not be treated in this study.

The "stationary state forecasts" approach was applied in the prediction of future trends in the market for California early potatoes. In this connection, the linearized system presented earlier was adopted. It was also assumed that changes in exogenous variables in the forthcoming years are to proceed according to trends existing during the last decade. Trends of exogenous variables were estimated by means of a simple linear regression on time and are presented in Appendix B.

Let $\hat{\mathbf{B}} y$ be the vector of predicted rates of change in endogenous variables. Then:

$$
\hat{\mathbf{B}} y=\left(I-\tilde{\Pi}_{1}\right)^{-1} \tilde{\Pi}_{2} \hat{\mathbf{B}}_{1}
$$

where $\tilde{\Pi}_{1}$ and $\tilde{\Pi}_{2}$ are defined, as before, to be the matrices of the linearized system and $\hat{\mathrm{B}}_{1}$ the vector of rates of changes in exogenous variables estimated for the period 1948-1958. Note that, provided the evolution of the exogenous variables is linear, the "dynamic discrepancy" is not involved in predicting changes but only in predicting absolute levels of endogenous variables. The predicted rates of change in selected endogenous variables are presented in table 23.

${ }^{115}$ See page 623. 
According to these results, further decline in per-capita production of late potatoes and a decline in early California potatoes is expected. The change in total California production $\left(Y_{11}^{0}\right)$ will depend, in addition, on the annual change in population. Since $Y_{11}^{0}(t)=Z_{4}(t) Y_{11}(t)$, we get:

$$
\begin{aligned}
d Y_{11}^{0} & =\frac{\partial Y_{11}^{0}}{\partial Z_{4}} d Z_{4}+\frac{\partial Y_{11}^{0}}{\partial Y_{11}} d Y_{11} \\
& =Y_{11} d Z_{4}+Z_{4} d Y_{11}
\end{aligned}
$$

Hence, the computed change in total California production evaluated at the 1958 levels of $Z_{4}$ and $Y_{11}$ is about -535.0 thousand bushels per annum, which is about 1.8 per cent of total production in 1958. On the other hand, production of early potatoes in other states will start rising, reversing the declining trend of the past two decades. Retail prices will rise at an annual rate of $\$ .118748$ per bushel, but the corresponding rate of increase in farm price will be much slower due to a simultaneous increase in the farm-to-retail spread.

The forecasts presented above are very crude and rest heavily on the assumptions concerning the future changes in the exogenous variables and the linearity of the system. A more detailed and careful study of the future evolution of the exogenous variables, together with use of the estimated unlinearized system rather than its linearized form, would be expected to give more reliable forecasts. The forecasts presented above are mainly for illustrative purposes and should be regarded as such. 


\section{REVIEW AND APPRAISAL OF METHODS}

\section{Review of Methods and Concluding Remarks}

The main objective of the present study has been to analyze quantitatively the market for California early potatoes. It is evident from the introductory chapters that this market is an integral part of a broader system embracing the entire United States potato industry. Hence, any attempt to analyze it as a separate entity, on the basis of ceterus paribus assumptions with respect to the rest of the industry, is bound to be futile.

Keeping this fact in mind, a detailed study of the main components of the industry and their interrelation was first undertaken. As a result, an econometric model of the industry consisting of 14 equations in 14 endogenous variables was developed.

In order to identify the variables entering the various relations, a theoretical economic analysis was first undertaken. In addition to the identification of variables, economic theory led to a priori determination of signs of certain partial derivations which served in appraisal of the empirical results.

In the estimation procedure, both direct least squares and two-stage least squares were employed. Direct least squares was a permissible procedure for certain relations owing to a certain degree of recursiveness inherent in the structure.

Having estimated the structure, a comparative analysis of the system's static properties was carried out. Long-run and impact multipliers, measuring the long-run and short-run effects of variation in exogenous variables, were derived. In this framework, the stationary levels of certain endogenous variables were obtained for selected years in the sample period.

The dynamic properties of the system constituted another line of inquiry. It was found that the system possesses stability of the first kind; that is, following any disturbance, it will converge to the equilibrium value. This was further verified by the observation that values of endogenous variables actually fluctuated about their calculated stationary levels.

When the stochastic process involved in the system was explored, it was suggested that the large observed short-run fluctuations are primarily due to random shocks and only secondarily due to erratic changes in exogenous variables. Similarly, the carry-over of random effects by means of the deterministic process is only secondary in importance. The implications of these findings for any stabilizing policy are that any attempt to stabilize the market through measures affecting the deterministic process alone are bound to yield only limited effects. If, however, the trends in exogenous variables observed during the sample period are to continue, a structural stabilizing policy may become much more effective.

In an ever-changing environment, one would hardly expect the actual evolution of the system to coincide with the equilibrium values. Indeed, it was 
possible to develop measures of dynamic discrepancy in a certain simple case. In the case of the potato industry, however, their numerical values were relatively small.

The use of the econometric model in formulating an optimum production policy under collusive action by California growers and the evolution of its consequences were explored. It was found that under a "short-sighted" policy, substantial gains in net income are possible, but an increase in market instability is to be expected. No success can be reported in developing a long-run optimization rule. When an optimum production policy is considered, it is worth noting that reference is made to a "true joint profit maximization." This, however, can hardly be conceived of as a realistic possibility. In fact, any successful attempt to raise income by means of production control requires also effective restrictive measures. Such measures are difficult to institute and even more difficult to maintain once the increase in income is actually realized.

The forecasting problem in relation to the econometric model is dealt with in a rather limited sense. Main emphasis centers on the use of "stationary state forecasts" for long-run predictions. The problem of forecast errors, a problem of extreme importance, is treated on the basis of large sample theory, and its application is demonstrated in the prediction of future trends in the market for California early potatoes.

\section{Appraisal of Methods and Suggestions for Additional Research}

In earlier stages of the present analysis, the greatest conceptual difficulty was in formulating the production response and supply-out-of-stocks relations. The main reason for these difficulties appears to be the lack of an adequate operational theory of individual behavior in an uncertain and ever-changing environment. In the case of production response relations, a simplified adjustment model was adopted, while the price anticipation model was, in fact, assumed away. This approach was adopted merely in order to gain simplicity and convenience. The extent to which these simplifications have actually distorted the picture is not clear.

In the case of supply out of stocks, the expectation model adopted appears inadequate, and a further exploration in developing a more adequate model seems desirable.

Another imperfection in the model is associated with the trend variable; it is felt that addition of higher polynomial terms of the trend variable may improve the fit in some relations and also increase the forecasting value of the model as a whole.

Turning now to the methods of analysis, which were used after the parameters of the structure were estimated, certain difficulties and shortcomings of method are apparent.

It appears that the gravest difficulties were due to two major factors: (1) the nonlinearity of the system with respect to certain exogenous variables and 
(2) the fact that the system is historical. While the former difficulty may not exist in some cases, the latter is omnipresent. To overcome the nonlinearity, a "linearization" process was applied. The resulting impact multipliers are, of course, valid for sufficiently small variations in exogenous variables, but one may doubt the validity of dynamic evaluations based on the "linearized" system. It particular, it would not seem advisable to use the linearized system for prediction.

An alternative procedure of analyzing dynamic properties is to generate the evolution of the system by "numerical extrapolation"; that is, for every period values assumed by endogenous variables are computed from the reduced form. These computed values are then used as "inputs" in computing values of current endogenous variables in the following period.

Somewhat unexpected results were obtained in the analysis of optimum policies for a collusion of California potato growers. Why a "short-sighted" policy led in the longer run to gains in net returns similar to those realized by an optimum policy based on long-run consideration is not at all clear. One is also puzzled by the increase in the oscillatory behavior of the market caused by the "short-sighted" centralized policy. A more careful appraisal of results obtained in the formation of optimum policy rules must take into consideration various biases which might have entered our analysis. One such consideration bears upon the effects on growers' revenue that the resulting expansion of other crops production may have. If the demand for competing crops is relatively inelastic, then the computed gains in net revenue are much too optimistic. In this case, the optimum level of output may in part be larger than the one obtained in our preceding analysis, the implication being that the market for competing crop constitutes an integral part of any study designed to develop optimum production policies for California potato growers. 


\section{APPENDIX A}

\section{Basic Sample Data: Derivation and Sources}

All data for $X_{1}, X_{2}, X_{5}, X_{6}, X_{7}, X_{10}, X_{11}, X_{12}, X_{13}, X_{14}, X_{15}, X_{16}, X_{17}$, and $X_{24}$ are from the following sources:

(1) U. S. Bur. of Agr. Econ., Potatoes-Acreage, Production, Value, Farm Disposition, January 1 Stocks, 1866-1950, by States, Dept. of Agr. Stat. Bul. 122 (Washington, 1953), $109 \mathrm{p}$.

(2) U. S. Dept. of Agr., Potatoes-Sweetpotatoes, Revised Estimates, by States, 1949-55; Acreage, Yield Production, Price and Value, Farm Disposition, and January 1 Stocks, Stat. Bul. 190 (Washington, 1956), 31 p. Processed.

(3) U. S. Agr. Marketing Serv., Potatoes and Sweetpotatoes; Estimates by States and Seasonal Groups; Acreage, Yield, Production, Price, Value, Farm Disposition, Stocks (Washington, 1957-1959).

$X_{1}=$ Acreage planted-late crop. ${ }^{1}$

$X_{2}=$ Total production late $\operatorname{crop}=X_{1} Z_{3}$.

$X_{5}=$ Late crop abandoned, fed to livestock, or lost $=\left(X_{1}-\right.$ acreage harvested) $Z_{3}+$ fed to livestock, etc.

$X_{6}=$ Total disappearance of late crop in September-February $=X_{2}-$ $X_{8}-X_{24}$.

$X_{7}=$ Total late crop consumed as food in September-February $=X_{6}-X_{5}$.

$X_{10}=$ Acreage planted-California early crop. ${ }^{2}$

$X_{11}=$ Total production of California early potatoes.

$X_{12}=$ California early potatoes used as seed or fed to livestock, etc. $=$ California early crop used as seed + California early crop fed to livestock, etc.

$X_{13}=X_{11}-X_{12}$.

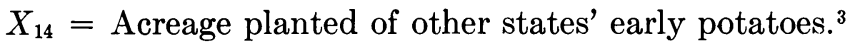

$X_{15}=$ Total production of other states' early crop.

$X_{16}=$ Other states' early potatoes used as seed or fed to livestock, etc. $=$ other states' early potatoes used as seed + other states' early potatoes fed to livestock, etc.

\footnotetext{
${ }^{1}$ Late crop includes late summer and fall potatoes.

${ }^{2}$ California early crop excluding winter potatoes.

${ }^{3}$ Other states' early crop includes: Florida (early spring); North Carolina (late spring and early summer); South Carolina; Georgia (late spring, early summer); Alabama; Mississippi; Arkansas; Louisiana; Oklahoma; Texas (early spring, late spring, and early summer); Arizona; Missouri; Kansas; Virginia (eastern shore, Norfolk). (Wherever original data on North Carolina do not distinguish between early crop and late summer crop, ratio estimates were used for the early crop.)
} 


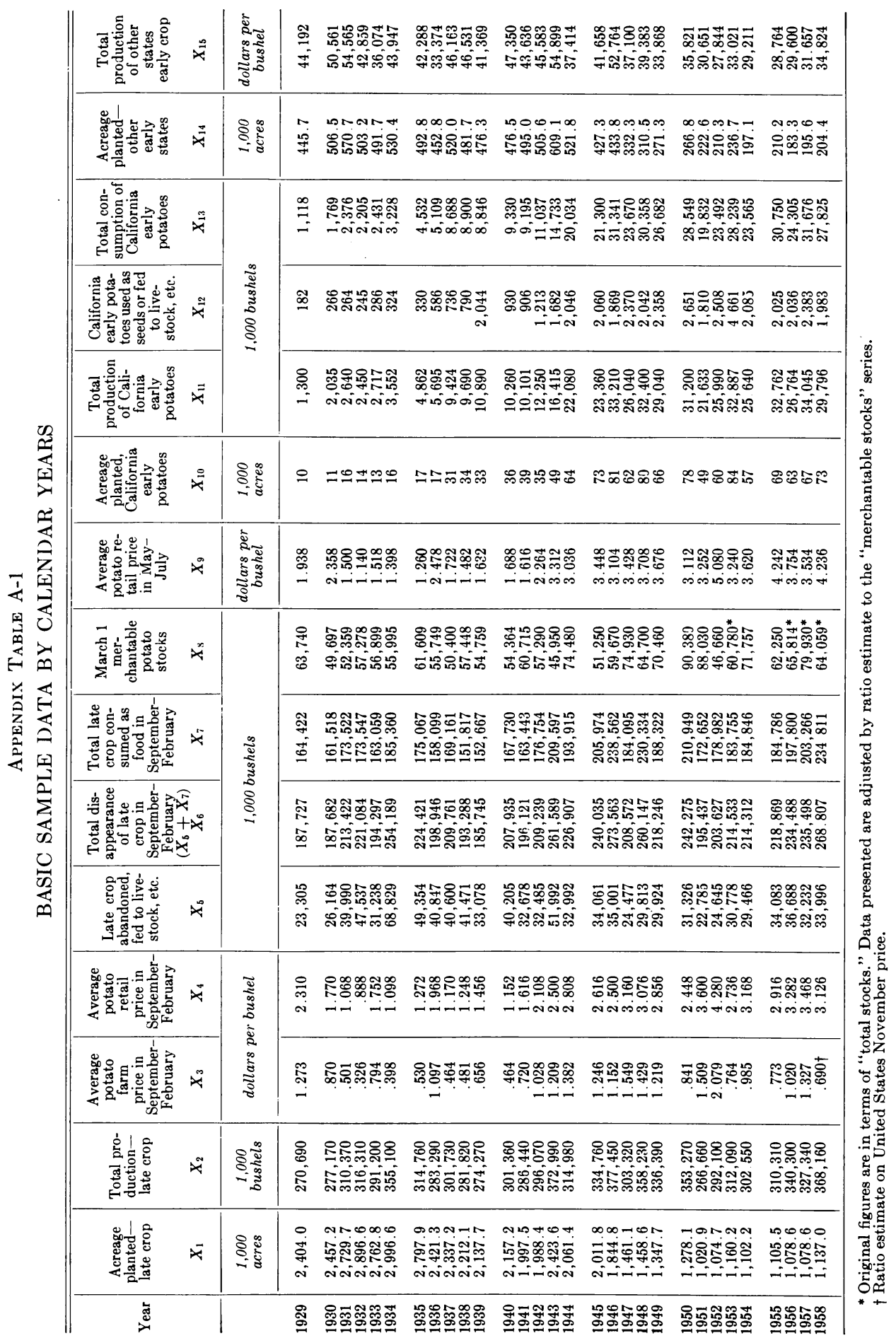




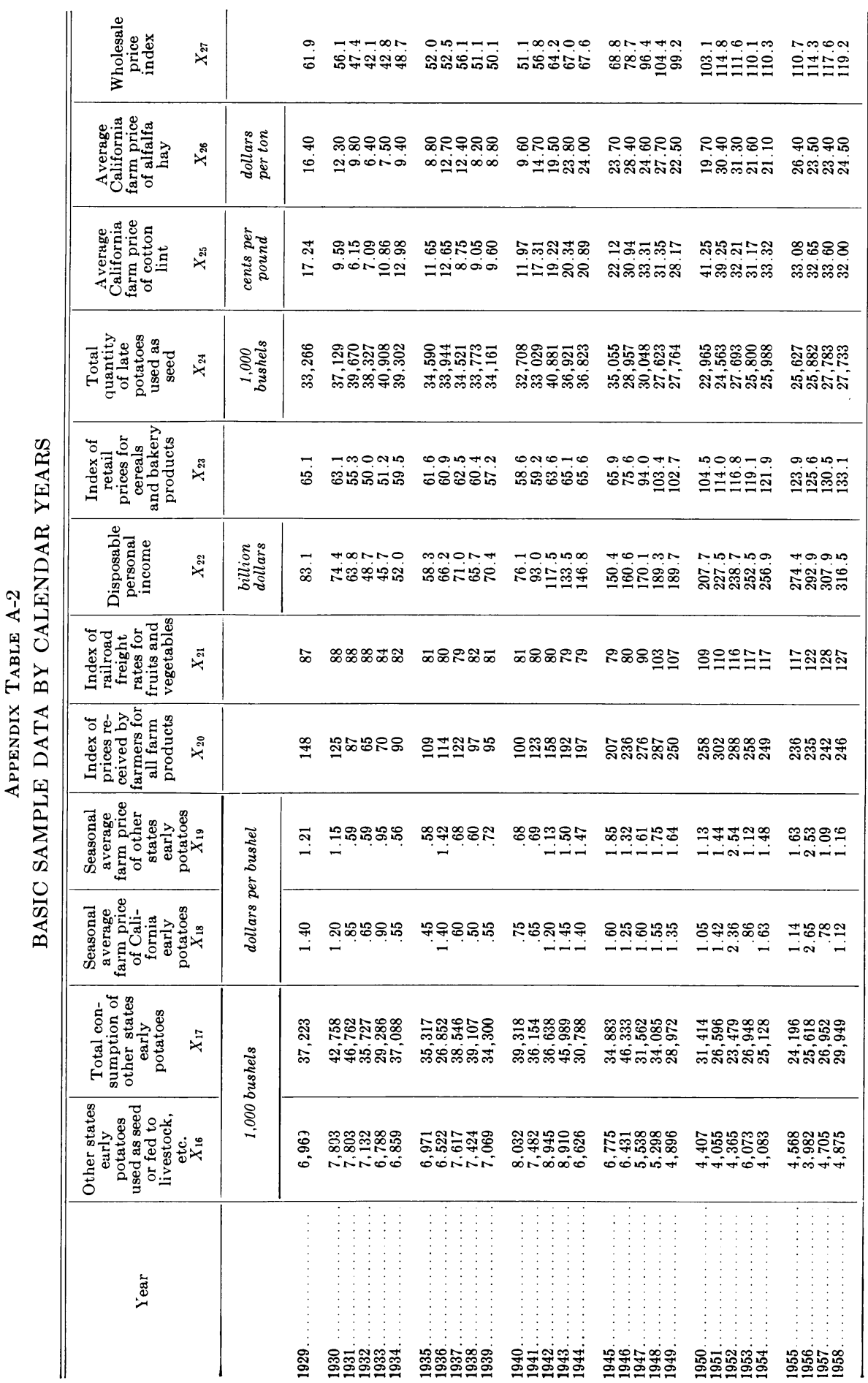




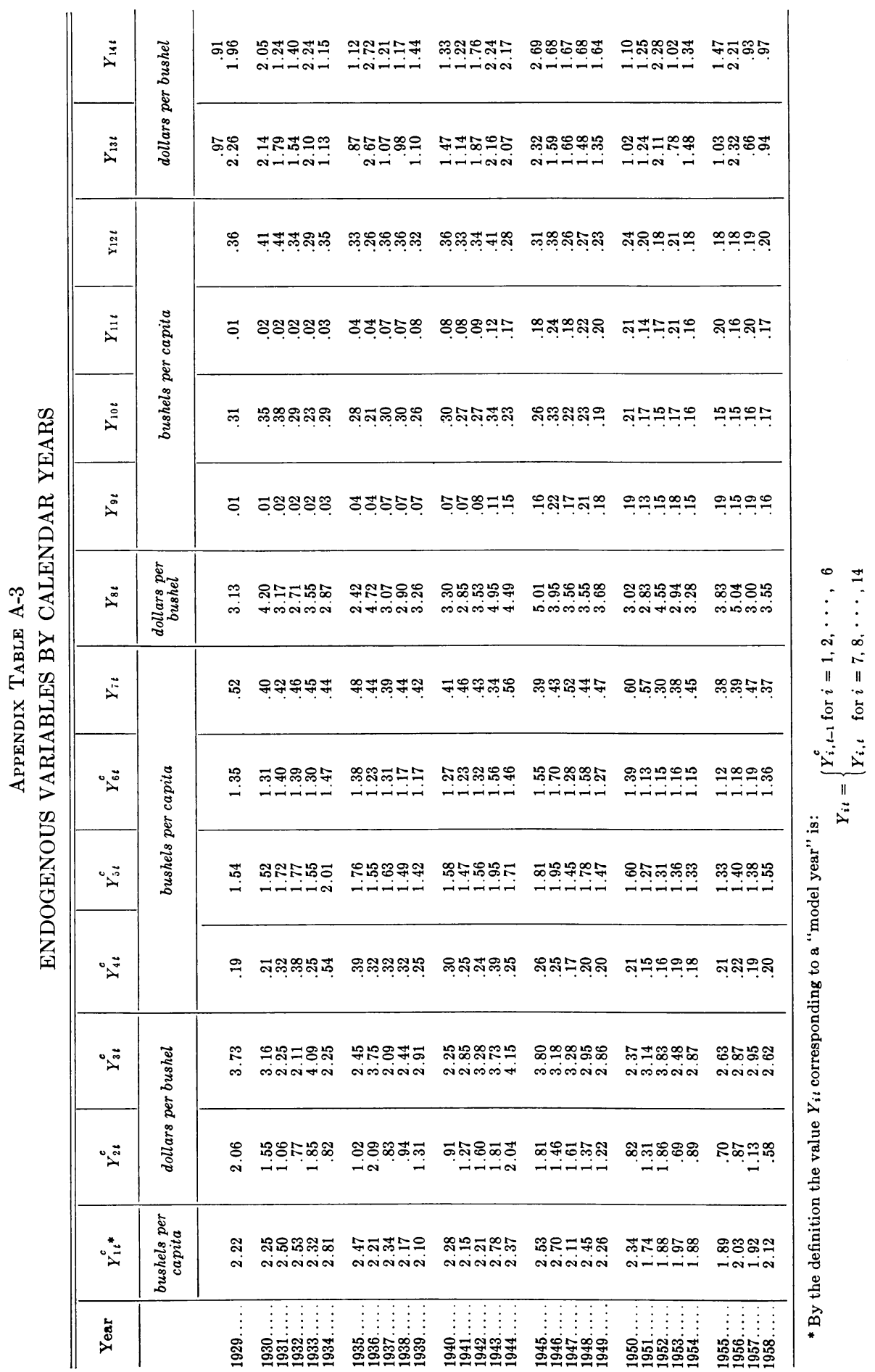




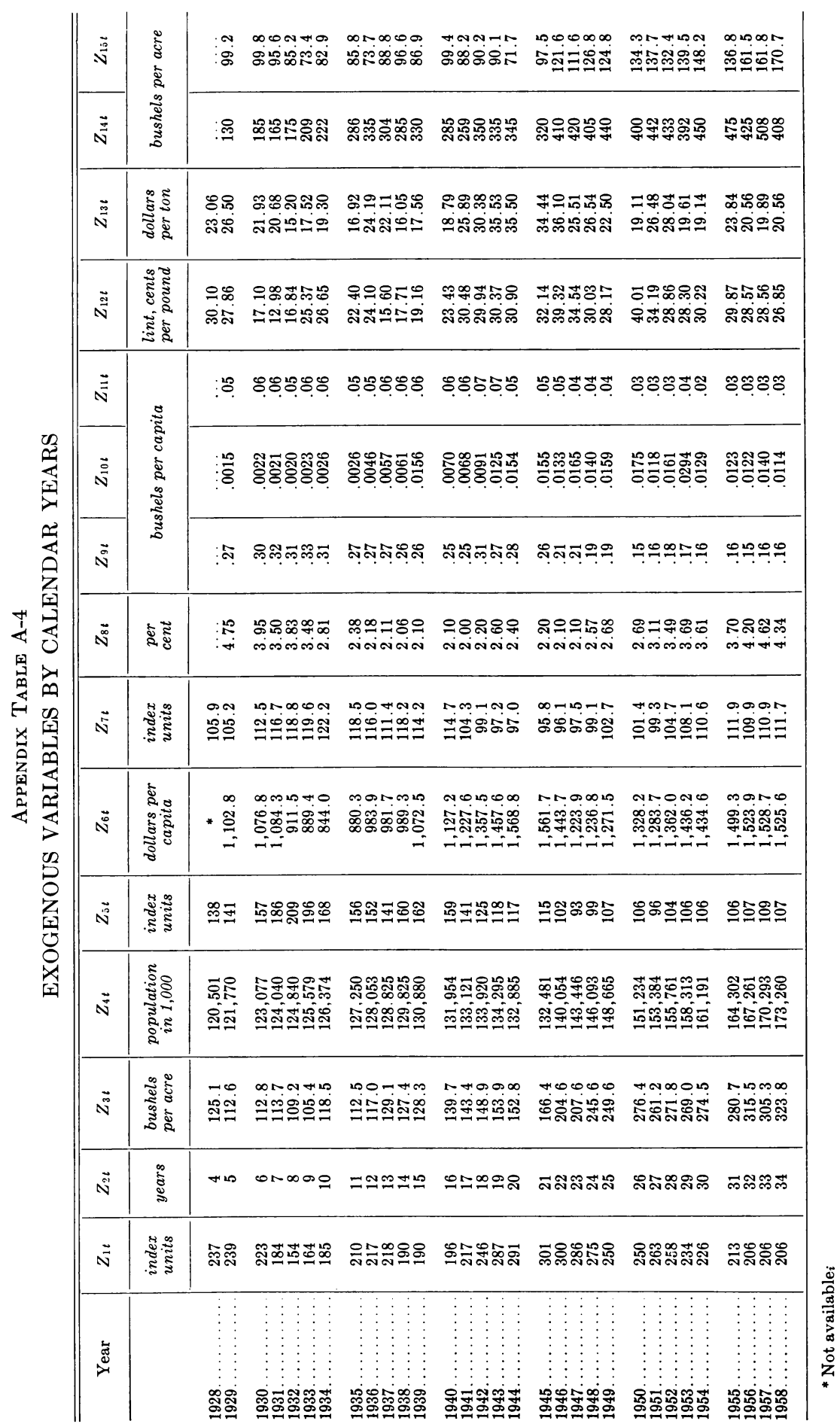


$X_{17}=$ Total consumption of other states' early potatoes $=X_{15}-X_{16}$.

$X_{24}=$ Total quantity of late potatoes used as seed. ${ }^{4}$

$X_{3}=$ Average potato farm price in September-February

$$
=\frac{\text { (Value of sales, late potatoes) }-X_{8} \text { (potato farm price in April) }}{\text { total quantity sold }-X_{8}} .
$$

$X_{18}=$ Seasonal average farm price of California early potatoes.

$X_{19}=$ Seasonal average farm price of other states' early potatoes (states' prices weighted by quantities sold).

Sources:

Prices in 1929-1952:

(4) U. S. Agr. Marketing Serv., Potato Prices, Monthly and Seasonal Average Prices Received by Farmers, by States and United States, 1909-1952, Dept. of Agr. Stat. Bul. 140 (Washington, 1954), p. 54. Processed.

Prices in 1953-1958:

(5) U. S. Agr. Marketing Serv., Agricultural Prices (Washington: monthly reports, 1958).

Data on volume of sales are from sources (1), (2), and (3).

$X_{4}=$ Average potato retail price in September-February (unweighted average of monthly retail prices).

$X_{9}=$ Average potato retail price in May-July (unweighted average of monthly prices).

$X_{23}=$ Index of retail prices for cereals and bakery products. Source:

All retail prices are from:

(6) U. S. Bur. of Labor Stat., Retail Prices of Food (Washington: annual and monthly reports).

$X_{8}=$ March 1 merchantable potato stocks. ${ }^{5}$

Sources:

1943-1958:

(7) U. S. Agr. Marketing Serv., Merchantable Potato Stocks, March 1 (Washington: monthly reports, 1943-1958).

1929-1942:

(8) Figures are regression estimates from January 1 stocks. (See source (1).)

$X_{20}=$ Index of prices received by farmers for all farm products.

${ }^{4}$ Seed potatoes are included in merchantable March 1 stocks only to the extent that they are sold after March 1. It is assumed that this quantity was relatively small during most of the sample period, since most of the seed were used on farms where grown and since some of the purchased seed most probably had been bought by growers before March 1 .

${ }^{5}$ Seed potatoes are included in merchantable March 1 stocks only to the extent that they are sold after March 1. It is assumed that this quantity was relatively small during most of the sample period, since most of the seed were used on farms where grown and since some of the purchased seed most probably had been bought by growers before March 1 . 
$X_{21}=$ Index of railroad freight rates for fruits and vegetables. Source:

(9) U. S. Dept. of Agr., Agricultural Statistics (Washington, 1958).

$X_{22}=$ Disposable personal income. Source:

(10) U. S. Dept. of Commerce, Supplement to the Survey of Current Business (Washington, 1959).

$X_{25}=$ Average California farm price of cotton lint.

$X_{26}=$ Average California farm price of alfalfa hay. Sources:

(11) California Crop and Livestock Reporting Service, California Field Crops Statistics, 1866-1946 (Sacramento, 1947), 68 p.

(12) California Crop and Livestock Reporting Service, California Field Crops Statistics, 1944-1957 (Sacramento, 1958), 47 p. Processed. Also, supplements for 1958.

$X_{27}=$ Wholesale price index.

Source:

(13) U. S. Bur. of Labor Stat., Wholesale Prices and Price Indexes (Washington: annual reports).

\section{Sample Data on Endogenous and Exogenous Variables}

For definition of variables, see pages 586 and 587 .

Sources:

For all endogenous variables and for $Z_{1 t}, Z_{5 t}, Z_{6 t}, Z_{7 t}, Z_{9 t}, Z_{10 t}, Z_{11 t}, Z_{12 t}$, and $Z_{13 t}$, see "Basic Sample Data," pages 656 to 659 .

$Z_{3 t}=$ Average yield of late potatoes.

$Z_{14 t}=$ Average yield of California early crop.

Sources:

U. S. Bur. of Agr. Econ., Potatoes-Acreage, Production, Value, Farm Disposition, January 1 Stocks, 1866-1950, by States, Dept. of Agr. Stat. Bul. 122 (Washington, 1953), $109 \mathrm{p}$.

U. S. Dept. of Agr., Potatocs-Sweetpotatoes, Revised Estimates, by States, 1949-55; Acreage, Yield Production, Price and Value, Farm Disposition, and January 1 Stocks, Stat. Bul. 190 (Washington, 1956), 31 p. Processed.

U. S. Agr. Marketing Serv., Potatoes and Sweetpotatoes; Estimates by States and Seasonal Groups; Acreage, Yield, Production, Price, Value, Farm Disposition, Stocks (Washington, 1957-1959).

$Z_{4 t}=$ United States population (as of July 1, excluding armed forces overseas).

Source:

U. S. Bur. of the Census, Statistical Abstract of the United States, 1959 (Washington, 1959), p. 5. 
$Z_{8 t}=$ Interest rate. Bank rates on business loans in 19 cities.

Source:

U. S. Office of Business Economics, Business Statistics, 1959 Edition; a Supplement to the Survey of Current Business (Washington, 1959), $351 \mathrm{p}$. Data for 1929-1938 were adjusted to the series of $1939-1958$ by ratio estimate.

$Z_{15 t}=$ Yield of early potatoes grown in states other than California = $\frac{\text { Total production in other early states }}{\text { Harvested acreage in other early states }}$.

See "Basic Sample Data," pages 656 to 659. 


\section{APPENDIX B}

\section{Estimated Trends of Exogenous Variables, 1948-1958}

Trends of exogenous variables during the period 1948-1958 were obtained by simple linear regression analyses. In each analysis, one exogenous variable was treated as a dependent variable and time $\left(Z_{2 t}\right)$ as an independent variable.

The following results were obtained:

Estimated equation

(1) $Z_{1 t}=279.733334-7.569697 Z_{2 t} \ldots \ldots \ldots \ldots$

(2) $Z_{3 t}=237.247276+7.025454 Z_{2 t} \ldots \ldots \ldots \ldots .8343$

(3) $Z_{4 t}=142830.963636+2706.30909 Z_{2 t} \ldots \ldots .9968$

(4) $Z_{5 t}=100.836366+.663636 Z_{2 t} \ldots \ldots \ldots \ldots . .3238$

(5) $Z_{6 t}=1208.389089+32.397273 Z_{2 t} \ldots \ldots \ldots .9368$

(6) $Z_{7 t}=98.078179+1.385455 Z_{2 t} \ldots \ldots \ldots \ldots . .8223$

(7) $Z_{8 t}=2.294182+.204000 Z_{2 t} \ldots \ldots \ldots \ldots \ldots .9380$

(8) $Z_{9 t}=.182186-.002637 Z_{2 t} \ldots \ldots \ldots \ldots \ldots \ldots .3717$

(9) $Z_{10 t}=.017339-.000352 Z_{2 t} \ldots \ldots \ldots \ldots \ldots . .0538$

(10) $Z_{11 t}=.037272-.000909 Z_{2 t} \ldots \ldots \ldots \ldots \ldots . .2504$

(11) $Z_{12 t}=33.381276-.508546 Z_{2 t} \ldots \ldots \ldots \ldots \ldots .2058$

(12) $Z_{13 t}=25.124728-.456091 Z_{2 t} \ldots \ldots \ldots \ldots \ldots .2080$

(13) $Z_{14 t}=410.090906+4.045455 Z_{2 t} \ldots \ldots \ldots \ldots . .1496$

(14) $Z_{15 t}=117.876364+4.210000 Z_{2 t} \ldots \ldots \ldots \ldots .8295$

\section{Estimated variance $\hat{\sigma}_{w}{ }^{2}$}

98.453030

119.827624

$283,039.652474$

11.243433

865.671136

5.056201

.033600

.000143

.000027

.000030

12.195106

9.678075

1,136.701906

44.519379 



\section{BIBLIOGRAPHY}

Adelman, I., and Adelman, F. L. "The Dynamic Properties of the Klein-Goldberger Model," Econometrica, 27 (4): 596-625, 1959.

Allen, R. G. D. Mathematical Economics. London: Macmillan Co., 1956.

Arrow, K., Harris, T., and MarschaK, J. "Optimal Inventory Policy," Econometrica, $19(3): 250-72,1951$.

BARger, H., and Klein, L. R. "A Quarterly Model for the U. S. Economy," Journal of the American Statistical Association, 49 (267): 413-37, 1954.

Baumol, W. J. Economic Dynamics. 2d ed. New York: Macmillan Co., 1959.

Bean, L. H. "The Farmers' Response to Price," Journal of Farm Economics, 11 (3): 368$85,1929$.

-. "Potato Prices and Acreage Stability," reprint from The Proceedings of the 7th Annual Meeting of the Potato Association of America, 1930.

Bellman, R. Dynamic Programming. Princeton: Princeton University Press, 1957.

Bemis, K. P. "Increasing Potato Use Through Sales Promotion," American Potato Journal, 32 (Jan.): 23-29, 1955.

. "Facts and Fancies in the Potato Industry Future," Fruit and Vegetable Review, 18 (Apr.): 16-17, 1956.

Benedict, M. R., and Stine, O. C. The Agricultural Commodity Programs. Two Decades of Experience. New York: The Twentieth Century Fund, 1956.

Black, J. D. "Elasticities of Supply of Farm Products," Journal of Farm Economics, 6 (2): 145-55, 1924.

Brennan, M. J. "A Model of Seasonal Inventories," Econometrica, 27 (2): 228-44, 1959.

Butz, E. L. "The Potato Problem," National Potato Council News, 2 (Aug.): 5-7, 1955.

California Crop and Livestock Service. California Field Crops Statistics, 1866-1946. Sacramento, 1947. Also supplements for 1958.

- California Field Crops Statistics, 1944-1957. Sacramento, 1958. (Processed.)

Carlson, Sune. A Study in the Pure Theory of Production. New York: Kelley \& Millman, Inc., 1956.

Chamberlin, E. H. The Theory of Monopolistic Competition, a Reorientation of the Theory of Value. 7th ed. Cambridge: Harvard University Press, 1958.

Cohen, R. L. Factors Affecting the Price of Potatoes in Great Britain. University of Cambridge, Dept. of Agr., Farm Economics Branch, Report No. 15. Cambridge, England, July, 1930.

Соок, A. C. "Price Factors," Kern County Potato Growers Association 11th Annual Convention. Bakersfield, California, March, 1955.

Dalrymple, D. G. Predicting August Potato Prices at Planting Time. University of Connecticut, Dept. of Agr. Econ. and Farm Mgmt., Progr. Rep. 29. Storrs, 1959.

Dvoretzky, A., Kiefer, J., and Wolfowitz, J. "The Inventory Problem: I. Case of Known Distributions of Demand," Econometrica, 20 (2): 187-222, 1952.

Ersenberg, I. "Trading of Potatoes on the Mercantile Exchange," Kern County Potato Growers Association 11th Annual Convention. Bakersfield, Calif. March, 1955.

Ezeniel, M. "The Cobweb Theorem," Quarterly Journal of Economics, 52 (2): 255-80, 1938.

Farrell, Kenneth R. California Early Potatoes; Statistical Report. Berkeley: Calif. Agr. Ext. Serv., 1958. (Processed.)

Fisher, M. R. "A Sector Model: The Poultry Industry of the U.S.A.," Econometrica, 26 (1): 37-66, 1958.

Fox, K. A. The Analysis of Demand for Farm Products. U. S. Bur. of Agr. Econ. Tech. Bul. 1081. Washington, 1953.

Frisch, R. "On the Notion of Equilibrium and Disequilibrium," Review of Economic Studies, 3 (2): 100-06, 1936.

- "Propagation Problems and Impulse Problems in Dynamic Economics," Economic Essays in Honour of G. Cassel. London: George Allen \& Unwin, Ltd., 1933.

Girshik, M. A., and Haavelmo, T. "Statistical Analysis of Demand for Food," Econometrica, 15 (2): 79-110, 1947.

Goldberger, A. S. Impact Multipliers and Dynamic Properties of the Klein-Goldberger Model. Amsterdam: North-Holland Publ. Co., 1959. 
Gray, Roger W., Sorenson, Vernon L., and Cochrane, Willard W. An Economic Analysis of the Impact of Government Programs on the Potato Industry of the United States. North Central Regional Publ. 42 and Minnesota Agr. Exp. Sta. Tech. Bul. 211. St. Paul, 1954.

Hartkemeier, H. P. "The Supply Function for Agricultural Commodities," The University of Missouri Studies, 7 (4), 1932.

Hawnins, A. "Highlights of a Half-Century in Potato Production," American Potato Journal, 34 (Jan.): 25-29, 1957.

Hee, Olman. "The Effect of Price on Acreage and Yield of Potatoes," Agricultural Economics Research, 10 (4): 131-140, 1958.

Hicks, J. R. Value and Capital. Oxford: Clarendon Press, 1939.

Hildreth, C., and JARrett, F. G. A Statistical Study of Livestock Production and Marketing. (Cowles Comm. for Res. in Econ. Mono. 15.) New York: John Wiley and Sons, 1955.

Hood, William C., and Koopmans, T. C. (eds.). Studies in Econometric Methods. (Cowles Comm. for Res. in Econ. Mono. 14). New York: John Wiley and Sons, 1953.

KALdor, N. "Speculation and Economic Stability," Review of Economic Studies, 7 (1): $1-27,1939$.

KIng, B. H., and Reed, D. W. Some Quick Highlights on Marketing Maine Potatoes. U. S. Farm Credit Admin. Spec. Rep. 91. Washington, December, 1941. (Processed.)

Klein, L. R., and Goldberger, A. S. An Econometric Model of the United States, 19291952. Amsterdam: North-Holland Publ. Co., 1955.

Lange, O. "The Theory of the Multiplier," Econometrica, 11 (3 and 4): 227-45, 1943.

Lee, Ivan M. California Early Potatoes: Situation and Outlook, 1948. Calif. Agr. Exp. Sta. Cir. 390. Berkeley, 1948.

ManN, H. B., and WaLd, A. "On the Statistical Treatment of Linear Stochastic Difference Equations," Econometrica, 11 (3 and 4): 173-220, 1943.

MarschaK, J. "Economic Measurements for Policy and Prediction," Studies in Econometric Methods. Edited by William C. Hood and T. C. Koopmans. (Cowles Comm. for Res. in Econ. Mono. 14). New York: John Wiley and Sons, 1953.

- . "Statistical Inference in Economics: An Introduction," Statistical Inference in Dynamic Economic Models. Edited by T. C. Koopmans. (Cowles Comm. for Res. in Econ. Mono. 10.) New York: John Wiley and Sons, 1950.

Martin, J. H., and Leonard, W. H. Principles of Field Crop Production. New York: Macmillan Co., 1951.

McCorkle, Chester O., Jr., and Mundlak, Yair. "Statistical Analysis of Supply Response in Late Spring Potatoes in California," Hilgardia, 24 (16), 1956.

Menren, G. L. "The Potato Industry," Kern County Potato Growers Association 11th Annual Convention. Bakersfield, Calif., March, 1955.

Metzler, L. A. "The Nature and Stability of Inventory Cycles," Review of Economic Statistics, 23 (3): 113-29, 1941.

Mood, A. M. Introduction to the Theory of Statistics. 1st ed. New York: McGraw-Hill Book Co., 1950.

Murdock, D. C Linear Algebra for Undergraduates. New York: John Wiley and Sons, 1957.

National Potato Council. "The Demand and Utilization of Potatoes," National Potato Council News, 4 (Jan.): 14-15, 1957.

Nerlove, Marc. "Distributed Lags and Estimation of Long Run Supply and Demand Elasticities: Theoretical Considerations," Journal of Farm Economics, 40 (2): 301-11, 1958.

- The Dynamics of Supply: Estimation of Farmers' Response to Price. Baltimore: Johns Hopkins Press, 1958.

and Adpison, W. "Statistical Estimation of Long Run Elasticities of Supply and Demand," Journal of Farm Economics, 40 (4): 861-80, 1958.

Pubols, B. H., and Klaman, S. B. Farmers' Response to Price in the Production of Potatoes, 1922-1941. U. S. Bur. of Agr. Econ. Washington, 1945. (Processed.)

Pusateri, F. P. "Can Efficiency, Supply-Demand Facts and Cooperation Create a Stable Potato Economy?" Potato Growers Association of California and Arizona, Inc., 1960 Yearbook. Bakersfield, Calif., 1960.

- "Potato Growing in California," Kern County Potato Growers Association 12th Annual Convention. Bakersfield, Calif., March, 1956. 
. "What Factors Influence the Price of Potatoes," Kern County Potato Growers Association 1959 Yearbook. Bakersfield, Calif., March, 1959.

Samuelson, P. A. Foundations of Economic Analysis. Cambridge: Harvard University Press, 1947.

_. "A Fundamental Multiplier Identity," Econometrica, 11 (3 and 4): 221-26, 1943. - "The Stability of Equilibrium: Comparative Statics and Dynamics," Econometrica, 9 (2): 97-120, 1941.

- "The Stability of Equilibrium: Linear and Nonlinear Systems," Econometrica, 10 (1): 1-25, 1942.

Schultz, H. The Theory and Measurement of Demand. Chicago: The University of Chicago Press, 1938.

Scotr, F. E. "An Analysis of the Factors Affecting the Price of California Early Potatoes." Unpublished Master's thesis, Univ. of Calif., 1942.

- and Mumford, Herbert W., Jr. Problems in Marketing Potatoes; Preliminary Results of Some Recent Research. U. S. Bur. of Agr. Econ: Washington, 1949. (Processed.)

Shuffetr, D. Milton. The Demand and Price Structure for Selected Vegetables. U. S. Dept. of Agr. Tech. Bul. 1105. Washington, 1954.

Slutzky, E. "The Summation of Random Causes as the Source of Cyclic Processes," Econometrica, 5 (2): 105-46, 1937.

Sorenson, V. L. "A Study of the Nature and Costs of Government Programs Affecting Potatoes and Their Impact on Intermarket Relationship," Journal of Farm Economics, 36 (4): 1281-84, 1954.

Suits, D. B. "An Econometric Model of the Watermelon Market," Journal of Farm Economics, 37 (2): 237-51, 1955.

- and Korzumi, S. "The Dynamics of the Onion Market," Journal of Farm Economics, 38 (2): 475-84, 1956.

Theil, H. Economic Forecasts and Policy. ("Contributions to Economic Analysis," No. 15.) Amsterdam: North-Holland Publ. Co., 1958.

Tinbergen, J. On the Theory of Economic Policy. "Contributions to Economic Analysis," No. 1.) Amsterdam: North-Holland Publ. Co., 1952.

. Statistical Testing of Business-Cycle Theories. Vol. II: Business Cycles in the United States of America, 1919-1932. Geneva: League of Nations Econ. Intelligence Serv., 1939.

U. S. Agricultural Marketing Service. Agricultural Economics Research, 10 (4), 1958.

- Agricultural Prices, monthly reports, 1958.

. Carlot Unloads of Certain Fruits and Vegetables in 100 U. S. Cities and 5 Canadian Cities, 1956.

—_. Carlot Unloads of Certain Fruits and Vegetables in 66 Cities, 1933.

- Farm-Retail Spreads for Food Products. Misc. Publ. 741, 1957.

. Marketing Kern District Early Long White Potatoes, Summary of 1955 Shipments. Bakersfield, Calif., 1956.

- Movements, Freight Rates, and Prices of Potatoes; Recent Trends in Nine Major Markets, November, 1953. (Processed.)

. Merchantable Potato Stocks, March 1, monthly reports, 1943-1958.

essed.) Potato Prices, Monthly and Seasonal Average Prices Received by Farmers, by

. Potato Marketing Agreements Under Federal Legislation, October, 1954. (ProcStates and United States, 1909-1952. Stat. Bul. 140, 1954.

States and United States, 1909-1952. Stat. Bul. 140, 1954.
. Potato Report Nos. 1-68. Bakersfield, Calif., daily issues, 1957.

Yield, Production, Price, Value, Farm Disposition, Stocks, 1955-1959.

Yield, Production, Price, Value, Farm Disposition, Stocks, 1955-1959.
. Potatoes and Sweetpotatoes; Usual Dates for Planting, Harvesting and Marketing by Seasons, in Principal Areas. Agr. Handbook 127, 1957. . Supplement for 1954 to the Consumption of Food in the United States, 1909-52.
Agr. Handbook 62, 1955.

U. S. Bureau of Agricultural Economics. Generalized Types of Farming in the United

States. Agr. Inf. Bul. 3, 1950.
1950, Potatoes-Acreage, Production, Value, Farm Disposition, January 1 Stocks, 1866-
Sept. of Agr. Stat. Bul. 122, 1953. 1950, by States. Dept. of Agr. Stat. Bul. 122, 1953. 
U. S. Bureau of the Census. Statistical Abstract of the United States, 1959, 1959.

U. S. Bureau of Labor Statistics. Retail Prices of Food, annual and monthly reports. . Wholesale Prices and Price Indexes, annual reports.

U. S. Commodity Exchange Authority. Futures Trading in Potatoes, 1954-55, 1955. (Processed.)

U. S. Congress, House. Potato Surpluses and Prevention of Wastage; Hearings Before the Subcommittee on Food Shortages of the Committee of Agriculture. 80th Cong., 1st Sess., 1947.

U. S. Department of Agriculture. Agricultural Statistics, annual issues.

. Potato Preferences Among Household Consumers. Misc. Publ. 667, 1948.

Potatoes-Sweetpotatoes, Revised Estimates, by States, 1949-55; Acreage, Yield, Production, Price and Value, Farm Disposition, and January 1 Stocks. Stat. Bul. 190, 1956. (Processed.)

U. S. Office of Business Economics. Business Statistics, 1959 Edition; a Supplement to the Survey of Current Business, 1959.

U. S. Production and Marketing Administration. Irish Potatoes: Price Support and Related Operations, Commodity Credit Corporation and Section 32 Funds, January 1, 1943-December 31, 1949, 1950. (Processed.)

- Report of the Administrator of the Production and Marketing Administration, 1950 and 1951.

Weekly Summary of Carlot Shipments, weekly issues.

Wold, H. A Study in the Analysis of Stationary Time Series. 2d ed. Stockholm: Almqvist and Wiksell, 1954.

and Jureen, L. Demand Analysis, a Study in Econometrics. New York: John Wiley and Sons, 1953.

Working, H. "The Theory of Price of Storage," American Economic Review, 39 (6): 1254$62,1949$.

Wright, D. N. Irish Potatoes, Costs and General Hints on Production. Bakersfield: Calif. Agri. Exit. Serv., March, 1957.

Yule, G. U. On a Method of Investigating Periodicity in Disturbed Series. ("Philosophical Transaction Series A," Vol. 226.) London: Royal Society, 1927. 
The journal Hilgardia is published at irregular intervals, in volumes of about 600 pages. The number of issues per volume varies.

Subscriptions are not sold. The periodical is sent as published only to libraries, or to institutions in foreign countries having publications to offer in exchange.

You may obtain a single copy of any issue free, as long as the supply lasts; please request by volume and issue number from:

\author{
Agricultural Publications \\ 207 University Hall \\ 2200 University Avenue \\ Berkeley 4, California
}

The limit to nonresidents of California is 10 separate issues on a single order. A list of the issues still available will be sent on request. 